William Reichenstein, Ph.D., CFA

Baylor University

Dovalee Dorsett, Ph.D.

Baylor University

\title{
Time Diversification Revisited
}

The Research Foundation of

The Institute of Chartered Financial Analysts 


\section{Research Foundation Publications}

Analysts' Earnings Forecast Accuracy in Japan and the United States

by Robert M. Conroy, Robert S. Harris, and Young S. Park

Active Currency Management

by Murali Ramaswami

Canadian Stocks, Bonds, Bills, and lnflation: 1950-1987

by James E. Hatch and Robert E. White

Closed-Form Duration Measures and Strategy Applications

by Nelson J. Lacey and Sanjay K. Nawalkha

Corporate Bond Rating Drift: An Examination of Credit Quality Rating Changes Over Time

by Edward I. Altman and Duen Li Kao

Corporate Governance and Firm Performance by Jonathan M. Karpoff, M. Wayne Marr, Jr., and Morris G. Danielson

Default Risk, Mortality Rates, and the Performance of Corporate Bonds by Edward I. Altman

Durations of Nondefault-Free Securities

by Gerald $O$. Bierwag and George $G$. Kaufman

Eamings Forecasts and Share Price Reversals by Werner F.M. De Bondt

The Effect of Illiquidity on Bond Price Data: Some Symptoms and Remedies by Oded Sarig and Arthur Warga

Equity Trading Costs

by Hans R. Stoll

Ethics, Faimess, Efficiency, and Financial Markets by Hersh Shefrin and Meir Statman

Ethics in the Investment Profession: A Survey by $\mathrm{E}$. Theodore Veit, CFA, and Michael R. Murphy, CFA

Ethics in the Investment Profession: An International Survey

by H. Kent Baker, CFA, E. Theodore Veit, CFA, and Michael R. Murphy, CFA

\author{
The Founders of Modem Finance: Their \\ Prize-Winning Concepts and 1990 \\ Nobel Lectures
}

Franchise Value and the Price/Earnings Ratio by Martin L. Leibowitz and Stanley Kogelman

Fundamental Considerations in Cross-Border Investment: The European View by Bruno Solnik

Global Asset Management and Performance Attribution by Denis S. Karnosky, and Brian D. Singer, CFA

Initial Public Offerings: The Role of Venture Capitalists by Joseph T. Lim and Anthony Saunders

Managed Futures and Their Role in Irvestment Portfolios by Don M. Chance, CFA

The Modern Role of Bond Covenants by Ileen B. Malitz

A New Method for Valuing Treasury Bond Futures Options by Ehud I. Ronn and Robert R. Bliss, Jr.

A New Perspective on Asset Allocation by Martin L. Leibowitz

Options and Futures: A Tutorial by Roger $\mathrm{G}$. Clarke

The Poison Pill Anti-Takeover Defense: The Price of Strategic Deterrence

by Robert F. Bruner

A Practitioner's Guide to Factor Models

Predictable Time-Varying Components of International Asset Returns

by Bruno Solnik

Program Trading and Systematic Risk by A.J. Senchack, Jr., and John D. Martin

The Role of Risk Tolerance in the Asset Allocation Process: A New Perspective

by W.V. Harlow III, CFA, and Keith C. Brown, CFA

Selecting Superior Securities by Marc R. Reinganum

Stock Market Structure, Volatility, and Volume by Hans R. Stoll and Robert E. Whaley 


\section{Time Diversification Revisited}


(C) 1995 The Research Foundation of the Institute of Chartered Financial Analysts

All rights reserved. No part of this publication may be reproduced, stored in a retrieval system, or transmitted, in any form or by any means, electronic, mechanical, photocopying, recording, or otherwise, without the prior written permission of the copyright holder.

This publication is designed to provide accurate and authoritative information in regard to the subject matter covered. It is sold with the understanding that the publisher is not engaged in rendering legal, accounting, or other professional service. If legal advice or other expert assistance is required, the services of a competent professional should be sought.

ISBN 978-0-94.3205-30-4

Printed in the United States of America

February 1995 


\section{Mission}

The Research Foundation's mission is to identify, fund, and publish research that is relevant to the CFA ${ }^{\circledR B}$ Body of Knowledge and useful for AIMR member investment practitioners and investors.

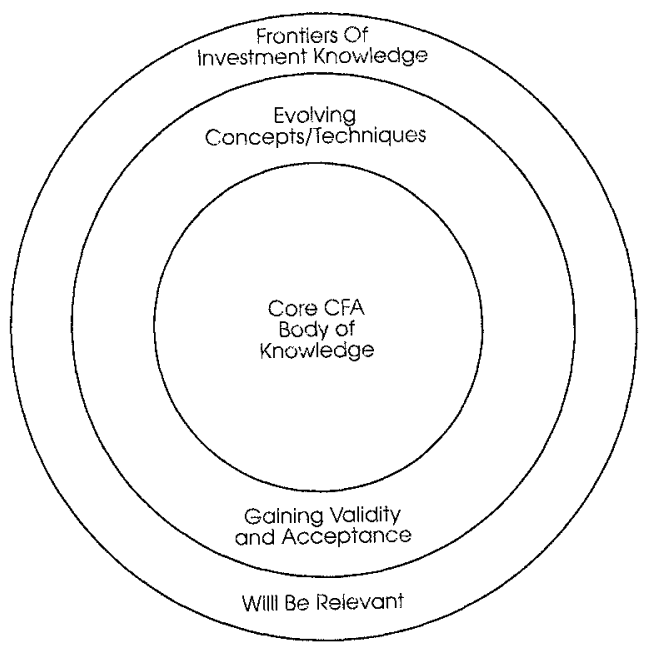

The Research Foundation of The Institute of Chartered Financial Analysts

P.O. Box 3668

Charlottesville, Virginia 22903

U.S.A.

Telephone: $804 / 980-3644$

Fax: 804/980-3634 


\section{Table of Contents}

Foreword $\ldots \ldots \ldots \ldots \ldots \ldots$ viii

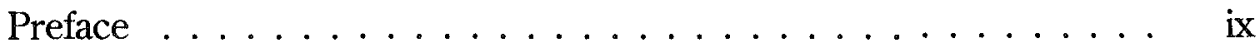

Chapter 1. Introduction $\ldots \ldots \ldots \ldots \ldots \ldots$

Chapter 2. Evidence against the Random Walk . . . . . . . . . . 9

Chapter 3. The Random Walk and Mean-Reversion Models . . . . 20

Chapter 4. Investment Implications of Time Diversification . . . . . 29

Chapter 5. The Risk-Return Trade-Off . . . . . . . . . . . . . . . . 43

Chapter $6 . \quad$ Summary . . . . . . . . . . . . . . 46

Appendix A. Risk-Return Trade-Offs Based on the Random Walk Model . . . . . . . . . . . . . . . . 48

Appendix B. Risk-Return Trade-Offs Based on the Mean-Reversion Model . . . . . . . . . . . . . 63

References $\ldots \ldots \ldots \ldots \ldots \ldots \ldots \ldots \ldots$ 


\section{Foreword}

With the publication of Time Diversification Revisited, Bill Reichenstein and Dovalee Dorsett broaden the scope of time-diversification theory and contribute to its practical utility. Discussion in the literature has centered on the role of history, past and future, in the financial markets: Are they governed by chance, as the random walk devotees contend? Or are they mean reverting, in which case portfolios diversified by investment horizon make sense?

The authors of Time Diversification Revisited contend that these two views of market behavior cannot be distinguished statistically, although they do produce different projections of ending wealth and shortfall risk. Accordingly, Reichenstein and Dorsett attack the problem pragmatically by examining corresponding sets of future returns under each assumption. Moreover, the portfolios they follow, rather than being full of stocks or bonds or cash, include a mixture of these assets allocated in the same proportions that actual investors choose, given their own risk preferences and life-cycle stages.

Investment practitioners will find most useful the two sets of graphic depictions of ending real wealth and shortfall risk for portfolios of various compositions. The asset allocations of these portfolios are similar to what an investment advisor might prescribe for individual or pension fund clients. With these exhibits, an advisor-whether of the random walk or the meanreversion persuasion - can illustrate for his or her clients the consequences of several conventional asset allocation choices over several investment horizons.

All in all, we believe this monograph is an eminently useful tool for practitioners. It will expand their own understanding of time diversification and enhance their ability to translate this knowledge for their clients. The Research Foundation is pleased to present this work.

Katrina F. Sherrerd, CFA

Senior Vice President and

Chief Operating Officer

The Research Foundation of

The Institute of Chartered

Financial Analysts 


\section{Preface}

The time-diversification literature asks what influence an investor's holding period (the number of years funds remain invested before being spent) should have on his or her portfolio's asset mix. The traditional view says that, as the holding period lengthens, the probability increases that high-risk assets will earn more than low-risk assets. Ergo, investors with long holding periods should devote a larger portion of their portfolios to stocks and other high-risk assets.

Time-diversification studies rely on projections of future returns. Previous studies assumed that financial markets follow a random walk or a random walk with positive drift. In particular, they assumed that the probability distribution of returns remains constant, and therefore, returns across years are independent. Recent research questions this last assumption.

Several studies report evidence that security markets are best characterized by mean reversion; that is, a stock's price may stray from its historical mean but will tend to return to it. If so, distant security returns are negatively correlated at some lags. A bad year is slightly more likely to be followed by a good year two years hence, three years hence, and so on. If markets are mean reverting, then previous studies underestimated the benefits of time diversification. The probability distribution of, say, ten-year stock returns is more concentrated than previous studies have suggested, and the probability that stocks will earn more than Treasury bills over ten years is larger than previously thought. The first goal of this study is to review this new research.

Statistical evidence cannot distinguish between the random walk and mean-reversion views of financial markets. The statistics support both views at traditional levels of significance. Consequently, the second goal of this study is to examine the investment implications of time diversification according to two sets of future returns projections, one based on a random walk model and one based on a mean-reversion model.

This study's third goal is to provide investors with a picture of the riskreturn trade-off of several portfolios for holding periods from 1 year through 30 years. A financial analyst should first decide if he or she believes financial markets are best described by a random walk or mean reversion and use the appropriate set of projections. The analyst can then show a client the projected probability distributions of ending wealth on several portfolios with distributions that correspond to the client's holding period. The graphs of ending wealth (per original $\$ 1$ investment) provide a picture (as we currently understand it) of the risk-return trade-offs of alternative asset mixes. These graphs 
should help clients make informed investment decisions that reflect their own risk tolerances. The relative risks of portfolios remain fairly stable, especially for longer holding periods, so the graphs should prove useful now and in future years.

Most previous time-diversification studies considered only a few extreme asset mixes, usually an all-S\&P 500 portfolio and an all-cash portfolio represented by Treasury bills. This study includes stock-only, cash-only, and bondonly portfolios, as well as portfolios diversified across large (S\&P 500) and small stocks and short-term, intermediate-term, and long-term debt. The mixed portfolios reflect those that financial analysts actually recommend and individuals actually hold. Thus, this study provides realism not present in prior time-diversification studies.

We acknowledge the financial support of the Research Foundation of the Institute of Chartered Financial Analysts. We also thank Dale Domian of the University of Regina in Regina, Saskatchewan, Canada, for his careful reading and helpful comments and Barbara A. Wiedman for her cheerful processing of the seemingly endless revisions.

We dedicate this volume to Peter L. Bernstein. As founder and first editor-in-chief of The Journal of Portfolio Management, he fostered the integration of academic research and professional practice. In addition, he may have been the first to advocate the benefits of time diversification. 


\section{Introduction}

The time-diversification literature asks what influence an investor's holding period, or investment horizon, should have on his or her portfolio asset mix. The traditional time-diversification view can be summarized in two tenets:

- The longer the investment horizon, the larger the portion of the portfolio that should be devoted to common stocks and other high-return assets.

- In the long run, we can be reasonably sure that a high-risk portfolio will earn more than a low-risk portfolio.

As an example of the first tenet, Malkiel (1990) presented model investment portfolios for typical individuals in their mid-20s, near age 40, in their mid-50s, and near age 70 . The stock portion of the recommended allocations declines from 70 percent for an investor in the mid-20s, to 60 percent near age 40 , to 50 percent in the mid-50s, and 30 percent near age 70 .

As an example of the second tenet, one study estimated that we can be 95 percent confident that stocks will earn more than high-grade bonds over 20 years. Although this traditional view is not universally accepted, it is accepted by most practitioners and by a growing consensus of academicians. One way to test the second tenet is to look at historical long-run returns. Stocks have earned more than Treasury bills in all 49 20-year holding periods since 1926. At first blush, these results seem to prove the second tenet. Since 1926, however, there have been only three nonoverlapping 20 -year periods. One great year for stocks, such as 1954, affects more than 40 percent of the 20-year periods. Thus, the dominance of stocks over debt in historical 20 -year holding periods may reflect a few lucky years.

To overcome this problem, most time-diversification studies have implicitly or explicitly assumed future returns come from a stable distribution; that is, stock prices follow a random walk with positive drift. ${ }^{1}$ For example, a researcher may simulate a 20-year stock return by randomly drawing (with

\footnotetext{
${ }^{1}$ See, for example, Reichenstein (1986 and 1987), Leibowitz and Krasker (1988), Ambachtsheer (1989), Arnott (1989), Leibowitz and Langetieg (1989), and Butler and Domian (1991 and 1992-93).
} 
replacement) 240 one-month returns from the historical distribution. The researcher then repeats the process perhaps 1,000 times and plots the distribution of the 1,000 simulated 20-year returns. Alternatively, the researcher may assume that annual excess returns (stock returns less returns on Treasury bills) come from a stable probability distribution, perhaps one with a mean return of 6 percent and standard deviation of 20 percent. In either case, the underlying distribution of returns is assumed to remain constant.

One implication of a stable distribution is that returns across periods are uncorrelated. Recent research questions this last assumption. For example, Lo and MacKinley (1988) found that consecutive monthly stock-index returns are positively correlated; a bad month is slightly more likely to be followed by a bad month than by a good month, and a good month is slightly more likely to be followed by a good month than by a bad month. More importantly for the time-diversification literature, several studies have reported evidence of weak negative correlations among distant yearly stock returns. ${ }^{2}$ A bad year is slightly more likely to be followed by a good year than by a bad year two years hence, three years hence, and so on.

If distant returns are negatively correlated, then prior studies have underestimated the benefits of time diversification. For instance, the probability distribution of ten-year stock returns is more concentrated than prior studies suggest, and the probability that stocks will earn more than Treasury bills over the years is larger than previously suggested.

\section{Views of Security Markets}

Many recent financial studies, although cast in different terms, are closely related to one another. For example, some studies examine whether required rates of return are mean reverting. Others ask if actual returns tend to reverse: Do good years follow bad years, perhaps with a lag? Still others ask if shortterm volatility is too large to be consistent with a random walk. Another group of studies tests for the existence of temporary price changes in securities. These studies are asking essentially the same question: What is the nature of the returns-generating process governing security markets? Stated more simply, how do security markets behave?

Figure 1 presents a hypothetical price history. ${ }^{3}$ It shows a sharp drop in price, perhaps like the October 1987 stock market crash, followed by three possible scenarios: random walk, mean reversion, and mean aversion. The

\footnotetext{
${ }^{2}$ See, for example, Fama and French (1988b), Poterba and Summers (1988), and Goetzmann (1993).

${ }^{3}$ The figure is similar to one in Nelson (1990).
} 
Figure 1. Hypothetical Price Paths

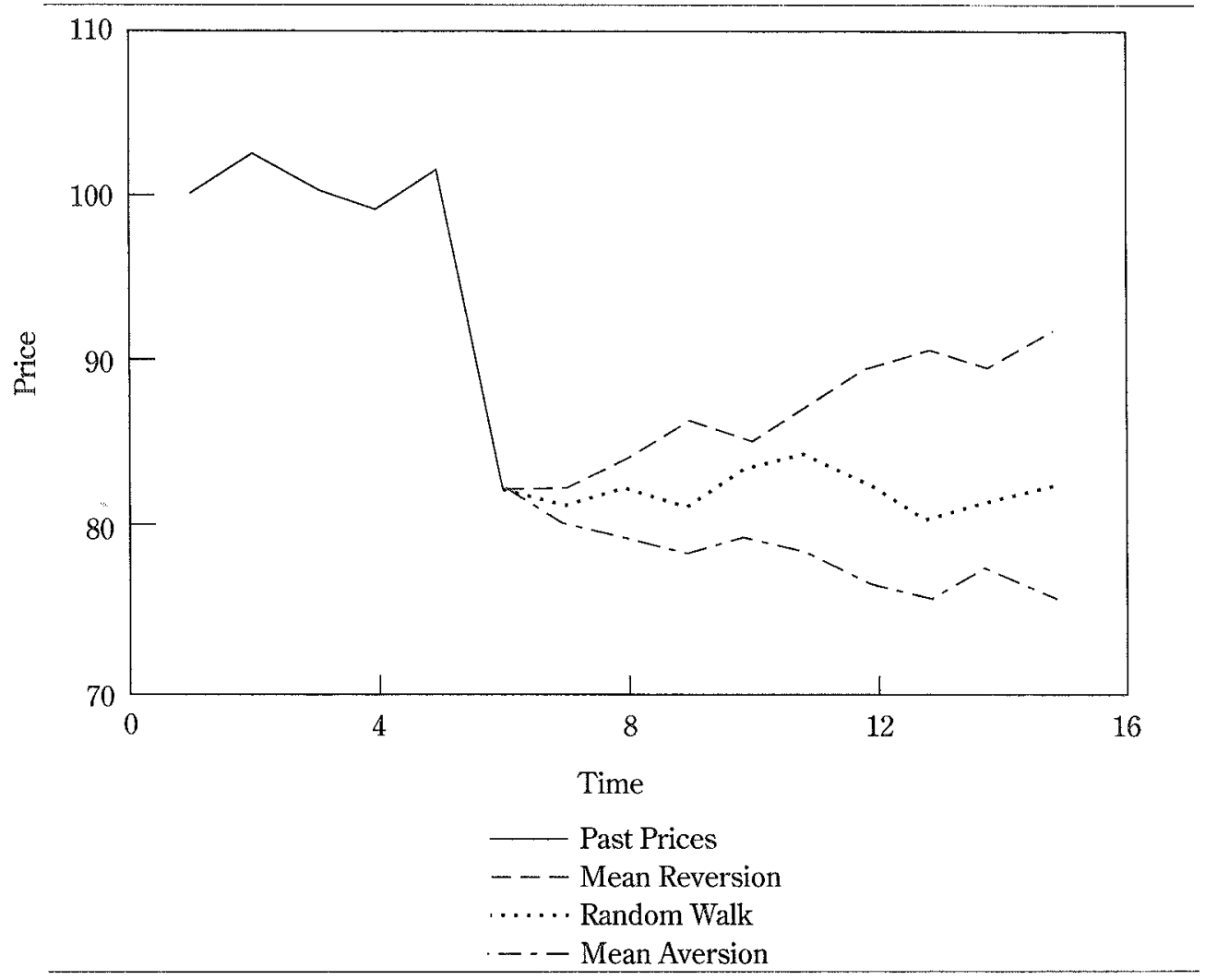

divergence of prices in the figure clarifies the importance of recent research issues and the implications of each view of security markets.

The Random Walk View. The random walk view assumes that future returns come from a stable probability distribution. Each period's return is like a random draw from the stable distribution. If returns come from a stable distribution, then prices follow a random walk or, more formally, a random walk with drift. $^{4}$

According to the random walk view, price changes following a price decline

${ }^{4}$ The random walk says that daily price changes are equally likely to be positive or negative; today's price is the best forecast of tomorrow's price. In a true random walk, the expected one-year return is zero (ignoring dividends). The random walk with drift says that daily price changes vary randomly around an upward drift; thus, the expected one-year return is positive. 
are equally likely to be positive or negative. According to the random walk with drift, returns following the price decline are equally likely to be above average or below average. The price drop could, by chance, be followed by a sequence of price increases or by a sequence of price declines. On average, the price decline foretells neither price recovery nor continuing losses. Returns across time periods are independent.

The random walk view has several implications:

- Required rates of returns are constant. Actual returns are independent.

- Because returns are independent, the variance of $n$-year returns is $n$ times the variance of one-year returns.

- Excess volatility does not exist; short-term returns are not too volatile to be consistent with a random walk.

- All price changes are permanent; temporary price changes do not exist.

The Mean-Reversion View. Implications of the mean-reversion view are quite different from those of the random walk view:

- Actual returns reverse and are negatively correlated at some lags.

- Because returns are reversing, the variance of $n$-year returns is less than $n$ times the variance of one-year returns; variance rises less than proportionately with the holding period.

- Short-term returns are too volatile to be explained by a random walk; excess volatility exists.

- Price changes consist of permanent and temporary components. The temporary or transitory part of a price decrease (increase) will be offset eventually by a price increase (decrease). Thus, only the part of short-term volatility associated with permanent price changes affects long-term volatility.

The mean-reversion view describes how security markets behave. Much of the recent financial debate centers on the merits of two economic storiesthe irrational markets story and the rational markets story - both of which try to explain why security markets are mean reverting. The irrational markets story says fads affect security prices. Prices can become overvalued or undervalued for long periods. For example, many financial analysts believe that the Japanese stock market was irrationally high at year-end 1989 and the U.S. stock market was irrationally high at the beginning of October 1987. The U.S. market may have been irrationally low after 1932 and 1975. If bubbles or fads affect security prices, then actual returns should be reversing. For example, the spectacular returns in Japanese stocks through 1989 gave rise to the dismal returns of the next 2.5 years, and the devastating U.S. stock losses of the 
1929-32 period gave rise to the spectacular returns of the 1933-36 period.

The rational markets story says that mean reversion is the natural product of efficient capital markets with time-varying risk premiums. Fama and French (1988a, 1989), Sharpe (1990), and Reichenstein and Rich (1993), among others, champion this story. They argue that required rates of return tend to be highly autocorrelated but slowly mean reverting. Suppose the market risk premium - the additional expected return on stocks above the Treasury bill rate-is above average. Then, by definition, future excess returns are expected to be above average. If the market risk premium tends to revert to its historical mean, then stock prospects look even brighter, because a falling market risk premium would, everything else held constant, produce a capital gain.

For example, a time-varying market risk premium can explain stock returns surrounding the Persian Gulf conflict. On August 2, 1990, Iraq invaded Kuwait and, within a few weeks, positioned its forces on the Saudi Arabian border. ${ }^{5}$ The S\&P 500 plunged 9 percent in August as the turmoil and uncertainty raised the market risk premium. Stock prices waffled in a narrow range between September and the beginning of the Gulf War in mid-January 1991. The quick victory reduced the market risk premium, and stock prices rose sharply by month's end.

Suppose that, before the onset of the conflict, stocks were priced to offer average rewards to risk. The increase in the market risk premium (and required return) reduced stock prices. At the lower prices, stocks offered above-average rewards for bearing risk. In the Persian Gulf conflict, the market risk premium reverted to its mean in about six months, although the reversion tends to occur slowly and often takes years. The initial increase in the market risk premium produced a capital loss and also gave rise to a later fall in the risk premium and a capital gain. Distant returns are negatively correlated. Actual returns reverse. ${ }^{6}$

${ }^{5}$ This example comes from Reichenstein and Rich (1993).

${ }^{6}$ Some people equate the efficient markets hypothesis with the random walk. A random walk is one version of an efficient market but so is the rational markets story. According to the random walk, markets are always in equilibrium, required returns never change, and returns are not predictable. According to the rational markets story, markets are always in equilibrium, but required returns vary through time and long-horizon returns are partially predictable. When required returns are above average, returns during the nextfew years will likely prove generous, and vice versa. Both the random walk view and rational markets story imply that short-term (weekly and monthly) returns cannot be meaningfully predicted, but they give different opinions about the predictability of long-term (one year and longer) returns. For more on this topic, see Reichenstein and Rich $(1993,1994)$ and the presentations in Quantifying the Market Risk Premium Phenomenon for Investment Decision Making (Charlottesville, Va.: Institute of Chartered Financial Analysts, 1990). 
Again, the mean-reversion view describes how security markets behave. The irrational and rational markets stories try to explain why markets are mean reverting. Thus, evidence of mean reversion equally supports both economic stories.

The Mean-Aversion View. Figure 1 also illustrates mean aversion. If markets overreact, then poor initial returns could encourage continuing poor returns, and vice versa. We do not know of any theory or economic story that would be consistent with long-run mean aversion of stock returns. Nevertheless, Nelson (1990) reports that excess returns on the value-weighted New York Stock Exchange (NYSE) have shown signs of mean aversion since 1946. Debt returns since 1926 also show signs of mean aversion.

\section{Desigin of the Study}

A review of recent research best supports the position that security markets either follow a random walk or are mean reverting. The evidence cannot distinguish between these competing views. Prior belief that markets follow a random walk will likely lead to belief that the evidence best supports this position; the same is true for the mean-reversion view. Consequently, in this study, we present two sets of projected returns: one based on the random walk model and one based on the mean-reversion model. Although projections from the two models differ, both sets of projections support six investment implications. Not surprisingly, the benefits of time diversification accrue more quickly according to the mean-reversion model.

The time-diversification literature relies on projections of future returns. This study uses 1926-93 historical returns to estimate probability distributions of excess returns, real returns, and ending wealth, based on the random walk and mean-reversion models, for each of eight portfolios for holding periods of 1 year through 30 years.

Most time-diversification studies have looked at only a few portfolios, perhaps a stock-only portfolio and a cash-equivalent portfolio represented by Treasury bills. A typical research approach would then address the probability that the stock portfolio will beat cash over a 20 -year holding period. This study analyzes stock-only, cash-only, and bond-only portfolios, as well as portfolios diversified across debt and equity markets. Few investors hold portfolios that contain only bonds or only stocks. The mixed portfolios reflect those that financial analysts actually recommend and individuals actually hold. For most investors, the critical decision is seldom between a bond-only or a stock-only portfolio. It is usually a choice between two portfolios with slightly different weights. The use of mixed portfolios provides realism and allows insights not 
found in prior studies.

Table 1 presents the asset allocations of the eight portfolios. The first four are the bond/stock portfolios. They include an S\&P 500 stock-only portfolio and a corporate-bond-only portfolio. The bond/stock portfolios also include portfolios $\mathrm{P} 46$ and $\mathrm{P} 64$, which contain, respectively, 40 percent bonds $/ 60$ percent $S \& P$ and 60 percent bonds $/ 40$ percent $S \& P$. These latter portfolios are termed the pension portfolios because of the frequent mandate for pensions to invest between 40 percent and 60 percent of assets in stocks and the remainder in long-term bonds. ${ }^{7}$

Table 1. Asset Allocation of Portfolios

\begin{tabular}{lccccc} 
Portfolio & Bills & Notes & Bonds & S\&P 500 & $\begin{array}{c}\text { Small } \\
\text { Stock }\end{array}$ \\
\hline Bonds and stocks & & & & & \\
S\&P & NA & NA & 0.00 & 1.00 & NA \\
P46 & NA & NA & 0.40 & 0.60 & NA \\
P64 & NA & NA & 0.60 & 0.40 & NA \\
Bonds & NA & NA & 1.00 & 0.00 & NA \\
Age & & & & & \\
A25 & 0.05 & 0.000 & 0.250 & 0.50 & 0.20 \\
A40 & 0.05 & 0.125 & 0.225 & 0.50 & 0.10 \\
A55 & 0.05 & 0.175 & 0.275 & 0.50 & 0.00 \\
A70 & 0.10 & 0.400 & 0.200 & 0.30 & 0.00 \\
& & & & &
\end{tabular}

Note: The assets used in this table are one-month Treasury bills; five-year Treasury notes; the Salomon Brothers Long-Term, High-Grade Corporate Bond Index; the S\&P 500 Index; and a small-stock portfolio. NA = not applicable.

Source: Ibbotson and Associates (1994).

The other four portfolios are the age portfolios, which contain short-term, intermediate-term, and long-term debt and small and large stocks. They vary in both debt/equity allocations and allocations within debt and within equity. The portfolio weights reflect Malkiel's (1990) recommended allocations of financial assets for typical investors in their mid-20s (A25), about 40 (A40), in their mid-50s (A55), and in their late 60s and beyond (A70). Peavy and Sherrerd (1990) recommended similar portfolios for individuals near these ages (who do not have unusual circumstances). Bogle (1994) recommended as a rule of thumb that the debt portion of a portfolio should roughly equal the investor's age with the remainder invested in equities. The debt/equity mixes in the age

\footnotetext{
${ }^{7}$ See Ambachtsheer (1987).
} 
portfolios approximate this rule of thumb; the debt portions are 30 percent for $\mathrm{A} 25,40$ percent for $\mathrm{A} 40,50$ percent for $\mathrm{A} 55$, and 70 percent for $\mathrm{A} 70$.

The probability distributions of real returns and excess returns from both the random walk and mean-reversion models were analyzed to ascertain the benefits of time diversification. The analysis, wholly or in part, supports the two basic tenets set forth above and four other specific investment implications:

- The longer the investment horizon, the larger the portion of the portfolio that should be devoted to common stocks and other highreturn assets.

- After 20 years, investors can be 90 percent confident that portfolios with at least a 20 percent stock exposure will earn more than Treasury bills. Even after 25 years, however, they cannot be 90 percent confident that long-term bonds will earn more than Treasury bills.

- Diversifying a portfolio between debt and equity reduces its downside risk and enhances the benefits of time diversification. Downside risk can be reduced by holding a diversified portfolio at all times and by holding a portfolio across time periods-that is, by time diversification. Both types of diversification reduce the probability of miserable returns.

- The relative risk of a portfolio depends upon the length of the holding period.

- The variance and standard deviation of a portfolio's returns do not reflect its relative risk when the holding period is long.

- The success of a portfolio chosen for its long-horizon prospects should not be judged by its returns over shorter horizons.

This study does have certain limitations. The key assumption is that the future will resemble to some extent the 1926-93 period. For example, S\&P returns are expected to exceed those on bills by about 6.21 percent annually. This estimate may be too low because it represents the continuously compounded, geometric mean excess return. Ibbotson and Associates (1994) encourage the use of the larger arithmetic mean; so, our conclusions may be considered conservative. On the other hand, if 1994 turns out to be the high-water mark of capitalism, the projections in this study will prove to have been too rosy. 


\section{Evidence against the Random Walk}

Prior to developing the random walk and mean-reversion models for forecasting returns, we examine research evidence against the random walk view. Three research approaches call into question the random walk view that the best forecast of future returns is the historical average return. Instead, the evidence suggests that returns for year-ahead and longer holding periods are partially predictable and security markets are mean reverting. The first approach uses regressions to examine the predictability of asset returns. The second uses Markov chains to examine patterns of asset returns; for example, does a good year in the stock market usually follow two bad years? The third examines historical autocorrelations.

\section{Regressions}

Fama and French (1988a), Campbell and Shiller (1988), Reichenstein and Rich (1993), and other authors have shown that the dividend yield on a stock index and, to a lesser extent, the earnings-price ratio can predict long-horizon stock returns. In academic work, earnings-price ratios are usually preferred to the more familiar price-earnings ratios. ${ }^{8}$ The first two rows of Table 2 summarize regression results from Fama and French. The regressions imply that high returns on stocks tend to follow high dividend yields and high earnings-price ratios (or low price-earnings ratios). The implication is that one cannot meaningfully predict short-term stock returns; dividend yield usually predicts 4 percent or less of the variation of monthly and quarterly returns. One-year-ahead and longer returns, however, are partially predictable. Dividend yield explains 25 percent or more of multiyear returns. The predictive

\footnotetext{
${ }^{8}$ Price-earnings ratios $(\mathrm{P} / \mathrm{Es})$ produce extreme values for firms with earnings per share (EPS) near zero. Suppose a firm has a stock price of $\$ 10$. If EPS is $\$ 0.01, P / E$ is 1,000 ; if EPS is $\$ 0.10$, then $\mathrm{P} / \mathrm{E}$ is 100 . We generally consider low-P/E firms desirable, which seems to suggest that a firm with EPS of $-\$ 0.01$ and a $\mathrm{P} / \mathrm{E}$ of $-1,000$ would be ideal. Inverting $\mathrm{P} / \mathrm{Es}$ to express them as earnings-price ratios avoids the extreme $\mathrm{P} / \mathrm{E}$ values (which wreak havoc in regressions) and the problem of negative earnings.
} 
Table 2. Predictable Portions of Bond and Stock Returns

\begin{tabular}{|c|c|c|c|c|c|c|c|c|}
\hline \multirow{3}{*}{$\begin{array}{l}\text { Dependent } \\
\text { Variable }\end{array}$} & \multirow{3}{*}{$\begin{array}{c}\text { Independent } \\
\text { Variable }\end{array}$} & \multirow{3}{*}{$\begin{array}{l}\text { Study } \\
\text { Period }\end{array}$} & \multicolumn{6}{|c|}{ Holding Period } \\
\hline & & & \multirow[b]{2}{*}{ Month } & \multirow[b]{2}{*}{ Quarter } & \multicolumn{4}{|c|}{ Years } \\
\hline & & & & & 1 & 2 & 3 & 4 \\
\hline Large stocks & $\mathrm{D} / \mathrm{P}$ & $1941-86$ & 0.01 & 0.02 & 0.09 & 0.25 & 0.36 & 0.45 \\
\hline Large stocks & $\mathrm{E} / \mathrm{P}$ & $1941-86$ & $\mathrm{NA}$ & NA & 0.04 & 0.15 & 0.21 & 0.30 \\
\hline Aa bonds & $\mathrm{D} / \mathrm{P}$, term & $1927-87$ & 0.04 & 0.04 & 0.33 & 0.22 & 0.19 & 0.19 \\
\hline Large stocks & $\mathrm{D} / \mathrm{P}$, term & $1927-87$ & 0.01 & 0.02 & 0.02 & 0.12 & 0.18 & 0.25 \\
\hline Small stocks & $\mathrm{D} / \mathrm{P}$, term & $1927-87$ & 0.01 & 0.04 & 0.07 & 0.22 & 0.27 & 0.34 \\
\hline
\end{tabular}

Note: The values denote the regression $R^{2}$, the percent of variance of returns that can be explained by the independent variables. The dependent variable on the first two regressions is real returns on the valueweighted NYSE. The dependent variable in the last three are excess returns on an Aa-rated bond portfolio, the value-weighted (i.e., large) NYSE, and the equally weighted (i.e., small) NYSE. Independent variables are dividend yield $(\mathrm{D} / \mathrm{P})$, earnings-price ratio $(\mathrm{E} / \mathrm{P})$, and term premium. $\mathrm{NA}=$ not available.

Sources: Large-stock regressions are from Fama and French (1988a); all others are from Fama and French (1989).

content of the earnings-price ratio also rises with the holding period, but it tends to explain a smaller fraction of returns than does dividend yield.

The apparent ability of dividend yield to predict long-term stock returns and the attempts to explain this apparent predictability are the heart of this line of research. The irrational markets school says high dividend yields tend to occur when prices are irrationally low and low dividend yields tend to occur when prices are irrationally high. ${ }^{9} \mathrm{~A}$ high dividend yield suggests irrationally low prices. Future returns will probably be strong as stock prices slowly move up toward intrinsic value. Security prices tend to be mean reverting, and actual returns tend to reverse. A similar argument explains the predictive content of earnings-price ratios.

The rational markets school also hails the regression results as evidence of mean reversion. The argument, however, is that high dividend yields tend to occur when required rates of return are historically large. If markets are rational, then on average, future stock returns should be above average when required returns are above average. ${ }^{10}$

\footnotetext{
${ }^{9}$ See, for example, De Bondt and Thaler $(1985,1987)$, Poterba and Summers (1988), and Shiller (1990).

${ }^{10}$ See, for example, Fama and French (1988a and 1989), Sharpe (1990), and Reichenstein and Rich (1993). For a similar discussion of bonds, see Chang and Huang (1990).
} 
Consider the constant-growth version of the dividend discount model:

$$
P=\frac{D(1+g)}{(r-g)}
$$

where $P$ denotes the stock price, $D$ the current-year dividends, $r$ the required rate of return on stocks, and $g$ the constant growth rate. The model implies that, in a rational market,

$$
\frac{D}{P}=\frac{(r-g)}{(1+g)}
$$

Everything else the same, the dividend yield, $D / P$, and required return, $r$, should move together. A large yield signals a large required return. ${ }^{11}$

The bottom three rows of Table 2 summarize regression results from a later study by Fama and French (1989). That study is an example of many recent studies that suggest variations in expected returns are common across security classes. ${ }^{12}$ Fama and French concluded that term premium (the spread of long-term over short-term bond yields) and dividend yield explain separate components of returns on bonds and stocks. Term premium seems to explain a return component for a cycle that corresponds to the traditional business cycle. Dividend yield explains a return component for a cycle that is much longer than the traditional business cycle.

Fama and French interpreted the regressions as support for the rational markets story. Term premium and dividend yield reflect separate risk premiums that are rationally embedded in prices across security markets. For example, the long-term predictive content of dividend yield increases going from bonds to large stocks and from large stocks to small stocks; that is, yield's predictive content rises moving from lower risk assets to higher risk assets. Dividend yield's predictive content is emphasized here because the coefficient on term premium is seldom significant in regressions of one-year or longer security returns.

The irrational markets school interprets the evidence differently. It says

\footnotetext{
${ }^{11}$ Sharpe (1990) and Reichenstein and Rich (1993) took the argument one step further by saying dividend yield and earnings-price ratio rise and fall with the market risk premium, where the required return is the sum of the risk-free rate plus the market risk premium.

${ }^{12}$ See, for example, Chen, Roll, and Ross (1986), Keim and Stambaugh (1986), Breen, Glosten, and Jagannathan (1989), Fama (1990), French (1990), Ferson and Harvey (1991), and Campbell and Hamao (1992).
} 
security prices sometimes exceed intrinsic value and sometimes are below intrinsic value. These pricing errors tend to be larger on the assets that are more difficult to value. That is, pricing errors tend to increase as we go from bonds to large stocks to small stocks.

The regressions support the mean-reversion view of security markets. The irrational markets and rational markets schools disagree as to why markets are mean reverting. Nevertheless, the statistical evidence has not convinced all observers that financial markets are truly mean reverting. Nelson (1990) wrote:

Let me suggest an explanation for this [evidence of mean reversion] by analogy to a single stock. Consider a company that markets a drug and there is a rumor that this drug causes cancer in rats. The stock price drops, but later it turns out that the rumor is groundless and the stock price recovers. In terms of the price action of the stock, this is a mean-reverting event. But for investors, it is only an even bet, not a profit opportunity, because the rumor might have proven true. Something like this might have happened to the market in the 1926-46 period. Both the Great Depression and World War II posed serious threats to the survival of the private economy of the United States. The outcome of World War II was by no means clear in the early years of the war, and there were widespread predictions that the Depression would resume following the war. Everything worked out better than predicted. But we are left with what appears, in retrospect, to have been a period of reverting to the mean, recovery in the market and the economy. This situation has not been repeated since, and instead there has been a tendency for moves to persist instead of reverse. (p. 44)

\section{Markov Chains}

Markov-chain tests differ from most statistical tests (including all other tests examined in this study) in that they use only a subset of all yearly returns. McQueen and Thorley (1991) examined the distribution of stock returns in the year following a two-year trend in stock prices. They found that a good year on the NYSE usually follows two bad years and a bad year usually follows two good years. In short, the stock market usually reverses after a two-year trend.

Suppose stock prices follow a random walk with drift. Then, stock returns following a two-year trend should be independent of the trend direction. Thus, a good year or a bad year would be equally likely to follow two bad years. If financial markets are mean reverting, however, then a good year would likely follow two bad years and a bad year would likely follow two good years. 
McQueen and Thorley used continuously compounded, yearly real and excess returns on equal-weighted and value-weighted portfolios of all NYSE stocks. The equal-weighted portfolios place more emphasis on small stocks, and the value-weighted portfolios emphasize large stocks. The authors considered several definitions of "good" and "bad" yearly returns, but their conclusions are not sensitive to the choice. Table 3 presents McQueen and Thorley's results for the 1947-87 period. Agood year is defined as one in which the return exceeds its prior 20-year average.

\section{Table 3. Summary of Markov-Chain Tests Using Portfolios of Annual NYSE Stock Returns, 1947-87}

\begin{tabular}{|c|c|c|c|c|c|c|c|c|}
\hline \multirow[b]{3}{*}{ Prior Two Years } & \multicolumn{4}{|c|}{ Equal-Weighted Portfolios } & \multicolumn{4}{|c|}{ Value-Weighted Portfolios } \\
\hline & \multicolumn{2}{|c|}{ Real Return } & \multicolumn{2}{|c|}{ Excess Return } & \multicolumn{2}{|c|}{ Real Return } & \multicolumn{2}{|c|}{ Excess Return } \\
\hline & Bad & Good & $\mathrm{Bad}$ & Good & $\mathrm{Bad}$ & Good & $\mathrm{Bad}$ & Good \\
\hline Bad and bad & 2 & 6 & 2 & 8 & 1 & 5 & 2 & 7 \\
\hline Good and good & 9 & 1 & 8 & 0 & 9 & 3 & 7 & 2 \\
\hline
\end{tabular}

Source: McQueen and Thorley (1991), Table II.

For the equal-weighted (small) stock portfolio, two consecutive bad real returns occurred eight times in the 41-year period and a good year followed in six of the eight times. Two consecutive bad excess returns occurred ten times, and a good year followed eight times. In addition, returns usually reversed following two good years. Two consecutive good real returns occurred ten times, and a bad year followed nine times. Two consecutive good excess returns occurred eight times, and a bad year followed all eight times. These results support the position that small stock returns tend to reverse following a two-year trend.

Returns on the value-weighted (large) stock portfolio also showed a tendency to reverse following a two-year trend, but this tendency was not quite as strong as for small stocks. For example, the excess returns on the valueweighted portfolio were either good two consecutive years or bad two consecutive years 18 times, and the returns reversed 14 times. Excess returns on the equal-weighted portfolio reversed 16 of 18 times.

The authors found that reversals also tend to occur following a three-year trend. A three-year trend (three consecutive bad years or three consecutive good years) occurred 13 times in the four portfolios; the process reversed itself 11 times. Thus, Markov-chain tests support mean reversion. ${ }^{13}$

\footnotetext{
${ }^{13}$ Table 3 and the discussion of the McQueen and Thorley paper rely on calendar-year
} 


\section{Autocorrelations}

The random walk view says asset returns should be uncorrelated through time, while the mean-reversion view says returns should be negatively correlated at some lags. This contrast suggests natural tests of the competing hypotheses: Calculate the autocorrelation coefficients for the eight portfolios and specific asset classes, and then test to see if the coefficients are significantly different from zero, either individually or as a group. We used three tests, one based on individual coefficients and two based on coefficients as a group. $^{14}$

We first looked at tests on real returns and concluded that Treasury-bill real returns are mean averting. We then looked at tests on excess returns and found that they are consistent with both the random walk and mean-reversion views. The evidence cannot distinguish between these two views. Our projections of a portfolio's real returns reflect this distinction between the market behavior of the real bill returns and the portfolio's excess returns.

Tests on Real Returns. The top half of Table 4 presents first-order through ninth-order autocorrelation coefficients of annual real returns for 1926 through 1993. Second-order autocorrelation refers to the correlation between returns in one year and returns two years earlier. To be considered significant at the 5 percent level, an individual autocorrelation coefficient must be two standard errors, or 0.24 , from zero. Three first-order coefficients are significantly different from zero: the correlations on Treasury-bill real returns, Treasury-note real returns, and corporate-bond real returns. The strong positive autocorrelation of 0.65 in the real bill returns shows up in the real returns on notes and bonds.

A chi-square statistic was used to test the joint hypothesis that the autocorrelation coefficients in a string are jointly zero. The probability column in

returns, January through December. The authors also reported that evidence of reversals of two-year trends is much weaker if yearly returns are calculated for July through June. Their study and others have shown that strong January returns usually follow weak prior-year returns. Investors dump losing stocks for tax reasons in December. In January, the selling pressure is lifted and returns tend to be positive. This persistent year-end phenomenon is an excellent example of the type of short-term volatility that is eliminated for long-term investors; that is, it supports the mean-reversion school. Not surprisingly, eliminating one type of reversal (by calculating July-June returns) weakens the overall evidence of reversals.

${ }^{14}$ Prior studies have also examined autocorrelation coefficients and variance ratios. See, for example, Fama and French (1988b); Poterba and Summers (1988); Nelson (1990); Cutler, Poterba, and Summers (1991) and the related Summers (1990); McQueen (1992); and Goetzmann (1993). 
Table 4. Autocorrolation Coefficients of Retums, 1926-93

\begin{tabular}{lrrrrrrrrrr}
\hline Portfolio $^{\mathrm{a}}$ & 1 & 2 & 3 & 4 & 5 & 6 & 7 & 8 & 9 & Prob $^{\mathrm{b}}$ \\
\hline Real returns & & & & & & & & & \\
S\&P & 0.00 & -0.21 & 0.01 & -0.09 & 0.01 & 0.04 & 0.09 & -0.06 & 0.12 & 0.71 \\
P46 & 0.02 & -0.19 & 0.01 & -0.04 & 0.05 & 0.08 & 0.09 & -0.15 & 0.10 & 0.73 \\
P64 & 0.09 & -0.14 & 0.03 & 0.01 & 0.07 & 0.13 & 0.08 & -0.19 & 0.07 & 0.72 \\
Bonds & 0.31 & 0.11 & 0.06 & 0.12 & 0.07 & 0.15 & -0.06 & -0.08 & 0.04 & 0.09 \\
& & & & & & & & & & \\
A25 & -0.01 & -0.23 & -0.07 & -0.12 & 0.03 & 0.03 & 0.06 & -0.09 & 0.13 & 0.50 \\
A40 & 0.00 & -0.21 & -0.04 & -0.08 & 0.05 & 0.07 & 0.07 & -0.14 & 0.11 & 0.62 \\
A55 & 0.04 & -0.18 & 0.01 & -0.02 & 0.07 & 0.10 & 0.08 & -0.18 & 0.08 & 0.75 \\
A70 & 0.12 & -0.10 & 0.04 & 0.07 & 0.12 & 0.15 & 0.06 & -0.23 & 0.04 & 0.54 \\
& & & & & & & & & & \\
SmStk & 0.07 & -0.12 & -0.10 & -0.20 & -0.07 & -0.08 & -0.04 & -0.01 & 0.11 & 0.43 \\
Notes & 0.35 & 0.18 & 0.10 & 0.22 & 0.15 & 0.17 & -0.01 & -0.01 & 0.01 & 0.01 \\
Bills & 0.65 & 0.34 & 0.21 & 0.35 & 0.34 & 0.16 & 0.02 & -0.04 & -0.06 & 0.01
\end{tabular}

Standard error $=0.12$

$\begin{array}{lrrrrrrrrrr}\text { Excess returns } & & & & & & & & \\ \text { S\&P } & 0.04 & -0.18 & 0.00 & -0.12 & -0.03 & 0.01 & 0.12 & 0.04 & 0.16 & 0.73 \\ \text { P46 } & 0.04 & -0.19 & 0.01 & -0.12 & -0.04 & 0.04 & 0.13 & -0.00 & 0.16 & 0.69 \\ \text { P64 } & 0.06 & -0.16 & 0.02 & -0.11 & -0.06 & 0.07 & 0.14 & -0.04 & 0.15 & 0.71 \\ \text { Bonds } & 0.16 & 0.06 & 0.04 & 0.01 & -0.10 & 0.11 & 0.09 & -0.06 & 0.09 & 0.66 \\ & & & & & & & & & & \\ \text { A25 } & 0.04 & -0.19 & -0.04 & -0.16 & -0.04 & -0.01 & 0.08 & 0.03 & 0.17 & 0.55 \\ \text { A40 } & 0.03 & -0.20 & -0.02 & -0.15 & -0.04 & 0.01 & 0.11 & 0.02 & 0.17 & 0.60 \\ \text { A55 } & 0.04 & -0.18 & 0.01 & -0.12 & -0.04 & 0.04 & 0.13 & -0.01 & 0.16 & 0.69 \\ \text { A70 } & 0.05 & -0.16 & 0.02 & -0.10 & -0.06 & 0.08 & 0.13 & -0.05 & 0.15 & 0.71 \\ & & & & & & & & & & \\ \text { SmStk } & 0.13 & -0.07 & -0.06 & -0.21 & -0.10 & -0.09 & -0.03 & 0.04 & 0.11 & 0.38 \\ \text { Notes } & 0.08 & 0.06 & 0.06 & 0.06 & -0.11 & 0.12 & -0.03 & 0.02 & 0.03 & 0.76\end{array}$

Standard error $=0.12$

Note: Columns 1 through 9 denote first-order through ninth-order autocorrelation coefficients.

${ }^{a}$ See Table 1 for asset allocation details.

${ }^{b}$ Prob is the significance level at which we can reject the null hypothesis of joint zero correlations through six lags.

Table 4 denotes the significance level at which the hypothesis of joint zero correlations through six lags can be rejected. We rejected the null hypothesis of no autocorrelation on real bill and real note returns at the 1 percent level and on real bond returns at the 9 percent level.

Variance ratios provide the final autocorrelation test. Poterba and Summers (1988) examined the power of several tests to identify correctly returns generated by a mean-reversion model. They found that, although no test proved strong, the variance ratio tests were best able to detect the autocorrelations left by the model. 
The variance ratio for an $n$-year return is defined as

$$
\operatorname{VR}(n)=\frac{\operatorname{var}\left(R_{t}^{n}\right) / n}{\operatorname{var}\left(R_{t}^{1}\right)},
$$

where $\quad R_{t}^{n}=\sum_{i=0}^{n} R_{t-i} \quad$ and $R_{t}$ denotes the return in year $t$. If yearly returns are independent, as is true of returns generated by the random walk model, then the variance of $n$-year return, $\operatorname{var}\left(R_{t}^{n}\right)$, is expected to be $n$ times the one-year variance and the variance ratio is expected to be 1.0. If financial markets are mean reverting, then returns should show negative autocorrelations at some lags and the variance ratio should be less than 1.0; if markets are mean averting, variance ratios should exceed 1.0. ${ }^{15}$

The top half of Table 5 reports variance ratios on real returns. The variance ratios on ten-year real bill returns is 4.09 , meaning that these returns have been 4.09 times as volatile as predicted by the random walk model. This confirms the evidence from the prior two tests and rejects the random walk model for Treasury bill real returns. These returns are mean averting; they tend to be poor for several consecutive years (e.g., 1973-80) or good for several consecutive years (e.g., 1981-89). Because good or bad returns are likely to persist, the volatility of long-horizon real bill returns is larger than predicted by the random walk model.

The mean aversion in Treasury-bill real returns can be reliably detected in the real returns on notes and bonds. Although mean aversion cannot be reliably detected in the real returns on the mixed and all-stock portfolios, we suspect it is present. For example, consider that the variance of A40 real returns consists of the sum of the variance of real bill returns plus the variance of A40 excess returns. The variance of A40 excess returns is almost ten times the variance of real bill returns. This makes trying to detect the mean-averting real bill returns embedded in A40 real returns like trying to find a needle in a

${ }^{15}$ The reported variance ratios are adjusted for small-sample bias by dividing by the expected value of $V R(n)$; that is,

$$
E[V R(n)]=1-\left(\frac{2}{n}\right) \sum_{j=1}^{n} \frac{(n-j)}{(N-j)},
$$

where $N$ is 68 , the number of years in the $1926-93$ sample. We thank James Poterba for help with this formula. 
Table 5. Variance Ratios, 1926-93

\begin{tabular}{|c|c|c|c|c|c|c|c|c|}
\hline \multirow[b]{2}{*}{ Portfolio $^{\mathrm{a}}$} & \multirow{2}{*}{$\begin{array}{l}\text { Innual Standard } \\
\text { Deviation }^{\mathrm{b}}\end{array}$} & \multicolumn{7}{|c|}{ Investment Horizon (years) } \\
\hline & & 2 & 3 & 4 & 5 & 6 & 8 & 10 \\
\hline \multicolumn{9}{|l|}{ Real retums } \\
\hline S\&P & 0.1992 & 1.03 & 0.90 & 0.80 & 0.73 & 0.71 & 0.73 & 0.80 \\
\hline P46 & 0.1350 & 1.05 & 0.94 & 0.86 & 0.82 & 0.82 & 0.94 & 0.97 \\
\hline P64 & 0.1103 & 1.12 & 0.90 & 0.89 & 0.93 & 0.98 & 1.15 & 1.21 \\
\hline Bonds & 0.0941 & 1.34 & 1.55 & 1.69 & 1.86 & 1.99 & 2.26 & 2.26 \\
\hline A25 & 0.1629 & 1.02 & 0.87 & 0.74 & 0.64 & 0.59 & 0.55 & 0.54 \\
\hline $\mathrm{A} 40$ & 0.1369 & 1.03 & 0.86 & 0.77 & 0.69 & 0.66 & 0.71 & 0.72 \\
\hline A55 & 0.1156 & 1.07 & 0.97 & 0.90 & 0.87 & 0.89 & 1.04 & 1.07 \\
\hline A70 & 0.0851 & 1.15 & 1.14 & 1.13 & 1.18 & 1.27 & 1.53 & 1.53 \\
\hline SmStk & 0.3139 & 1.10 & 1.08 & 1.02 & 0.91 & 0.78 & 0.48 & 0.39 \\
\hline Notes & 0.0671 & 1.38 & 1.67 & 1.88 & 2.12 & 2.33 & 2.67 & 2.76 \\
\hline Bills & 0.0429 & 1.70 & 2.20 & 2.60 & 3.02 & 3.42 & 3.86 & 4.09 \\
\hline Standard error ${ }^{c}$ & & $(0.11)$ & $(0.18)$ & $(0.23)$ & $(0.28)$ & $(0.32)$ & $(0.39)$ & $(0.45)$ \\
\hline \multicolumn{9}{|l|}{ Excess returns } \\
\hline S\&P & 0.1990 & 1.07 & 0.99 & 0.94 & 0.88 & 0.84 & 0.78 & 0.89 \\
\hline $\mathrm{P} 46$ & 0.1299 & 1.07 & 0.98 & 0.93 & 0.87 & 0.83 & 0.81 & 0.92 \\
\hline P64 & 0.1011 & 1.09 & 1.02 & 0.99 & 0.95 & 0.91 & 0.94 & 1.04 \\
\hline Bonds & 0.0761 & 1.20 & 1.33 & 1.41 & 1.48 & 1.50 & 1.66 & 1.71 \\
\hline $\mathrm{A} 25$ & 0.1616 & 1.07 & 0.98 & 0.92 & 0.83 & 0.75 & 0.58 & 0.63 \\
\hline $\mathrm{A} 40$ & 0.1335 & 1.06 & 0.97 & 0.90 & 0.82 & 0.75 & 0.65 & 0.72 \\
\hline A55 & 0.1089 & 1.07 & 0.98 & 0.93 & 0.87 & 0.83 & 0.81 & 0.92 \\
\hline A70 & 0.0729 & 1.08 & 1.01 & 0.98 & 0.94 & 0.89 & 0.91 & 1.00 \\
\hline SmStk & 0.3185 & 1.16 & 1.19 & 1.19 & 1.10 & 0.98 & 0.63 & 0.55 \\
\hline Notes & 0.0438 & 1.10 & 1.20 & 1.25 & 1.33 & 1.34 & 1.48 & 1.53 \\
\hline Standard error $^{c}$ & & $(0.11)$ & $(0.18)$ & $(0.23)$ & $(0.28)$ & $(0.32)$ & $(0.39)$ & $(0.45)$ \\
\hline
\end{tabular}

${ }^{a}$ See Table 1 for asset allocation details.

${ }^{\mathrm{b}}$ The standard deviation for ten years reflects the pattern from Years 2 through 8.

${ }^{\mathrm{c} S t a n d a r d ~ e r r o r s ~ f r o m ~ P o t e r b a ~ a n d ~ S u m m e r s ~(1988) . ~ S t a n d a r d ~ e r r o r s ~ a r e ~ f r o m ~ a ~ s i m u l a t i o n ~ b a s e d ~ o n ~ 25,000 ~}$ replications and 60 years of returns. The study provides standard errors through eight years.

haystack. In this study, real bill returns are projected from a time-series model that reflects their historical mean-averting behavior.

Tests on Excess Returns. Historical returns support the hypothesis that excess returns come from the random walk model. First, no individual autocorrelation coefficient in the bottom half of Table 4 is two standard errors from zero. Second, even at the 20 percent level, we never reject the null hypothesis that the first six autocorrelation coefficients are jointly zero. Third, 
none of the variance ratios is two standard errors from 1.0.

The finding that autocorrelation coefficients on excess returns are consistent with the random walk model does not necessarily imply that the meanreversion model is wrong. Poterba and Summers (1988) showed that standard statistical tests have little ability to distinguish returns generated by a random walk from plausible alternatives, including mean reversion.

Summers (1990) constructed a simple model of an irrational, mean-reverting market. In this model, the market is, on average, 30 percent away from its fundamental value and deviations from fundamental value have a half-life of three years; when the market is 50 percent too high, it takes, on average, three years for the market to become 25 percent too high. In the model, 75 percent of the monthly variance is transitory. Despite a clearly inefficient market and 60 years of simulated returns, standard statistical tests could reject the random walk model only 7.6 percent of the time.

The lesson is clear: Failure to reject the random walk model does not imply rejection of the mean-reversion model. Even if financial markets are mean reverting, we would not expect autocorrelation coefficients to be significantly negative. Instead, we would expect a clustering of weak negative coefficients over a range of lags. In fact, most of the second-order through fifth-order autocorrelation coefficients on excess returns in Table 4 are negative. Although they are not significant individually or collectively at the 5 percent level, the coefficients reflect the negative correlations one might expect if markets are mean reverting.

Similarly, as shown in Table 5, most of the variance ratios on stocks, especially on small stocks, are below 1.0, which suggests mean reversion. For example, the variance ratio on the S\&P reaches a minimum of 0.78 after eight years. The variance ratio on small stocks is 0.55 after ten years. This finding suggests that almost half of the variance of annual small-stock returns is attributable to temporary price changes and thus is eliminated for the longterm investor. ${ }^{16}$

The variance ratios on debt exceed 1.0, which suggests mean aversion. For example, the ten-year variance ratios on bonds and notes are 1.71 and 1.53 , respectively. These ratios suggest the risk of an all-debt portfolio to a long-term investor is more than 50 percent larger than previously believed. Thus, prior time-diversification studies, which generally rely on the random walk model, may

\footnotetext{
${ }^{16}$ Variance ratios can be calculated for holding periods longer than ten years. The $1926-93$ period, however, provides few nonoverlapping observations for long periods. For example, there are only five nonoverlapping 12-year returns since 1926 . Thus, we use ten-year variance ratios for holding periods of ten years and longer.
} 
have substantially underestimated the long-horizon risk of an all-debt portfolio.

Long-horizon variance ratios on the mixed (debt and stock) portfolios are generally slightly less than 1.0. Ten-year variance ratios on age portfolios A25 and $\mathrm{A} 40$ of 0.63 and 0.72 , respectively, show the strongest evidence of mean reversion among the mixed portfolios. Not surprisingly, they are also the only mixed portfolios with small-stock exposure. Variance ratios on mixed portfolios also benefit from the generally negative correlations between stock returns in one year and stock and debt returns in later years.

Table 6 presents serial correlations and averages of cross-correlations among asset-class excess returns. For example, S\&P excess returns for one year show weak negative average correlations with the next five annual excess returns on S\&P, small stocks, corporate bonds, and Treasury notes. A similar relationship exists for small-stock returns. These findings imply that mixed portfolios have been less risky than previously believed.

\section{Table 6. Serial Correlations and Avorages of Cross-Corrolations of Excess Retums}

\begin{tabular}{lrrrr}
\hline Next Five Observations & S\&P & SmStk & \multicolumn{1}{c}{ Bond } & \multicolumn{1}{c}{ Note } \\
\hline S\&P & -0.059 & -0.000 & 0.019 & 0.022 \\
SmStk & -0.148 & -0.067 & -0.015 & -0.004 \\
Bond & -0.097 & -0.120 & 0.031 & 0.059 \\
Note & -0.086 & -0.093 & 0.009 & 0.031 \\
\hline
\end{tabular}

Source: Ibbotson and Associates (1994) portfolios of S\&P 500, small stocks, corporate bonds, and Treasury notes.

\section{Summary}

Regression studies generally support the mean-reversion view of financial markets. Nelson (1990) and some other scholars, however, remain unconvinced. Markov-chain tests also support the mean-reversion view; stock returns tend to reverse after two-year and three-year trends. Autocorrelation tests, a third line of research, support the random walk view but do not reject the mean-reversion view. We conclude that Treasury-bill real returns are mean averting and that portfolio excess returns are consistent with both the random walk and mean-reversion views. 


\section{The Random Walk and Mean-Reversion Models}

This chapter begins with an example to illustrate the process of projecting probability distributions of portfolio real returns. Suppose we want the probability distribution on ten-year S\&P real returns. By definition, the ten-year $S \& P$ real return equals the ten-year Treasury-bill real return plus the ten-year S\&P excess return:

$\begin{aligned} & \text { 10-year } \mathrm{S} \& \mathrm{P} \\ & \text { real return }\end{aligned} \quad=\quad \begin{aligned} & \text { 10-year T-bill } \\ & \text { real return }\end{aligned}+\begin{aligned} & 10 \text {-year } \mathrm{S} \& \mathrm{P} \\ & \text { excess return }\end{aligned}$

The probability distribution of ten-year real bill returns comes from a timeseries model that reflects their historical mean-averting behavior. The probability distribution of excess returns comes from either the random walk model or the mean-reversion model. The real return probability distribution takes the name of the excess returns model. Thus, the random walk probability distribution of S\&P real return combines the distribution of real bill returns and the distribution of S\&P excess returns from the random walk model.

\section{Random Walk Model of Excess Returns}

Historical excess returns were found to be consistent with the random walk theory; that is, we cannot reject the hypothesis that historical excess returns resemble random draws from a stable probability distribution. As a result, future excess returns can be projected by randomly drawing from the stable distribution with mean and standard deviation set equal to their historical values. Specifically, assume that the excess return in year $i$ comes from a normal distribution with true mean $x$ and true standard deviation $\sigma$ :

$$
x_{i} \sim N(x, \sigma) .
$$

Because each year's excess return is a random draw, returns across years are independent and thus uncorrelated. The distribution of $n$-year cumulative excess return, $x n_{i}$, follows a normal distribution with mean $x n$ and standard 
deviation $\sigma n^{0.5 .17}$

$$
x n_{i} \sim N\left(x n, \sigma n^{0.5}\right) .
$$

A key issue addressed in the time-diversification literature is shortfall risk - the probability that a portfolio will earn less than Treasury bills for a specific holding period. Given the assumptions of the random walk model, shortfall risk can be precisely stated. The shaded area to the left of the negative of the standard normal $Z$ score in Figure 2 reflects shortfall risk for an $n$-year holding period, where $Z=\left(x n^{0.5}\right) / \sigma$. The area to the right reflects the probability that $n$-year excess returns will be positive. Notice that $Z$ increases in proportion to the square root of the holding period; thus, $-Z$ moves farther left of the mean as the holding period lengthens. As the time horizon lengthens, the probability increases that a portfolio's cumulative return will exceed the

\section{Figure 2. Shortfall Risk}

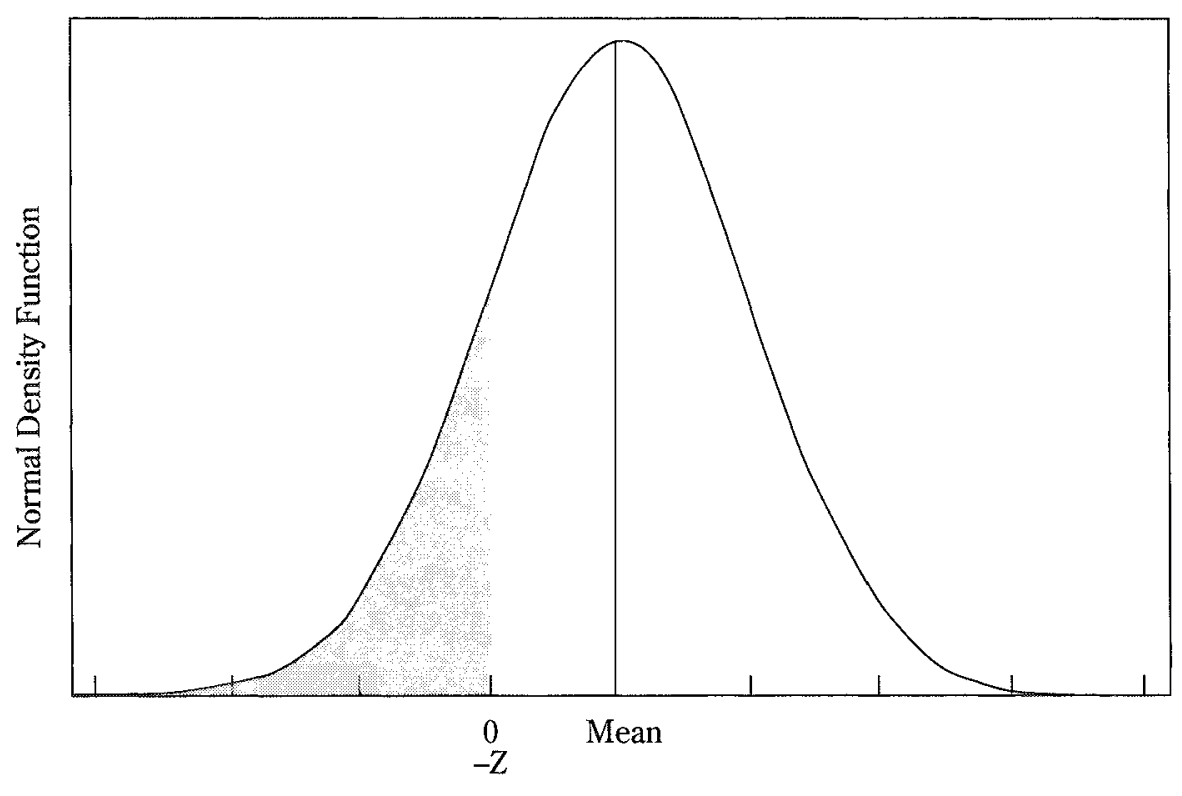

Return (\%)

\footnotetext{
${ }^{17}$ The variance of the sum of independent events is the sum of the variances. If each year's variance is $\sigma^{2}$, then assuming independence, the $n$-year variance is $\sigma^{2} n$ and the $n$-year standard deviation is $\sigma n^{0.5}$.
} 
cumulative Treasury-bill return; that is, shortfall risk declines.

For purposes of time diversification, the random walk model has one key assumption and two key values: the assumption of independence among yearly returns, and the estimates of $x$ and $\sigma$. The assumption that individual yearly returns follow a normal distribution is not critical. Even if the distribution of one-year returns is nonnormal, the central limit theorem assures that the distribution of $n$-year returns is approximately normally distributed with mean $x n$ and standard deviation $\sigma n^{0.5}$. Thus, the probability distribution of multiyear returns-which is the major interest of the time-diversification literature-is approximately normally distributed whether or not yearly returns come from a normal distribution.

In the random walk model, estimates of $x$ and $\sigma$ should be based on the longest reliable period of historical returns. We rely on the 1926-93 period and the returns series from Ibbotson and Associates (1994). The series include returns on small and large stocks and on short-, intermediate-, and long-term debt. Return series before 1926 exist on large stocks, but there is no reliable series on small stocks. Moreover, debt markets before 1926 were substantially different. The federal government was small and, at times, had no debt. Default-free Treasury securities, as we know them today, did not exist.

S\&P excess returns averaged 6.21 percent for the 1926-93 period with a standard deviation of 19.9 percent. The random walk model thus projects the distribution of $n$-year S\&P excess returns to be normally distributed; that is,

$$
N \sim\left(0.0621 n, 0.199 n^{0.5}\right) .
$$

The mean return increases linearly with the length of the holding period, $n$. The standard deviation widens with the square root of the length of the holding period. The shortfall risk on the S\&P portfolio is the area in Figure 2 to the left of $-Z=-0.3121 n^{0.5}$.

For example, the probability distribution of five-year excess return has a mean of 0.3105 and a standard deviation of 0.4450 . A five-year return of 31.05 percent corresponds to an ending wealth of 1.36 , or $e^{0.3105}$. The shortfall risk is the area to the left of $-Z=0.6979$, or 16.2 percent.

The distribution of average annual excess return in the random walk model has a mean of $x$ and a standard deviation of $\sigma / n^{0.5}$. The distribution of average S\&P excess return has a mean of 6.21 percent and a standard deviation of $19.9 n^{0.5}$. This standard deviation decreases through time by the square root of the holding period. Thus, the probability that average $S \& P$ excess returns will be within, say, 3 percent of 6.21 percent increases with the length of the holding period. At first glance, this relationship suggests that returns become 
more certain the longer the holding period. This fortuitous feature of long holding periods has been hailed as a risk-reduction feature of time diversification.

McEnally (1985) disproved this erroneous claim. Although the standard deviation of average annual return decreases through time, the standard deviations of cumulative return and ending wealth increase through time. An investor's ability to consume- the ultimate object of investment-depends upon ending wealth, which becomes more uncertain as the holding period lengthens.

\section{Mean-Reversion Model of Excess Returns}

Historical excess returns are consistent both with the random walk model and with mean reversion. As we saw earlier, stock-heavy portfolios, especially those containing small stocks, exhibit reasonable evidence of mean reversion for long holding periods.

The mean-reversion model assumes that the distribution of $n$-year cumulative excess return, $x n_{i}$, follows a normal distribution with mean $x n$ and standard deviation $\sigma n^{0.5}\left[\operatorname{VR}(n)^{0.5}\right]$; that is,

$$
x n_{i} \sim N\left(x n, \sigma n^{0.5}\left[\operatorname{VR}(n)^{0.5}\right]\right) .
$$

The $n$-year variance is set at its historical average, $\sigma^{2} n[V R(n)]$, where $V R(n)$ is the variance ratio of $n$-year excess return. Thus, the model assumes that the historical tendency in most portfolios toward weak mean reversion will continue.

Table 7 shows the values of $V R(n)$ for all eight portfolios. The historical variance of annual S\&P excess returns is 0.039601 (or $0.199^{2}$ ). The random walk model projects a probability distribution of ten-year S\&P returns with a variance equal to ten times the annual variance, 0.39601 . The mean-reversion model projects a variance of 0.3513 , or $(0.39601) \times(0.8770)$, where 0.8770 is the variance ratio of ten-year returns. The mean-reversion model projects a tighter probability distribution than the random walk model, one that reflects the historical tendency of S\&P returns toward mean reversion.

For the corporate-bond portfolio, the mean-reversion model projects wider probability distributions than does the random walk model. This result also reflects historical experience. When the variance ratio is near 1.0 , as it is for many of the debt-heavy mixed portfolios, the random walk and mean-reversion models project similar probability distributions.

Real Returns on Treasury Bills necall that Treasury-bill real returns 
Table 7. Variance Ratios of Excess Returns by Holding Period

\begin{tabular}{lccc}
\hline Portfolio $^{\mathrm{a}}$ & One Year & Five Years & Ten Years or Longer \\
\hline S\&P & 1.00 & 0.8770 & 0.8870 \\
P46 & 1.00 & 0.8263 & 0.9187 \\
P64 & 1.00 & 0.9486 & 1.0432 \\
Bonds & 1.00 & 1.4838 & 1.7122 \\
A25 & & & \\
A40 & 1.00 & 0.8255 & 0.6349 \\
A55 & 1.00 & 0.8169 & 0.7231 \\
A70 & 1.00 & 0.8721 & 0.9176 \\
\hline
\end{tabular}

${ }^{\mathrm{a} S e e}$ Table 1 for asset allocation details.

Source: Table 5.

exhibit strong mean-averting behavior. A good (i.e., above-average) year tends to be followed by a good year, and vice versa. We used 1926-93 continuously compounded real returns on Treasury bills to estimate several specifications of time-series models. We then applied diagnostic checks to the estimated models, including autocorrelation checks for white noise and comparisons of the autocorrelation function of the time series generated by the models with the 1926-93 autocorrelation function. The models that passed these tests were then judged by their closeness of fit as measured by the Akaike Information Criterion and Schwartz Bayesian Criterion.

The second-order moving-average model, MA(2), was deemed the best. The first-order and second-order parameters were -0.86726 and -0.63767 , respectively, and the $t$-ratios of -9.02 and -6.63 were significant beyond the 1 percent level. The model says that a below-average real bill return will tend to persist for two years and vice versa. Suppose a financial shock lowers the real return 1 percent below its mean. In the absence of further shocks, the real rate is expected to be 0.87 percent below its mean next year, 0.64 percent below its mean in the second year, and at its mean thereafter. Time-series models are not designed to determine the cause of the shock.

Real bill returns in 1992 and 1993 were below average. Consequently, forecasts for 1994 and 1995 are below the long-run average real return (as estimated by the model) of 0.82 percent. Individual-year forecasts as of yearend 1993 were:

\begin{tabular}{ccc}
\multicolumn{1}{c}{ Year } & Return & \\
1994 & Forecast & Standard Error \\
1995 & $-0.59 \%$ & $3.08 \%$ \\
1996 and beyond & -0.05 & 4.08 \\
& 0.82 & 4.53
\end{tabular}


Other time-series models produce similar forecasts.

The means and standard deviations of cumulative real returns for holding periods from 1 year through 40 years are shown in Table 8 .

Table 8. Means and Standard Deviations of Cumulative Real Returns on Treasury Bills by Holding Period

\begin{tabular}{ccc} 
Holding Period (years) & Mean & Standard Deviation \\
\hline 1 & -0.0059 & 0.0308 \\
3 & 0.0018 & 0.0683 \\
5 & 0.0182 & 0.0937 \\
7 & 0.0346 & 0.1134 \\
10 & 0.0592 & 0.1379 \\
15 & 0.1002 & 0.1711 \\
20 & 0.1412 & 0.1989 \\
25 & 0.1822 & 0.2232 \\
30 & 0.2232 & 0.2451 \\
35 & 0.2642 & 0.2652 \\
40 & 0.3052 & 0.2839 \\
\hline
\end{tabular}

Real Returns on Portfolios. Real returns on portfolios are projected as the sum of portfolio excess returns plus real returns on Treasury bills. The mean of $n$-year real returns equals the sum of the mean of $n$-year excess returns and the mean of $n$-year real bill returns. The variance of $n$-year real returns equals the sum of the variance of $n$-year excess returns and the variance of $n$-year real returns.

Table 9 summarizes the probability distributions of real return forecasts for the random walk and mean-reversion models for each portfolio for holding periods of 1 year through 40 years. Table 10 summarizes the probability distributions of excess returns. Probability distributions from the two models are identical for one-year holding periods. For longer periods, the random walk model assumes that variance rises linearly with the holding period, whereas the mean-reversion model relies on historical patterns to estimate how quickly variance rises.

Ending Wealth. The probability distributions of real returns and excess returns are normally distributed. Ending wealth is $e^{x}$, where $x$ is the continuously compounded, $n$-year return. If $x$ is a real return, then $e^{x}$ denotes ending real wealth; if $x$ is excess return, then $e^{x}$ denotes ending excess wealth. Ending wealth follows a lognormal distribution and is skewed to the right. The expected wealth equals $e^{x+0.5 \sigma^{2}}$, where $\sigma^{2}$ is the variance of n-year returns. 

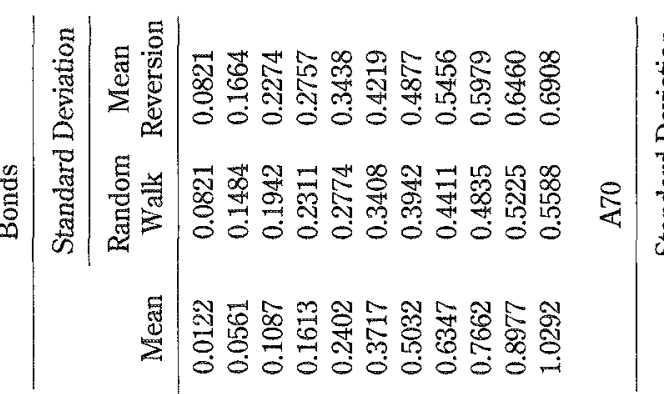

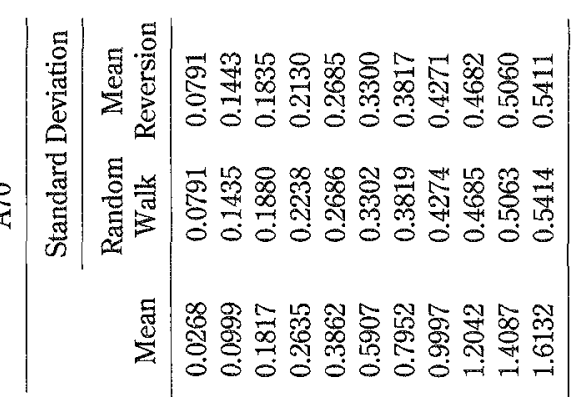

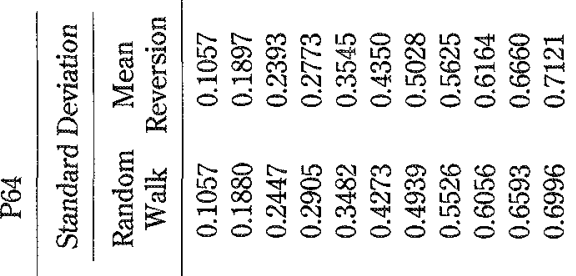

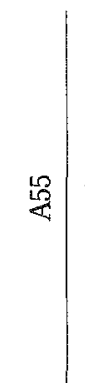

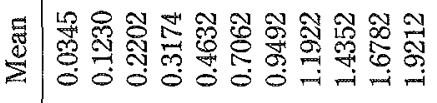

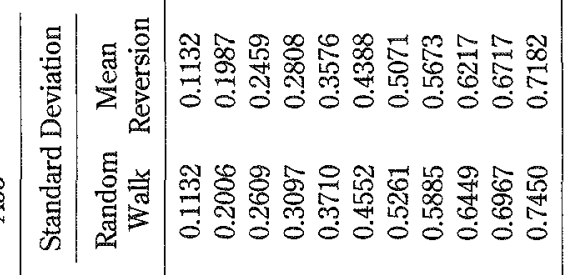

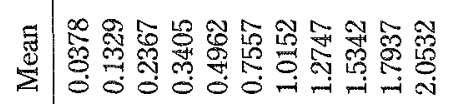

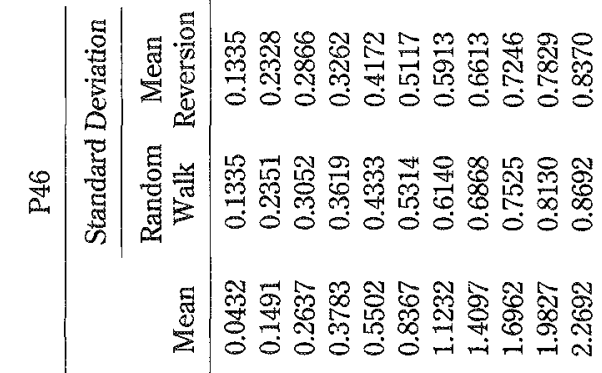

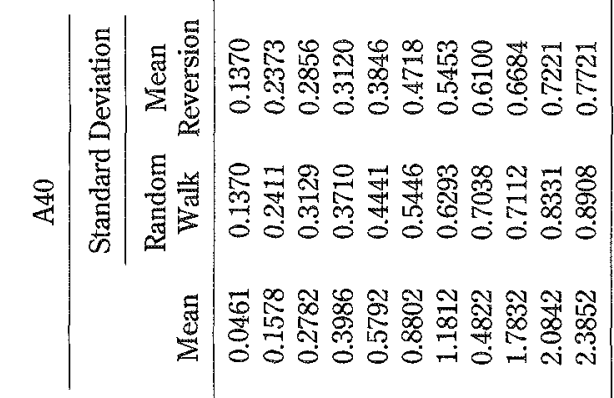

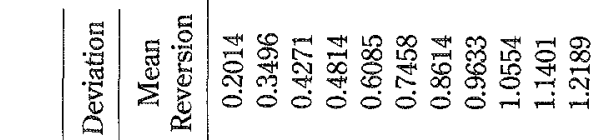

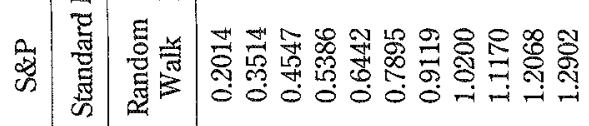

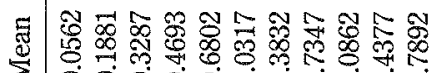

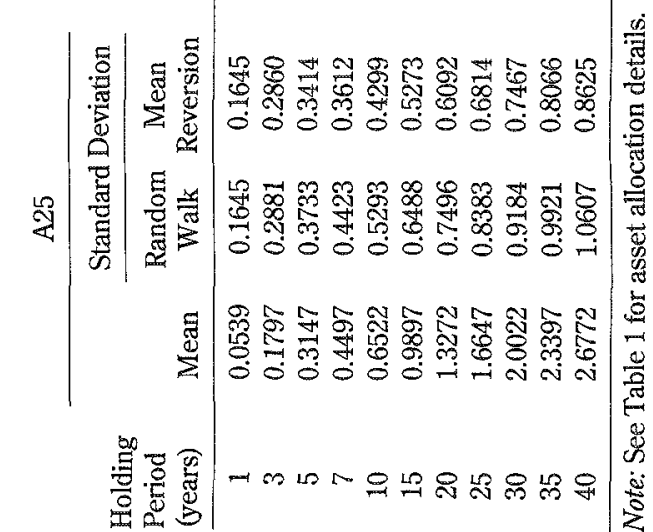



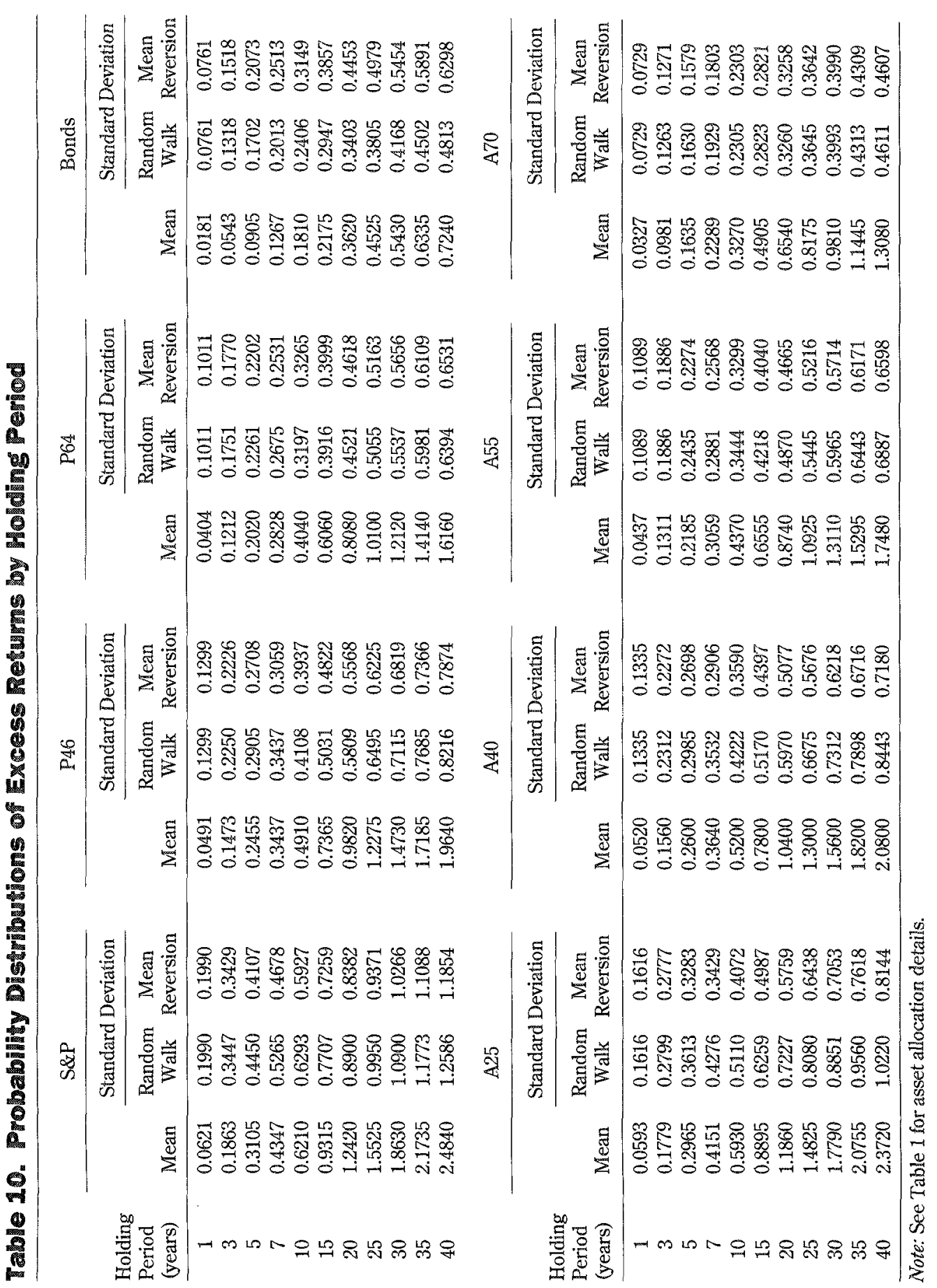
A comparison of Tables 9 and 11 should clarify properties of the lognormal distribution and help distinguish projected returns and projected ending wealth. For example, the probability distribution of ten-year S\&P real returns from the random walk model has a mean of 68.02 percent and standard deviation of 64.42 percent. Ending real wealth associated with the mean return is $e^{0.6802}$, or 1.97 . This result implies that a $\$ 1$ investment in the S\&P will most likely grow in ten years to an inflation-adjusted $\$ 1.97$.

The mean, median, and modal ten-year return is 68.02 percent. ${ }^{18}$ The median and modal ending wealth are also $\$ 1.97$, but the mean ending wealth exceeds $\$ 1.97$. The fates of fortune are equally likely to produce a ten-year return one standard deviation (or any other amount) below or above the mean. That is, the probability is equal that the ten-year return will be 3.6 percent or 132.44 percent. ${ }^{19}$ The dollar gain from a higher-than-expected return exceeds the dollar loss from a lower-than-expected return. Consequently, the expected ending wealth exceeds the wealth associated with the expected return. In this study, we concentrated on median and modal ending wealth of $\$ 1.97$; the expected ending wealth is $\$ 2.43 .^{20}$

\section{Key Assumptions}

This study relies on 1926-93 returns, especially excess returns, to project future returns, implicitly assuming that the future will look somewhat like the study period. Of course, the mean and standard deviations of future returns are not guaranteed to approximate those of the past. Siegel (1992), however, studied U.S. stock returns since 1802 and concluded that long-term real returns (which are close to excess returns) have remained "remarkably steady" during the past two centuries. Moreover, the analysis in this study implies that, since 1926, excess returns have been more stable than real returns, and we rely primarily on excess returns in our projections. Nevertheless, the projections of returns in this study implicitly assume that the future will resemble (at least somewhat) the 1926-93 period.

\footnotetext{
${ }^{18}$ By definition, the median return is the 50 th percentile return; the actual return is equally likely to be above or below the median. The modal return is defined as the most likely return.

${ }^{19}$ Note that $\left(e^{0.036}+e^{1.3244}\right) / 2=\$ 2.40$ exceeds $e^{0.6802}=\$ 1.97$.

${ }^{20}$ We discourage financial analysts from highlighting expected wealth. Because of the diminishing marginal utility of money, the utility gain from higher-than-expected returns may not exceed the utility loss from lower-than-expected returns; the pain from a $\$ 1,000$ loss exceeds the joy from a $\$ 1,000$ gain. Furthermore, most clients interpret "expected" to mean most likely, but $\$ 1.97$ is the median and modal ending wealth. Because the chance that the ending wealth will be below $\$ 2.43$ is greater than 50 percent, analysts who highlight expected wealth will probably end up with disappointed clients.
} 


\section{Investment Implications of Time Diversification}

A major factor in the implications time diversification has for investment decision making is the investor's holding period, or investment horizon. Therefore, this chapter first discusses typical investment horizons. The chapter then states and discusses specific implications of time diversification supported by the forecasts in this study.

\section{Investment Horizons}

The investment horizon is the length of time before investment funds will be spent, and the length of this period is an important determinant of the relative benefits of time diversification. An individual may invest in a stock mutual fund, switch in three years to a money market fund, switch a year later to a bond fund, and continue to switch among funds for years. If 20 years pass between the initial investment and liquidation and expenditure of the funds, then the holding period is 20 years. The good news is that many investors have holding periods of $10-30$ years and longer.

Individuals save for many reasons. As a rule of thumb, investments for nonretirement goals, such as a car, boat, or down payment on a house, typically have investment horizons of a few years or less. The benefits of time diversification are minimal for these holding periods. Investments for retirement and some other goals, however, typically have much longer horizons.

Most retirement funds have an investment horizon of 20 years or more. A 55-year-old worker may plan to retire in 10 years but has a life expectancy of 20 to 30 years. Most workers do not plan to cash in their assets at retirement, so why should they set their investment horizons at their retirement dates? If the 55 year old expects to live until 85 and to withdraw funds evenly between the ages of 65 and 85, then he or she has an average investment horizon of 20 years. By similar logic, a retirement fund for a 40 year old has a holding period in excess of 30 years. In general, caution suggests that individuals should plan for longer-than-expected investment horizons in case they live longer than expected. 
Employers provide defined-contribution or defined-benefit pension plans and profit-sharing plans. In a defined-contribution plan, the firm may make specific dollar contributions annually to its employees' retirement programs. Retirement wealth depends upon the investment performance of the fixeddollar contributions. The employee usually decides whether to invest in a bond fund, a stock fund, or a mix of funds. In a profit-sharing plan, the firm usually makes this asset allocation decision. Regardless of who makes the decision, the appropriate holding period is not the time remaining until retirement. An employee is more likely to reinvest the funds at retirement than to spend them all in the first year. Setting the investment horizon at the retirement date will lead to an overly conservative asset allocation and will deprive the beneficiary of the risk-reducing benefits of time diversification.

The liabilities of defined-benefit plans are usually formula driven. Management makes the investment decision in these plans and provides a guaranteed amount upon retirement. Firms with young work forces face pension liabilities with long investment horizons, often in excess of 30 years. Even the investment horizons for pension funds of firms with mature work forces, although shorter in length, are seldom less than ten years.

Endowment funds share some similarities with pension funds, including a long holding period. Some such funds limit spending to the amount of investment income with the idea that the principal should remain intact. The flaw with this thinking became apparent as inflation eroded the purchasing power of principal. Today, many endowments espouse a total return approach with a balance between the need for current income and the need for capital gains to preserve the purchasing power of principal. A total return approach with an annual spending rate of 5 percent may translate into an average holding period of 20 years.

By recognizing the likelihood of long holding periods and by choosing appropriate asset allocations, investors can enjoy the benefits of time diversification. A key question is whether they will "hold the course" during the inevitable periods of market volatility; they must recognize their long-term horizons and adopt strategies that reflect those horizons.

\section{Six Implications}

The forecasts in this study support six specific investment implications of time diversification. The first two implications correspond to the two traditional tenets of time diversification. The last four cover other investment implications supported by the forecasts.

Implication 1: The longer the investment horizon the larger the portion 
of the portfolio that should be devoted to common stocks and other high-return assets. Tables 11 and 12, respectively, present random walk and mean-reversion forecasts from the probability distributions of ending real wealth for the eight portfolios for holding periods of 1 year through 30 years. For a one-year horizon, median ending real wealth for the S\&P 500 portfolio according to the random walk model is 1.06 , only slightly above the 1.01 ending value on bonds. Ending real wealth of 1.06 implies that a $\$ 1$ original investment will be worth an inflation-adjusted $\$ 1.06$ at the end of one year. The difference between the S\&P and bond portfolios rises sharply as the holding period lengthens. For a 30-year holding period, median real wealth is 8.05 on the S\&P and 2.15 on bonds. Because of compounding, a small annual return advantage produces a huge return advantage over a long holding period.

A comparison of median wealth values for A25 and A70, the extremes of the age portfolios, indicates similar results. Median real wealth after one year is 1.05 on A25 and 1.03 on A70. After 30 years, the values are 7.41 and 3.33, respectively. A25, the more volatile portfolio, has a relatively small one-year ending wealth advantage, but it has a huge expected wealth advantage for a long-term investor. Comparisons of median ending wealth support the first implication. $^{21}$

Many investors, especially individual investors, define risk as potential loss. The fifth-percentile values of the portfolios provide one measure of potential loss, or downside risk. For a one-year holding period, the fifth-percentile values on the S\&P and bonds are, respectively, 0.76 and 0.88 ; that is, for a one-year holding period, the $S \& P$ has a 5 percent chance of losing at least 24 percent of its real value and the bond portfolio has a 5 percent chance of losing at least 12 percent. Clearly, stocks are risky for an investor with a one-year holding period.

For long holding periods, even the low-end values favor riskier portfolios. After 30 years, the fifth-percentile values from the random walk model are 1.28 on the S\&P and 0.97 on bonds. The corresponding mean-reversion values are 1.42 and 0.81 , respectively. For long-run investors, the larger short-term volatility of the $\mathrm{S} \& \mathrm{P}$ does not translate into a larger potential loss. This result illustrates a theme that is repeated throughout this analysis: For long-term investors, larger short-term volatility (as measured by variance and standard deviation) need not translate into larger downside risk.

A comparison of fifth-percentile ending wealth values on the extremes of the age portfolios also supports this position. Based on the random walk model,

\footnotetext{
${ }^{21}$ We prefer comparing the median and modal ending wealth values. Comparisons of mean ending wealth would produce even larger long-run return advantages for risky portfolios.
} 
Table 11. Probability Distributions of Ending Real Wealth: Random Walk Model

\begin{tabular}{|c|c|c|c|c|c|c|c|c|c|}
\hline $\begin{array}{l}\text { Holding } \\
\text { Period } \\
\text { (years) }\end{array}$ & Percentile & S\&P & P46 & P64 & Bonds & A25 & $\mathrm{A} 40$ & A55 & A70 \\
\hline \multirow[t]{7}{*}{1} & 5 & 0.76 & 0.84 & 0.87 & 0.88 & 0.80 & 0.84 & 0.86 & 0.90 \\
\hline & 10 & 0.82 & 0.88 & 0.90 & 0.91 & 0.85 & 0.88 & 0.90 & 0.93 \\
\hline & 25 & 0.92 & 0.95 & 0.96 & 0.96 & 0.94 & 0.95 & 0.96 & 0.97 \\
\hline & 50 & 1.06 & 1.04 & 1.04 & 1.01 & 1.05 & 1.05 & 1.04 & 1.03 \\
\hline & 75 & 1.21 & 1.14 & 1.11 & 1.07 & 1.18 & 1.15 & 1.12 & 1.08 \\
\hline & 90 & 1.37 & 1.24 & 1.19 & 1.12 & 1.30 & 1.25 & 1.20 & 1.14 \\
\hline & 95 & 1.47 & 1.30 & 1.23 & 1.16 & 1.38 & 1.31 & 1.25 & 1.17 \\
\hline \multirow[t]{7}{*}{5} & 5 & 0.66 & 0.79 & 0.83 & 0.81 & 0.74 & 0.79 & 0.82 & 0.88 \\
\hline & 10 & 0.78 & 0.88 & 0.91 & 0.87 & 0.85 & 0.88 & 0.91 & 0.94 \\
\hline & 25 & 1.02 & 1.06 & 1.06 & 0.98 & 1.06 & 1.07 & 1.06 & 1.06 \\
\hline & 50 & 1.39 & 1.30 & 1.25 & 1.11 & 1.37 & 1.32 & 1.27 & 1.20 \\
\hline & 75 & 1.89 & 1.60 & 1.47 & 1.27 & 1.76 & 1.63 & 1.51 & 1.36 \\
\hline & 90 & 2.49 & 1.92 & 1.71 & 1.43 & 2.21 & 1.97 & 1.77 & 1.53 \\
\hline & 95 & 2.93 & 2.15 & 1.86 & 1.53 & 2.53 & 2.20 & 1.95 & 1.63 \\
\hline \multirow[t]{7}{*}{10} & 5 & 0.68 & 0.85 & 0.90 & 0.81 & 0.80 & 0.86 & 0.89 & 0.95 \\
\hline & 10 & 0.86 & 0.99 & 1.02 & 0.89 & 0.97 & 1.01 & 1.02 & 1.04 \\
\hline & 25 & 1.28 & 1.29 & 1.26 & 1.05 & 1.34 & 1.33 & 1.28 & 1.23 \\
\hline & 50 & 1.97 & 1.73 & 1.59 & 1.27 & 1.92 & 1.78 & 1.64 & 1.47 \\
\hline & 75 & 3.05 & 2.32 & 2.01 & 1.53 & 2.74 & 2.41 & 2.11 & 1.76 \\
\hline & 90 & 4.51 & 3.02 & 2.48 & 1.81 & 3.78 & 3.15 & 2.64 & 2.08 \\
\hline & 92 & 5.70 & 3.54 & 2.82 & 2.01 & 4.58 & 3.71 & 3.02 & 2.29 \\
\hline \multirow[t]{7}{*}{20} & 5 & 0.89 & 1.12 & 1.15 & 0.86 & 1.10 & 1.16 & 1.16 & 1.18 \\
\hline & 10 & 1.24 & 1.40 & 1.37 & 1.00 & 1.44 & 1.45 & 1.41 & 1.36 \\
\hline & 25 & 2.16 & 2.03 & 1.85 & 1.27 & 2.27 & 2.13 & 1.94 & 1.71 \\
\hline & 50 & 3.99 & 3.07 & 2.58 & 1.65 & 3.77 & 3.26 & 2.76 & 2.21 \\
\hline & 75 & 7.38 & 4.65 & 3.61 & 2.16 & 6.25 & 4.98 & 3.94 & 2.87 \\
\hline & 90 & 12.83 & 6.75 & 4.87 & 2.74 & 9.85 & 7.30 & 5.42 & 3.61 \\
\hline & 95 & 17.87 & 8.44 & 5.82 & 3.16 & 12.94 & 9.17 & 6.56 & 4.15 \\
\hline \multirow[t]{7}{*}{30} & 5 & 1.28 & 1.58 & 1.55 & 0.97 & 1.63 & 1.67 & 1.61 & 1.54 \\
\hline & 10 & 1.92 & 2.08 & 1.93 & 1.16 & 2.28 & 2.21 & 2.03 & 1.83 \\
\hline & 25 & 3.79 & 3.28 & 2.79 & 1.55 & 3.99 & 3.54 & 3.00 & 2.43 \\
\hline & 50 & 8.05 & 5.45 & 4.20 & 2.15 & 7.41 & 5.95 & 4.64 & 3.33 \\
\hline & 75 & 17.11 & 9.06 & 6.32 & 2.98 & 13.76 & 10.01 & 7.16 & 4.57 \\
\hline & 90 & 33.72 & 14.31 & 9.13 & 4.00 & 24.03 & 15.98 & 10.60 & 6.08 \\
\hline & 95 & 50.60 & 18.80 & 11.37 & 4.77 & 33.55 & 21.15 & 13.40 & 7.21 \\
\hline
\end{tabular}

Note: See Table 1 for asset allocation details.

after 30 years, the fifth-percentile value on A25 exceeds the corresponding value on $A 70$. Based on the mean-reversion model, the fifth-percentile value on A25 exceeds the corresponding value on A70 for holding periods in excess of ten years. Again, larger short-term volatility need not translate into larger downside risk for long-term investors. Thus, analysis of both median wealth 
Table 12. Probability Distribution of Ending Real Wealth: Mean-Reversion Model

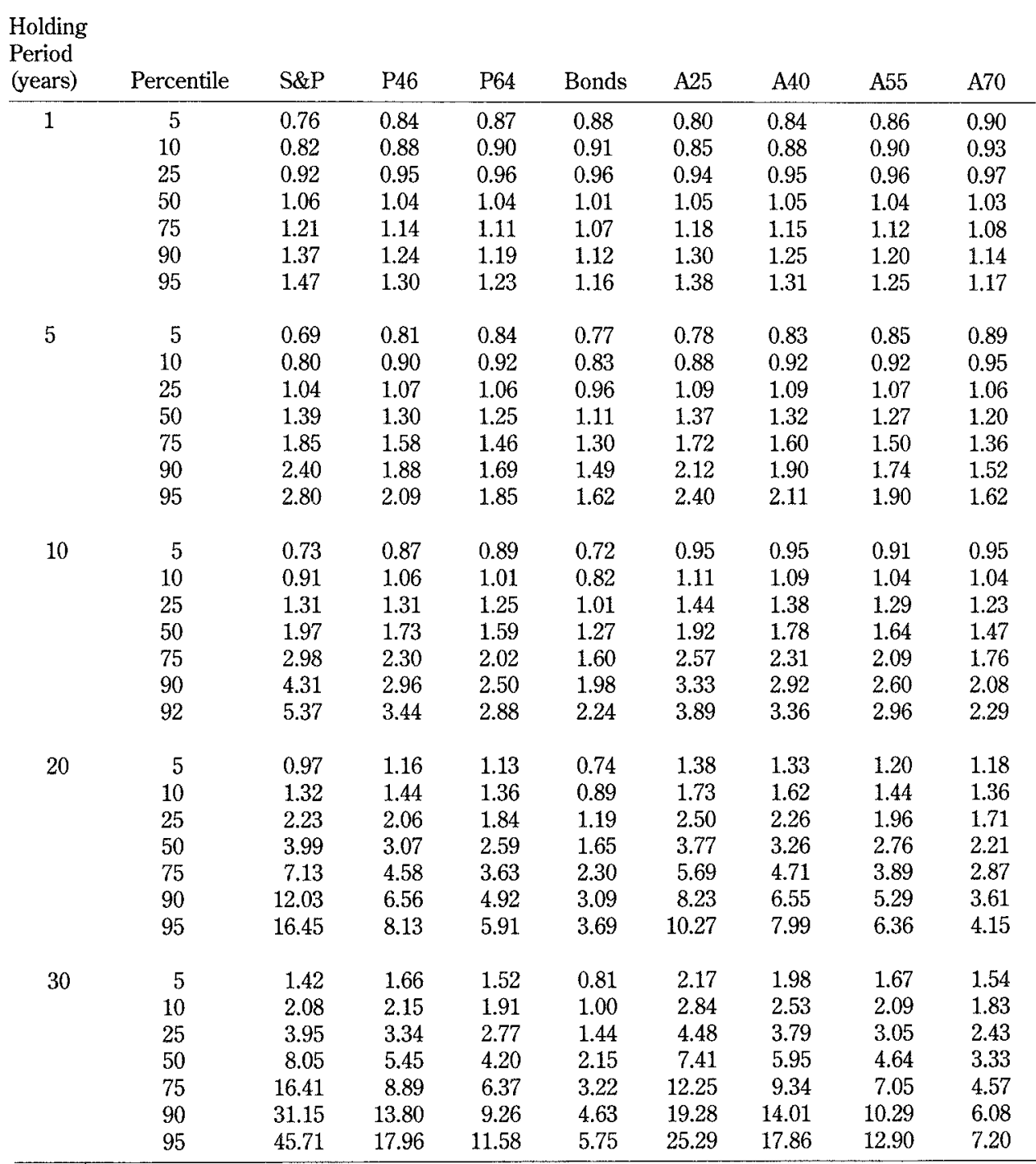

Note: See Table 1 for asset allocation details.

and fifth-percentile wealth values support Implication 1.

Not all researchers agree with Implication 1, however. In separate articles published in 1969, Nobel Laureate economist Paul A. Samuelson and Robert C. Merton each set about to determine how the optimal portfolio should 
change as the investor ages. To simplify the analysis, they assumed two assets-riskless debt with a constant return and risky stocks. Their models rely on two key assumptions: (1) Investors seek to maximize expected utility, which equals the logarithm of ending wealth $(U=\log W)$ and (2) stock prices follow a random walk - that is, each period's distribution of total return is independent of all others. They reached the surprising conclusion that investors should put the same fraction of their financial portfolios into stocks during every period. A 70-year-old widow should devote the same fraction of her financial portfolio to stocks as would her 25-year-old grandson. Given the implicit and explicit assumptions of the model, the conclusion is correct. Based on these results, some academic economists argue that an investor's age should not influence the composition of his or her portfolio of financial assets. The 25-year-old grandson should hold the same portfolio as his 70-year-old grandmother.

Twenty years later, Samuelson (1989) presented three cases with different implicit or explicit assumptions. Each case justified younger people investing more of their portfolios in risky assets than older people. The first two cases apply regardless of whether the random walk or the mean-reversion model is used.

In the first case, suppose Mary, a portfolio manager, believes Bob, her client, should increase the risk level of his portfolio. She could emphasize the importance of labor flexibility. Even if early returns prove disastrous, Bob can offset the loss with a little more work each year, a little less consumption each year, or a delay in retirement.

In the second case, suppose that "human nature is such that we are each most anxious not to fall below a 'subsistence' level of terminal wealth-so that $\log (W-S)$ [where $S$ denotes subsistence wealth] and not $\log W$ is the utility whose Expected Value we seek to maximize."22 In this case, the young should place more in risky assets than the old. In other words, a slight change in the utility function is sufficient to support Implication 1.

Most financial literature says that the wealthy have a larger risk tolerance because of their larger safety cushion. The idea of a "safety cushion" implies a minimum acceptable or subsistence level of wealth. Moreover, the subsistence wealth should certainly be cast in real terms. Because the analysis in this study relies on real returns and the closely aligned excess returns, it would seem to fit the $\log (W-S)$ format.

The third case changes both of the key assumptions in the 1969 papers. It assumes that returns are mean reverting and that investors are more risk

${ }^{22}$ Samuelson (1989), p. 11, emphasis his. 
averse than the $\log W$ utility function implies. Samuelson noted that "the bulk of the empirical evidence, cross-sectional and from time series, is that real-life investors are more risk-averse than $[\log W] . "{ }^{23}$ Consequently, if real-life investors believe that security markets are mean reverting, then, everything else the same, they should reduce their exposure to risky assets as they age.

The most general justification of Implication 1 is Samuelson's first case, which relies on Bodie, Merton, and Samuelson (1992). They justify the implication whether stock returns follow a random walk or are mean reverting, noting that disastrous initial portfolio returns for the young can be offset by working more or consuming less. At the margin, the cost of more work or less consumption each year is relatively low. Also, young people could choose to delay retirement. Moreover,

the ability to vary labor supply ex post tends to induce the individual to assume greater risks in his investment portfolio ex ante. An individual who has flexibility in choosing how much or how long to work later in life will prefer to invest substantially more of his money in risky assets than if he has no such flexibility. Viewed in this way, labor supply flexibility creates a kind of insurance against adverse investment outcomes. Thus, our framework explains why the young (with greater labor flexibility over their working lifetimes) may take significantly greater investment risks than the old. ${ }^{24}$

The recognition that the young have labor supply flexibility supports Implication 1. Also, investors who are interested in maintaining their terminal wealth at or above some subsistence level should follow the implication. Finally, investors who believe that security markets are mean reverting should follow the implication.

Implication 2: After 20 years, investors can be 90 percent confident that portfolios with at least a 20 percent stock exposure will earn more than Treasury bills. Even after 25 years, they cannot be 90 percent confident that long-term bonds will earn more than Treasury bills. This implication says that, in the long run, we can be reasonably sure that a high-risk portfolio will earn more than a low-risk portfolio. The research generally supports this statement for stockonly and mixed portfolios but rejects it for bond-only portfolios. To be more conclusive, we must give specific meaning to the terms "in the long run" and "reasonably sure."

Statements such as "we can be reasonably confident that stocks will beat

\footnotetext{
${ }^{23}$ Samuelson (1989), p. 10, emphasis his.

${ }^{24}$ Bodie, Merton, and Samuelson (1992), p. 428.
} 
cash in the long-run" are common. The estimates of shortfall risk in Table 13 help clarify this statement's meaning. Shortfall risk denotes the probability that a portfolio will earn less than Treasury bills for a specific holding period. The good news is that both models support this statement at the 90 and 95 percent confidence levels. The bad news is that "the long run" is longer than many investors believe. For the S\&P 500 - perhaps the most widely accepted market benchmark - at least 15 years are needed to reach 90 percent confidence that stocks will beat cash and at least 25 years to reach 95 percent confidence. For a stock-only portfolio, the long run can be very long indeed.

Table 13. Estimates of Shortfall Risk by Holding Period

\begin{tabular}{|c|c|c|c|c|c|c|c|c|}
\hline $\begin{array}{l}\text { Holding } \\
\text { Period } \\
\text { (years) }\end{array}$ & S\&P & $\mathrm{P} 46$ & $\mathrm{P} 64$ & Bonds & A25 & $\mathrm{A} 40$ & A55 & A70 \\
\hline \multicolumn{9}{|c|}{ Random walk model } \\
\hline 1 & $37.8 \%$ & $35.3 \%$ & $35.5 \%$ & $40.6 \%$ & $35.7 \%$ & $34.9 \%$ & $34.4 \%$ & $32.7 \%$ \\
\hline 5 & 24.3 & 19.9 & 18.6 & 29.8 & 20.6 & 19.2 & 18.5 & 15.8 \\
\hline 10 & 16.2 & 11.6 & 10.3 & 22.6 & 12.3 & 10.9 & 10.2 & 7.8 \\
\hline 15 & 11.3 & 7.2 & 6.1 & 17.9 & 7.8 & 6.6 & 6.0 & 4.1 \\
\hline 20 & 8.1 & 4.5 & 3.7 & 14.4 & 5.0 & 4.1 & 3.6 & 2.2 \\
\hline 25 & 5.9 & 2.9 & 2.3 & 11.7 & 3.3 & 2.6 & 2.2 & 1.2 \\
\hline 30 & 4.4 & 1.9 & 1.4 & 9.6 & 2.2 & 1.6 & 1.4 & 0.7 \\
\hline \multicolumn{9}{|c|}{ Mean-reversion model } \\
\hline 1 & 38.8 & 35.3 & 34.5 & 40.6 & 35.7 & 34.9 & 34.4 & 32.7 \\
\hline 5 & 22.8 & 14.9 & 18.09 & 33.1 & 18.3 & 16.8 & 16.8 & 15.0 \\
\hline 10 & 14.7 & 11.2 & 10.8 & 28.3 & 7.3 & 7.4 & 9.3 & 7.8 \\
\hline 15 & 10.0 & 6.3 & 6.5 & 24.1 & 3.7 & 3.8 & 5.2 & 4.1 \\
\hline 20 & 6.9 & 3.9 & 4.0 & 20.8 & 2.0 & 2.0 & 3.1 & 2.2 \\
\hline 25 & 4.9 & 2.4 & 2.5 & 18.2 & 1.1 & 1.1 & 1.8 & 1.2 \\
\hline 30 & 3.5 & 1.9 & 1.6 & 16.0 & 0.1 & 0.6 & 1.1 & 0.7 \\
\hline
\end{tabular}

Note: See Table 1 for asset allocation details.

The results are more encouraging for the diversified age portfolios. For example, for the ten-year holding period for the mean-reversion model in Table 13 , shortfall risk is estimated at less than 10 percent on all of the age portfolios. Not surprisingly, estimates of shortfall after ten years are slightly larger according to the random walk model. They range from 7.8 percent on A70 to 12.3 percent on A25. Generalizing, we can be about 90 percent confident that portfolios diversified across debt and equity and within debt and equity classes will earn more than Treasury bills after ten years.

We also examined shortfall probabilities on portfolios diversified across the S\&P and bonds. We raised the S\&P weight in 10 percent increments from zero to 10 percent to 20 percent and so on. Based on the less optimistic random 
walk model, we can be 90 percent confident that portfolios with at least a 20 percent stock exposure will earn more than Treasury bills after 20 years. Based on this finding, the minimum meaningful stock exposure is 20 percent. Allocations below that amount are too small reasonably to assure positive excess returns after 20 years.

The long-run scenario is not rosy for the long-term bond. Even after 25 years, the shortfall probability on bonds is 11.7 percent according to the random walk model and 18.2 percent according to the mean-reversion model. Clearly, based on most investors' interpretations of "in the long run" and "reasonably sure," the following statement applies: In the long run, we cannot be reasonably sure that long-term bonds will earn more than Treasury bills.

Some financial analysts may be surprised at the persistence of shortfall risk in the bond-only portfolio. One way to test the reasonableness of the estimates is to look at the historical record of returns. Since 1926, 39 overlapping 30-year holding periods have occurred, beginning with the 1926-55 period and ending with the 1964-93 period. High-grade corporate bonds earned less than Treasury bills in 15 , or 38.5 percent, of these 30 -year periods. Similarly, corporate bonds earned less than Treasury bills in 38.8 percent of the 20-year periods and 45.8 percent of the 10-year periods since 1926 .

We compared long-term historical returns on Treasury bonds and Treasury notes with returns on Treasury bills. Comparing Treasury security returns removes the influence of the default premium in corporate bonds and allows a purer analysis of the impact of maturity alone on security returns. Table 14 presents estimates of shortfall risk from the random walk model, the meanreversion model, and historical returns. Treasury bonds earned less than Treasury bills in 51.3 percent (20 of 39) of the 30-year holding periods since 1926. The random walk and mean-reversion models estimate shortfall risk after 30 years of 18.3 percent and 23.2 percent, respectively. Clearly, the evidence does not imply reasonable assurance that long-term debt will earn more than cash in the long run.

The analysis of returns on Treasury notes is instructive. Treasury notes earned less than Treasury bills in 7.7 percent of the 30-year holding periods since 1926. The random walk and mean-reversion models estimate shortfall risk of 3.0 percent and 6.5 percent, respectively. Shortfall risk decreases much more quickly on Treasury notes than on Treasury bonds.

The liquidity preference theory argues that all investors consider longterm debt to be riskier than short-term debt, and they demand and receive a positive risk premium for extending maturity. We believe that this view generally describes the view of individual investors, commercial banks, and others who dominate the short- to intermediate-term debt markets. For these 
Table 14. Comparison of Shortfall Risk of Treasury Bonds and Notes versus Treasury Bills

\begin{tabular}{lcccc}
\hline Asset & $\begin{array}{c}\text { Holding Period } \\
\text { (years) }\end{array}$ & Random Walk & Mean Reversion & Historical Returns \\
\hline 20-year Treasury bonds & 20 & $23.8 \%$ & $27.3 \%$ & $46.9 \%$ \\
& 30 & 18.3 & 23.2 & 51.3 \\
5-year Treasury notes & 20 & 6.3 & 10.8 & 16.3 \\
& 30 & 3.0 & 6.5 & 7.7 \\
\hline
\end{tabular}

investors, five-year notes are riskier than one-month Treasury bills, and they demand a larger expected return before they are willing to bear the additional interest rate risk. As a result, returns on five-year notes generally exceed returns on bills. Therefore, in the long run, we can be reasonably confident that five-year Treasury notes will earn more than one-month Treasury bills.

Pensions and life insurance companies have strong demand for long-duration assets and hence dominate the long-term end of the bond market. For them, the critical assumption of the liquidity preference theory does not hold; they do not consider long-term debt to be riskier than short-term debt, and they do not demand a larger return for extending maturity. For these institutional investors, longer maturity means longer duration and less risk. Consequently, a move from intermediate- to long-term debt does not necessarily increase the maturity risk premium. In fact, it may fall, which may explain the larger returns since 1926 on Treasury notes than on Treasury bonds.

Thus, the analysis supports only part of the second tenet, the argument that, in the long run, we can be reasonably sure that portfolios with at least 20 percent stock exposure will earn more than Treasury bills; the analysis does not support a similar statement for a portfolio of long-term bonds. Moreover, to reach the 90 percent confidence level, the "long run" means at least 15 years for a stock-only portfolio and about 10 years for a mixed portfolio.

Implication 3: Diversifying a portfolio between debt and equity reduces its downside risk and enhances the benefits of time diversification. Figure 3 presents the probability distributions after five years of ending real wealth for the S\&P portfolio, the mixed portfolio $\mathrm{P} 64$, and bonds. The figures and tables in this section come from the mean-reversion model, but the random walk model also supports this implication. The mixed portfolio has the lowest downside risk. Despite the 40 percent stock exposure, fifth-percentile wealth on P64 is 0.84; low-end wealth on bonds is 0.77 . This example shows that 
adding some stock to a bond portfolio need not raise the portfolio's risk. Financial analysts may be able to use Figure 3 and related material to impress upon their clients the need to look at portfolio risk, rather than single-asset risk, and at the idea that adding some stock to a bond portfolio can reduce portfolio risk.

Figure 3. Distributions of Five-Year Ending Real Wealth on the S\&P, P64, and Bonds: Mean-Reversion Model

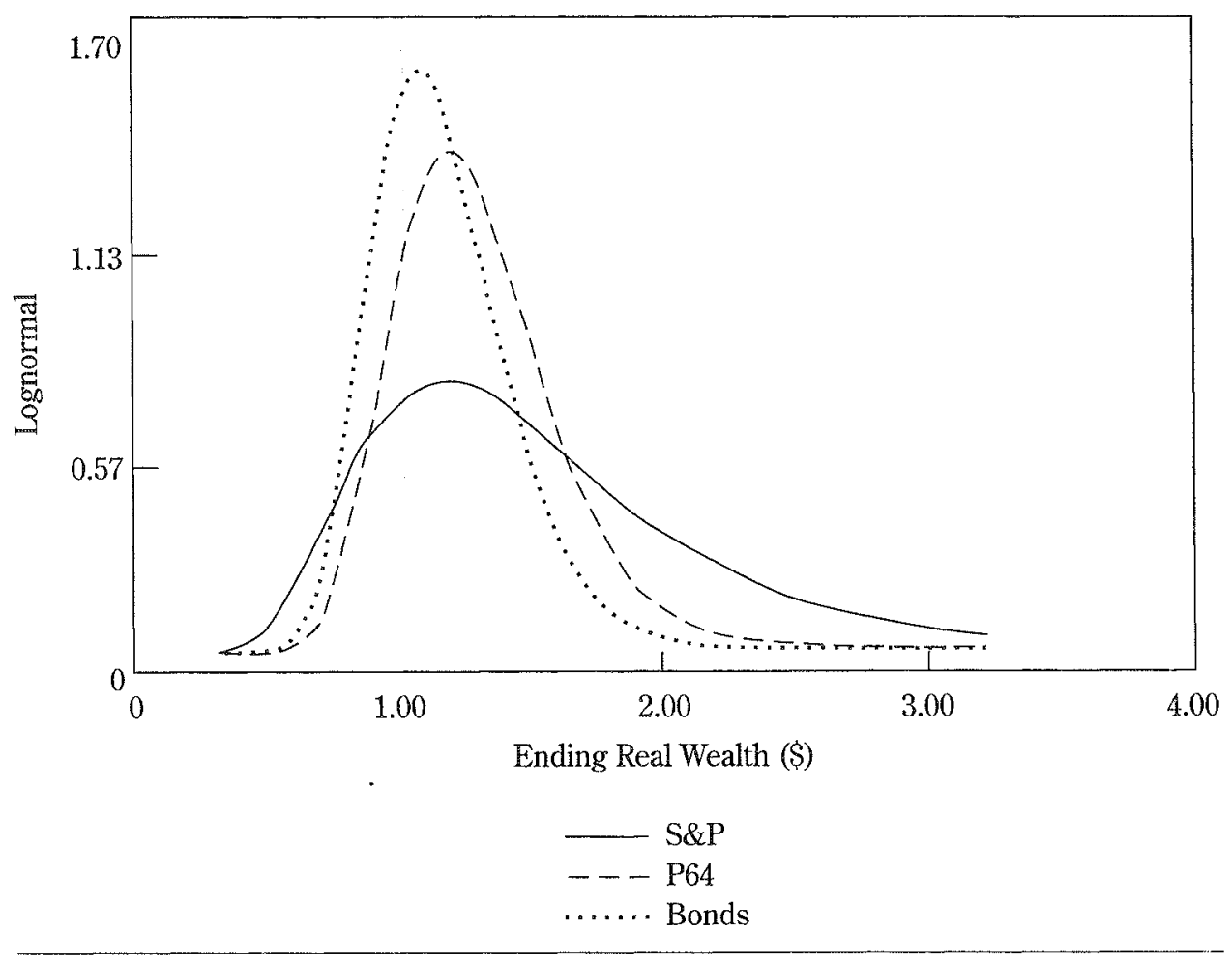

Table 15 shows the fifth-percentile ending real wealth values on the $S \& P$, $\mathrm{P} 64$, and bond portfolios for holding periods of 5 through 30 years. Notice that the values for P64 consistently exceed the values on the stock-only and bond-only portfolios. Many investors are more concerned with downside risk than upside potential. These investors may practice a maximin strategy, one designed to maximize the minimum wealth (defined here as the fifth-percentile value). These investors must hold a portfolio diversified across debt and equity regardless of their holding periods. What may be less clear is that they 
Table 15: Fifth-Percentile Values of Ending Real Wealth by Holding Period: Mean-Reversion Model

\begin{tabular}{lccc}
\hline $\begin{array}{l}\text { Holding Period } \\
\text { (years) }\end{array}$ & S\&P & P64 & Bonds \\
\hline 5 & 0.69 & 0.84 & 0.77 \\
10 & 0.73 & 0.89 & 0.72 \\
20 & 0.97 & 1.13 & 0.74 \\
30 & 1.42 & 1.52 & 0.81 \\
\hline
\end{tabular}

Note: See Table 1 for asset allocation details.

Source: Table 11.

must hold a diversified portfolio at all times. Downside risk can be reduced by holding a diversified portfolio at all times and by holding a portfolio that is diversified across time periods, that is, by time diversification. Samuelson $(1989,1990)$ showed that both types of diversification reduce the possibility of unfavorable long-run returns.

The fifth-percentile values in Table 12 for A40 and P46 imply that investors can further benefit by diversifying within asset classes, that is, by holding more than one type of equity and more than one type of debt. Both portfolios contain 40 percent debt and 60 percent equity, but A40 contains two types of equity and three types of debt. After ten years, the fifth-percentile value on A40 is 0.95 , which is considerably above the 0.87 value on P46. The lower downside risk on A40 reflects the benefits of diversification within asset classes.

This study relies on returns on U.S. investments since 1926 . The lack of a good return series on international stocks and bonds since 1926 precludes formal analysis of the benefits of international diversification. A reasonable extension of the above analysis, however, and one that is consistent with available evidence, implies that a modest international stock exposure will further reduce portfolio risk. Investors can reduce risk by not placing all their "eggs" in one country.

A further extension of the diversification theme is to expand the portfolio to include real assets, especially real estate. Although liquidity problems may prevent an investor with a short holding period from buying real estate, historical correlations suggest that most long-term investors should hold a portfolio diversified across debt, equity, and real estate. Ibbotson, Siegel, and Love (1985-86), for example, examined 1960-84 historical correlations between U.S. total bonds, U.S. equities, and two types of U.S. real estate (residential and business) for the 1960-84 period. The strongest correlation across asset types was 0.192 between bonds and business real estate. A correlation coefficient of 0.192 implies that the variance of one asset can explain 3.7 percent 
of the variance of the other; some 96.3 percent of the variance is unrelated. High-grade debt, equity, and real estate are distinct asset types with historically weak correlations with one another. Investors should be able to reduce downside risk by holding portfolios diversified across all three asset classes.

Implication 4: The relative risk of a portfolio depends upon the length of the holding period. An example can help to distinguish between the concepts of absolute risk and relative risk. Which of two investments, one offering $\$ 1$ outright and the other $\$ 1$ per spot on the roll of a die, is riskier?

According to traditional financial risk measures, such as standard deviation and variance, the roll of the die is riskier. We would probably not think of it as riskier, however, because it has no chance of underperforming the sure thing. Either investment can claim to produce a certain return. If we define uncertainty in absolute dollar returns, the first investment-the $\$ 1$ outrightis certain. If we define uncertainty in relative terms, the roll of the die presents the certain alternative because it is certain to produce at least as large a return.

Suppose the investment alternatives are a sure $\$ 3$ or $\$ 1$ per spot on the roll of a pair of dice. The roll of the dice produces a less certain absolute dollar return, but we would hesitate to call it riskier because there is only about a 3 percent chance that it will earn less than the sure $\$ 3$ return.

Whether an investment in A40 or Treasury bills is riskier depends upon the length of the holding period. For a 25-year period, the relative riskiness of A40 is similar to the dice example above. The absolute dollar return on the mixed portfolio is less certain, but we would hesitate to call it riskier, because both models estimate less than a 3 percent chance that it will earn less than Treasury bills.

A cornerstone of modern portfolio theory says that the riskiness of an investment cannot be determined independently from the portfolio setting; an investment may be very risky if held alone but have lower risk if held in a diversified portfolio. Similarly, a portfolio's risk cannot be determined independently from the planned holding period; the portfolio may be very risky if the holding period is short but of modest risk if the holding period is long.

Implication 5:Variance and standard deviation do not reflect a portfolio's risk when the holding period is long. This implication of time diversification follows directly from the previous one. The variance and standard deviation of ending wealth increase with the length of the holding period. The uncertainty of the absolute ending wealth on A40 after 25 years exceeds that on Treasury bills. This larger absolute-dollar uncertainty, however, does not translate into a larger perceived risk for long-term investors. After 25 years, the major 
uncertainty is how much more A40 will be worth than Treasury bills, but such uncertainty does not reflect perceived risk.

Implication 6: We should not judge the success or failure of a portfolio chosen for its long-horizon prospects by its returns over shorter horizons. This statement applies whether stocks follow a random walk or are mean reverting. If returns are mean reverting, however, then judging the success or failure of a portfolio over short horizons is even less appropriate. Weak returns in one period will likely be followed by strong returns in the next.

The ill-timed Barker-Bundy Report of the Ford Foundation in 1969 encouraged colleges, with their long investment horizons, to increase permanently the equity weight of their endowment portfolios. The poor stock returns of the next decade were considered the death knell of this policy. Ten years, however, is too short a period of time to assure decent stock returns. For a ten-year holding period, the more optimistic mean-reversion model estimates shortfall risk at about 15 percent. The trustees judged the portfolio strategy over too short an investment horizon, and history shows that they should have "held the course." Most college endowments have holding periods much longer than ten years.

Investors tend to abstract from the recent past-five to ten years or sometimes fewer. Consequently, they underestimated stocks' risk after 1968 and overestimated stocks' risk after the 1973-74 debacle. This psychology may explain the tendency of pensions and college endowments to move into stocks after an epoch of strong returns and out of stocks after an epoch of poor returns. If financial markets are mean reverting, these investors should modestly adjust their portfolio weights in the opposite direction. If financial markets follow a random walk, the investors should consider a constant-weight strategy. A constant-weight strategy is contrarian: Buy after a falling market, and sell after a rising market. Investors who judge the riskiness of assets based on returns in the past few years do the opposite, selling after a falling market and buying after a rising market. A major contributor to this perverse behavior is judging a portfolio's success over too short a horizon. 


\section{The Rislk-Return Trade-Off}

Even unsophisticated investors are aware of the trade-off between risk and return, but they seldom have a feel for the dimensions of the trade-off. The figures presented in Appendixes A and B and discussed in this section are intended to provide investors with a picture (as we currently understand it) of risk-return trade-offs by holding period and for several portfolios. Moreover, these portfolios reflect asset mixes recommended by Malkiel (1990), Peavy and Sherrerd (1990), and other investment professionals. With these figures, a financial analyst can better assess a client's risk tolerance and help him or her make an informed asset allocation decision.

Two sets of figures are presented: one based on the random walk view (Appendix A) and one on the mean-reversion view (Appendix B). The sequence of the figures is the same in both sets. Figures 1 through 18 in both sets are designed for individual investors. Figures 1 through 15 present probability distributions of ending real wealth per $\$ 1$ original investment. They represent forecasts for holding periods of 1, 5, 10,20, and 30 years. For each holding period, they show probability distributions for each age portfolio plus the S\&P 500 portfolio. For one- and five-year horizons, they also show the distribution of ending wealth on Treasury bills. Figures 16 through 18 graph the shortfall risk on various portfolios for holding periods from 1 year through 30 years.

For each holding period, the probability distribution of each portfolio can be compared with the distributions on the next less risky and the next more risky age portfolios. Thus, one figure may graph the distributions of A70, A55, and A40, and the next graphs the distributions of A40, A25, and S\&P. This arrangement allows investors to compare directly the distribution of $A 40$ with the distributions of A55 and A25.

Financial advisors may find several figures useful in conveying the benefits of diversification. Figures 1,4 , and 12 in the appendixes highlight the benefits of diversification across debt and equity. For example, portfolio A70 provides a more desirable distribution of returns than the bond-only portfolio. Figure 13 in the appendixes and, to a lesser extent, Figure 1 highlight the benefits of diversification within each asset class-that is, the benefits of diversifying 
across short-term, intermediate-term, and long-term debt and across small and large stocks.

Figures 19 through 24 of the appendixes present the risk-return trade-off on P64 and P46, the pension fund portfolios. Pension funds frequently invest between 40 percent and 60 percent of pension assets in long-term bonds and the remainder in common stocks. In fact, Ambachtsheer (1987) presents a formal defense of the 60/40 debt/equity asset mix for most defined-benefit plans. Because their liability is long term, pensions have little interest in short-term or intermediate-term debt. Thus, P64 and P46 contain only longterm bonds and common stocks, specifically 60 percent bonds/40 percent S\&P and 40 percent bonds $/ 60$ percent $S \& P$, respectively. Separate figures show probability distributions for holding periods of $1,5,10,20$, and 30 years. Figure 24 graphs the shortfall risk for holding periods out to 30 years.

We recommend that financial analysts or planners follow a three-step procedure. First, they must determine their own views of financial markets. More formally, what do they believe is the returns-generating process governing financial markets? Do the markets follow a random walk or exhibit mean reversion? Both views have statistical support. We present sets of graphs for each model, but the choice of which set to use depends upon the analyst's view of the financial markets.

The second step is to estimate the client's holding period or investment horizon. Individuals saving for retirement will probably have long holding periods; those saving for a down payment on a house will have shorter holding periods. Institutional investors, such as pension and endowment funds, often have holding periods of 20 years or longer. Each client, with the help of a financial advisor, should estimate the planned holding period.

Third, the advisor can show the client the risk-return trade-off for each portfolio. For example, an adviser who believes in the random walk view can show a client who has a ten-year holding period Figures A-8 and A-9. These figures consist of graphs that portray the probability distributions of ending real wealth on A25, A40, A55, A70, and S\&P.

Although the figures reflect year-end 1993 forecasts, we believe they will continue to depict closely the relative risks of the portfolios. Forecasts of precise ending real wealth values will change, however. Recall that ending real wealth consists of the sum of the Treasury-bill real return plus the portfolio's excess return. Precise dollar values in the figures reflect the year-end 1993 projections of below-average real bill returns for 1994 and 1995, followed by normal returns thereafter. If the real bill rate is higher a few years from now, then the distributions of ending real wealth on all portfolios will be slightly higher. The relative attractiveness of the portfolios depends only on distribu- 
tions of excess returns, however, and these distributions have remained relatively stable. Tables A-1 and B-1 provide these distributions.

As noted earlier, the statistical tests support the random walk model and its hypothesis that the distributions of excess returns have remained constant. The random walk model implies that its figures will continue to depict precisely the relative risks of the portfolios. According to the mean-reversion model, portfolios' relative risks change through time. Even in this case, the figures should closely depict the relative risks for longer holding periods.

Suppose an analyst believes markets are mean reverting and projects below-average stock returns for the next few years. A forecast for a 20-year horizon would then predict below-average excess stock return for perhaps 5 years followed by average returns for the next 15 years. No model implies a meaningful ability to predict returns beyond a few years. Consequently, today's prediction of 20-year excess return on A40 should be similar to a later year's prediction, because the two forecasts contain the same forecast for the last 15 years. Moreover, adjacent portfolios (e.g., A40 and A55) contain similar asset weights, so below-average or above-average prospects for an asset class will similarly affect the adjacent portfolio's prospects. In short, according to the random walk model, the figures should precisely depict the relative risks of portfolios. If markets are mean reverting, the figures should continue to depict relative risks, especially for adjacent portfolios and for holding periods of ten years or longer. 


\section{Summary}

This study had three goals. The first was to review recent research on the behavior of financial markets. Do security prices follow a random walk, or are they either mean reverting or mean averting? Do security returns reverse? Are security prices too volatile to be explained by a random walk? Regression tests and Markov-chain tests generally support the mean-reversion view of financial markets: Good epochs tend to follow bad epochs, and bad epochs tend to follow good epochs. The autocorrelation tests show that Treasury-bill real returns follow the mean-aversion view of financial markets, but historical excess returns on portfolios are consistent with both the random walk and meanreversion views of financial markets.

A second goal was to assess the investment implications of time diversification. How should the length of the holding period affect an investor's asset allocation? Based on the evidence about how security markets behave, we developed two sets of future return projections, one based on a random walk model and one based on a mean-reversion model. Both models provide support for the following six investment implications:

- The longer the investment horizon, the larger the portion of the portfolio that should be devoted to common stocks and other high-return assets.

- After 20 years, an investor can be 90 percent confident that portfolios with at least a 20 percent stock exposure will earn more than Treasury bills. Even after 25 years, however, he or she cannot be 90 percent confident that long-term bonds will earn more than Treasury bills.

- Diversifying a portfolio between debt and equity reduces its downside risk and enhances the benefits of time diversification. Downside risk can be reduced by holding a diversified portfolio at all times and by holding a portfolio across time periods--that is, by time diversification. Both types of diversification reduce the probability of miserable longrun returns.

- The relative risk of a portfolio depends upon the length of the holding period. A portfolio may be very risky if the holding period is short but of modest risk if the holding period is long. 
- Variance and standard deviation do not reflect a portfolio's perceived risk when the holding period is long.

- We should not judge the success or failure of a portfolio chosen for its long-horizon prospects by its returns over shorter horizons.

The third goal of the study was to provide investors with a picture of the risk-return trade-off of several portfolios for holding periods of 1 through 30 years. These portfolios were carefully selected to reflect asset allocations generally recommended by Malkiel (1990), Peavy and Sherrerd (1990), and other investment professionals. A financial analyst should first decide if he or she believes financial markets are best described by a random walk or mean reversion and use the appropriate set of projections. The analyst can then show a client the projected probability distributions of ending wealth on several portfolios with distributions that correspond to the client's holding period. The graphs of ending real wealth (per $\$ 1$ invested) provide a picture of the risk-return trade-offs of alternative asset mixes. These should help clients make informed investment decisions that reflect their own risk tolerances. The relative risks of portfolios remain fairly stable, especially for longer holding periods, so the graphs should prove useful now and in future years. 


\section{Appendix A: Risk-Return Trade-Offs Based on the Random Walk Model}

\section{Probability Distributions of Ending Real Wealth: Individual Investors}

The following figures are distributions of 1-year to 30-year ending real wealth per dollar of original investment according to the random walk model. Each figure compares the probability distributions of three portfolios. The vertical shaded lines denote wealth of $\$ 1$.

Figure A-1. One-Year Ending Real Wealth on T-Bills, Bonds, A70

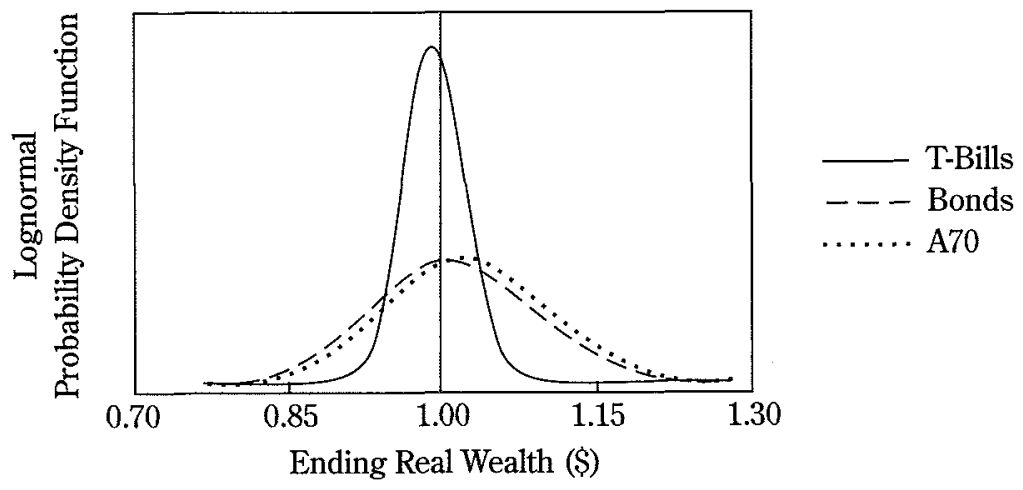

\begin{tabular}{lccccccc} 
& \multicolumn{8}{c}{ Percentiles of Distributions } \\
\cline { 2 - 8 } & 5 & 10 & 25 & 50 & 75 & 90 & 95 \\
\hline T-bills & 0.95 & 0.96 & 0.97 & 0.99 & 1.01 & 1.03 & 1.05 \\
Bonds & 0.88 & 0.91 & 0.96 & 1.01 & 1.07 & 1.12 & 1.16 \\
A70 & 0.90 & 0.93 & 0.97 & 1.03 & 1.08 & 1.14 & 1.17 \\
\hline
\end{tabular}


Figure A-2. One-Year Ending Real Wealth on A70, A55, A40

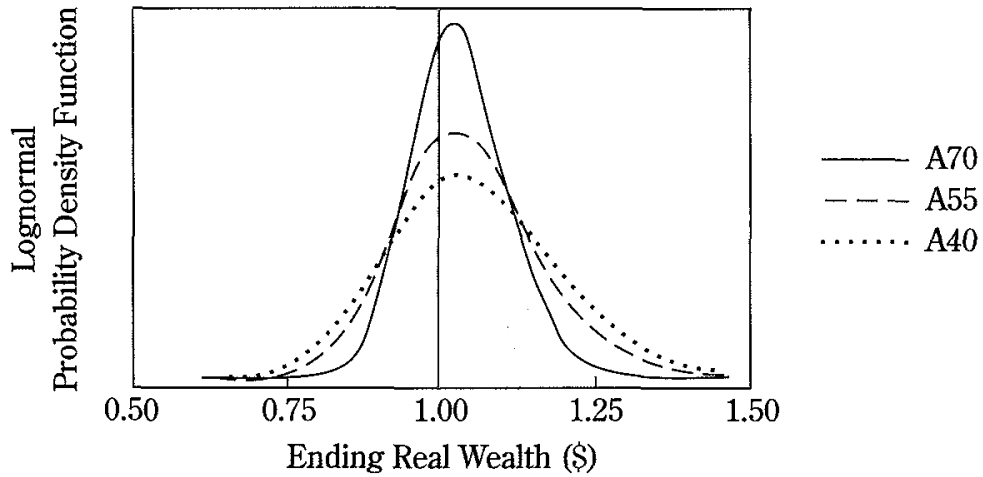

\begin{tabular}{lccccccc} 
& \multicolumn{7}{c}{ Percentiles of Distributions } \\
\cline { 2 - 8 } & 5 & 10 & 25 & 50 & 75 & 90 & 95 \\
\hline A70 & 0.90 & 0.93 & 0.97 & 1.03 & 1.08 & 1.14 & 1.17 \\
A55 & 0.86 & 0.90 & 0.96 & 1.04 & 1.12 & 1.20 & 1.25 \\
A40 & 0.84 & 0.88 & 0.95 & 1.05 & 1.15 & 1.25 & 1.31 \\
\hline
\end{tabular}

Figure A-3. One-Year Ending Real Wealth on A40, A25, S\&P

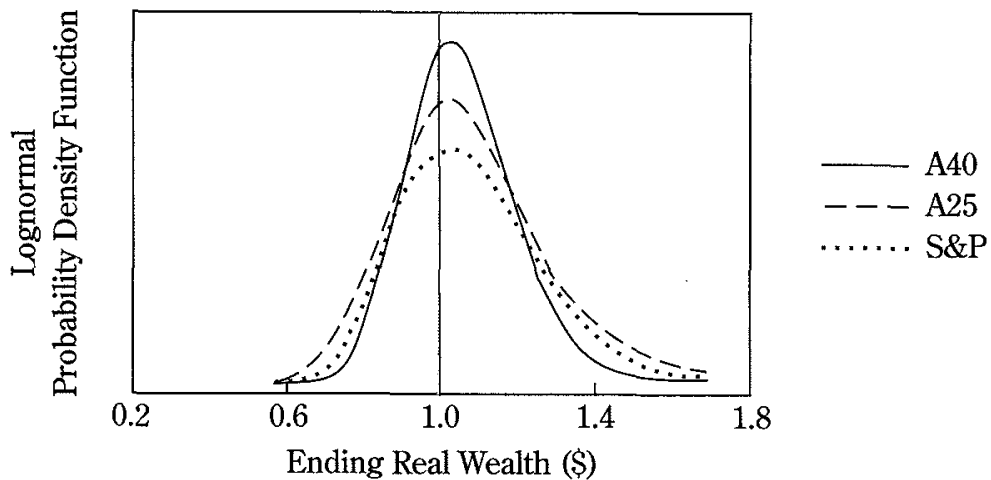

Percentiles of Distributions

\begin{tabular}{lccccccc} 
& 5 & 10 & 25 & 50 & 75 & 90 & 95 \\
\hline A40 & 0.84 & 0.88 & 0.95 & 1.05 & 1.15 & 1.25 & 1.31 \\
A25 & 0.80 & 0.85 & 0.94 & 1.05 & 1.18 & 1.30 & 1.38 \\
S\&P & 0.76 & 0.82 & 0.92 & 1.06 & 1.21 & 1.37 & 1.47 \\
\hline
\end{tabular}


Figure A-4. One-Year Ending Real Wealth on Bonds, P64, S\&P
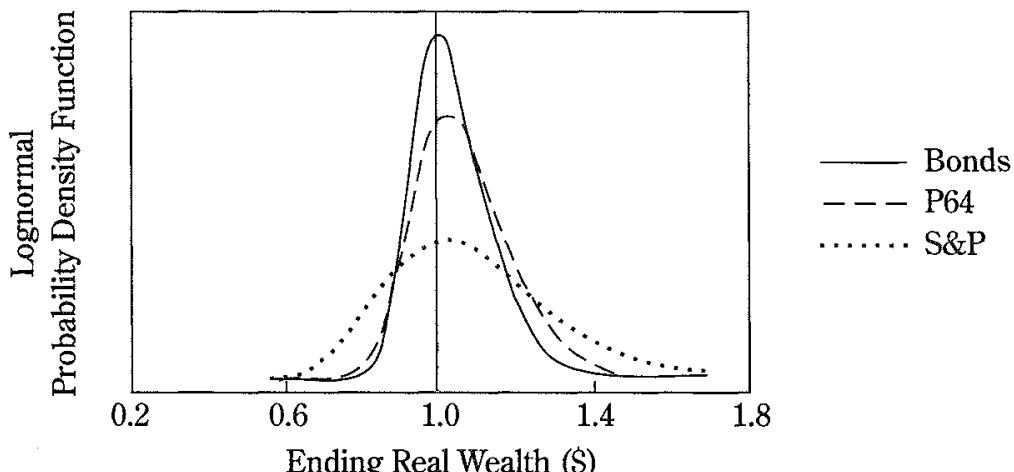

Ending Real Wealth (\$)

Percentiles of Distributions

\begin{tabular}{lccccccc}
\cline { 2 - 7 } & 5 & 10 & 25 & 50 & 75 & 90 & 95 \\
\hline Bonds & 0.88 & 0.91 & 0.96 & 1.01 & 1.07 & 1.12 & 1.16 \\
P64 & 0.87 & 0.90 & 0.96 & 1.04 & 1.11 & 1.19 & 1.23 \\
S\&P & 0.76 & 0.82 & 0.92 & 1.06 & 1.21 & 1.37 & 1.47 \\
\hline
\end{tabular}

Figure A-5. Five-Year Ending Real Wealth on T-Bills, A70, A55

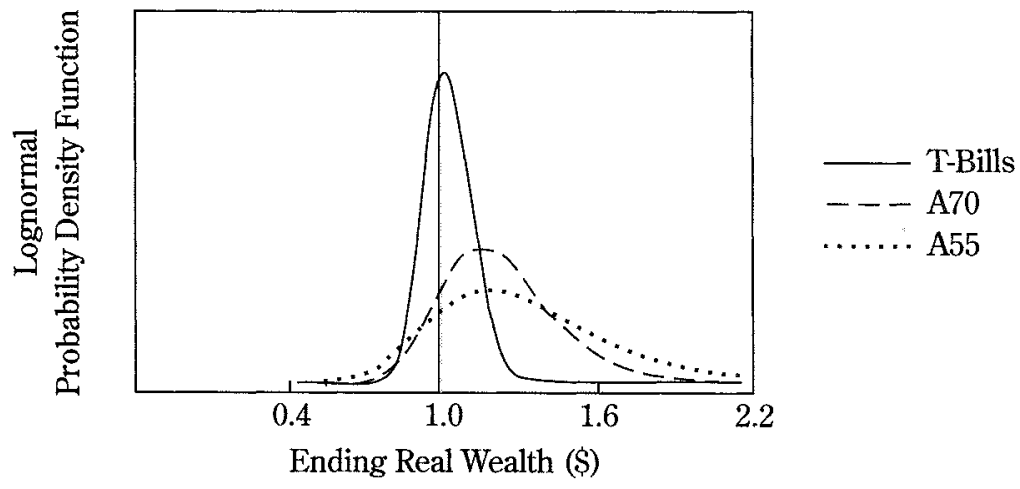

Percentiles of Distributions

\begin{tabular}{lccccccr} 
& 5 & 10 & 25 & 50 & 75 & 90 & 95 \\
\hline T-bills & 0.78 & 0.84 & 0.95 & 1.10 & 1.26 & 1.43 & 1.55 \\
A70 & 0.88 & 0.94 & 1.06 & 1.20 & 1.36 & 1.53 & 1.63 \\
A55 & 0.82 & 0.91 & 1.06 & 1.27 & 1.51 & 1.77 & 1.95 \\
\hline
\end{tabular}


Figure A-6. Five-Year Ending Real Wealth on A70, A55, A40

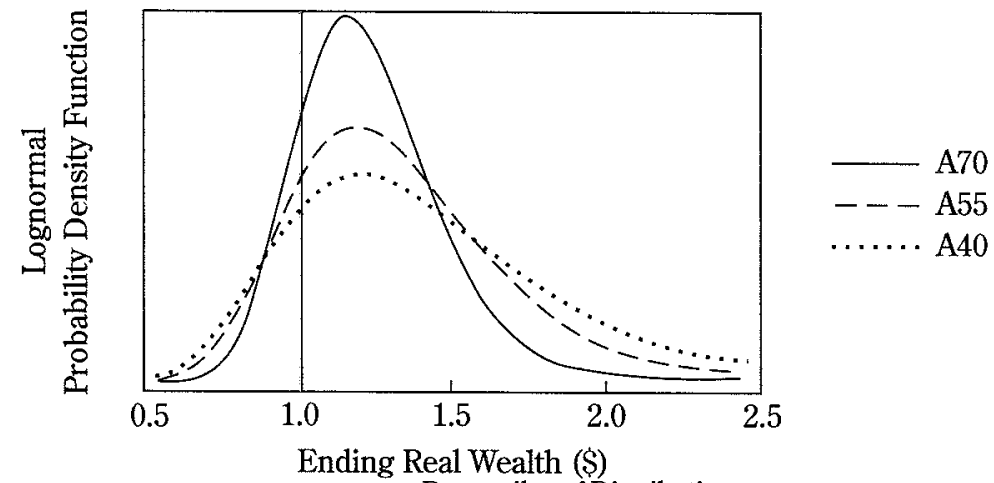

\begin{tabular}{lcccccccc} 
& \multicolumn{7}{c}{ Percentiles of Distributions } \\
\cline { 2 - 8 } & 5 & 10 & 25 & 50 & 75 & 90 & 95 \\
\hline A70 & 0.88 & 0.94 & 1.06 & 1.20 & 1.36 & 1.53 & 1.63 \\
A55 & 0.82 & 0.91 & 1.06 & 1.27 & 1.51 & 1.77 & 1.95 \\
A40 & 0.79 & 0.88 & 1.07 & 1.32 & 1.63 & 1.97 & 2.20 \\
\hline
\end{tabular}

Figure A-7. Five-Year Ending Real Wealth on A40, A25, S\&P

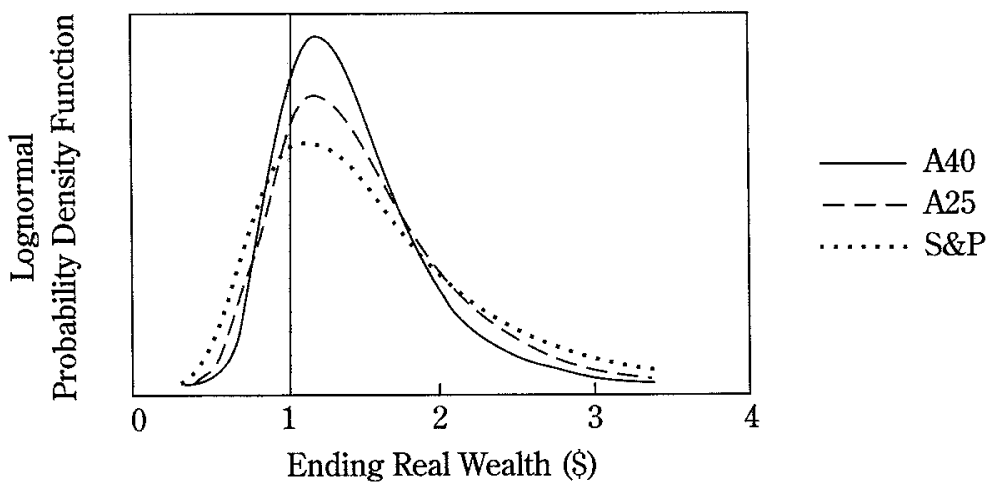

\begin{tabular}{lccccccc} 
& \multicolumn{7}{c}{ Percentiles of Distributions } \\
\cline { 2 - 7 } & 5 & 10 & 25 & 50 & 75 & 90 & 95 \\
\hline A40 & 0.79 & 0.88 & 1.07 & 1.32 & 1.63 & 1.97 & 2.20 \\
A25 & 0.74 & 0.85 & 1.06 & 1.37 & 1.76 & 2.21 & 2.53 \\
S\&P & 0.66 & 0.78 & 1.02 & 1.39 & 1.89 & 2.49 & 2.93 \\
\hline
\end{tabular}


Figure A-8. Ten-Year Ending Real Wealth on A70, A55, A40

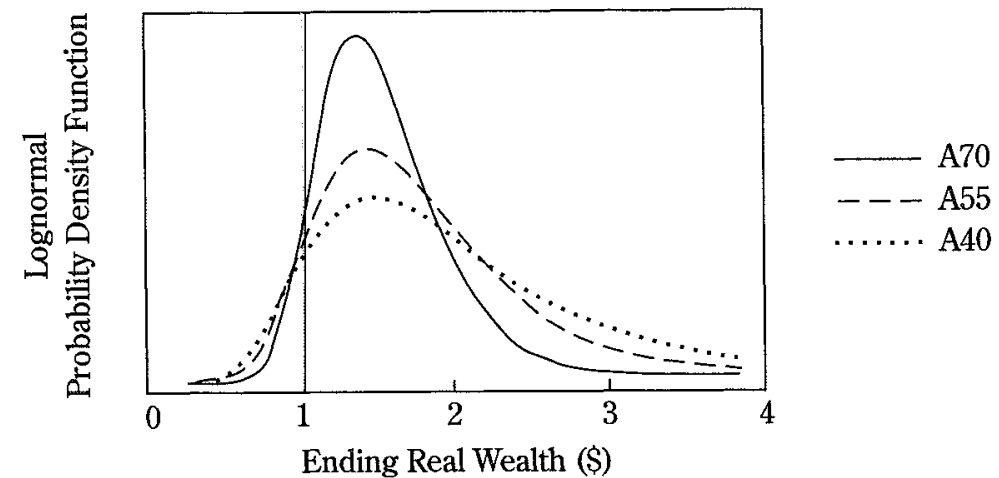

Ending Real Wealth (\$)

\begin{tabular}{lccccccc} 
& \multicolumn{7}{c}{ Percentiles of Distributions } \\
\cline { 2 - 7 } & 5 & 10 & 25 & 50 & 75 & 90 & 95 \\
\hline A70 & 0.95 & 1.04 & 1.23 & 1.47 & 1.76 & 2.08 & 2.29 \\
A55 & 0.89 & 1.02 & 1.28 & 1.64 & 2.11 & 2.64 & 3.02 \\
A40 & 0.86 & 1.01 & 1.33 & 1.78 & 2.41 & 3.15 & 3.71 \\
\hline
\end{tabular}

Figure A-9. Ten-Year Ending Real Wealth on A40, A25, S\&P

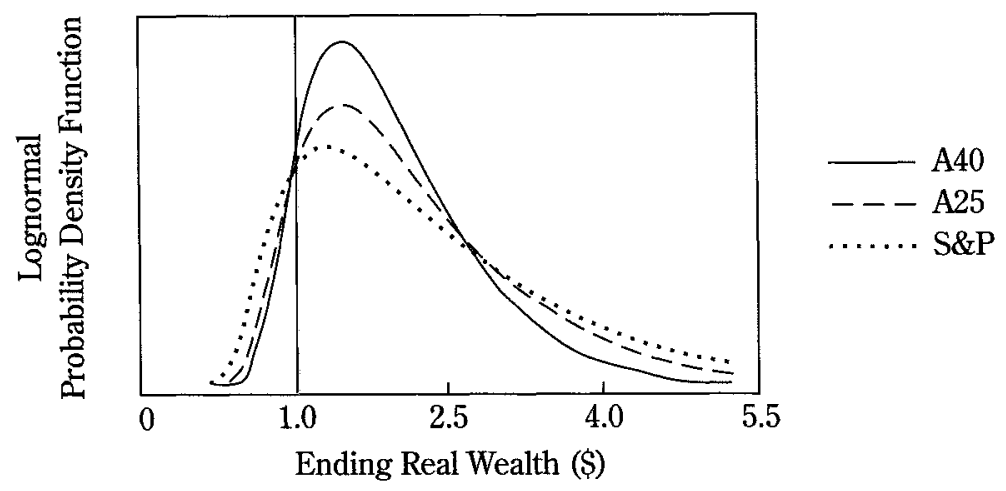

Percentiles of Distributions

\begin{tabular}{lccccccr} 
& 5 & 10 & 25 & 50 & 75 & 90 & 95 \\
\hline A40 & 0.86 & 1.01 & 1.33 & 1.78 & 2.41 & 3.15 & 3.71 \\
A25 & 0.80 & 0.97 & 1.34 & 1.92 & 2.74 & 3.78 & 4.58 \\
S\&P & 0.68 & 0.86 & 1.28 & 1.97 & 3.05 & 4.51 & 5.70 \\
\hline
\end{tabular}


Figure A-10. Twenty-Year Ending Real Wealth on A70, A55, A40

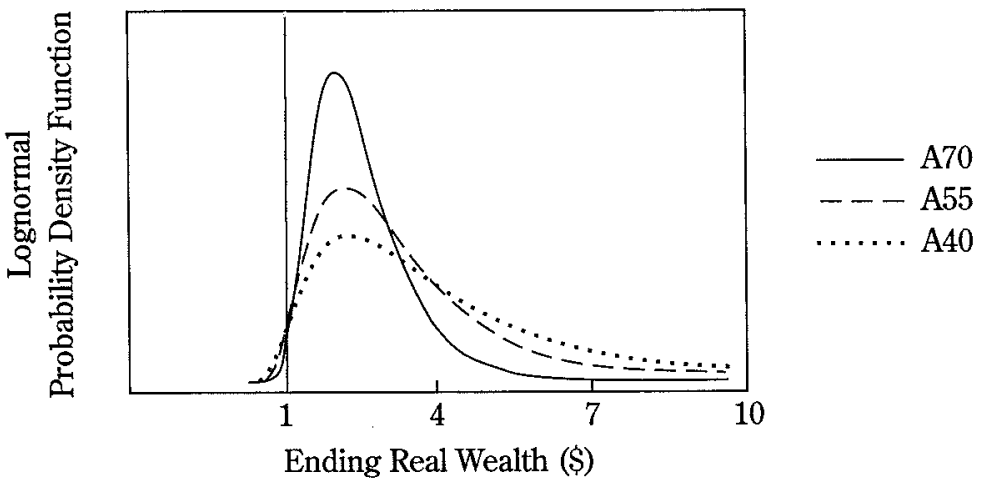

Percentiles of Distributions

\begin{tabular}{lccccccc} 
& 5 & 10 & 25 & 50 & 75 & 90 & 95 \\
\hline A70 & 1.18 & 1.36 & 1.71 & 2.21 & 2.87 & 3.61 & 4.15 \\
A55 & 1.16 & 1.41 & 1.94 & 2.76 & 3.94 & 5.42 & 6.56 \\
A40 & 1.16 & 1.45 & 2.13 & 3.26 & 4.98 & 7.30 & 9.17 \\
\hline
\end{tabular}

Figure A-11. Twenty-Year Ending Real Wealth on A40, A25, S\&P

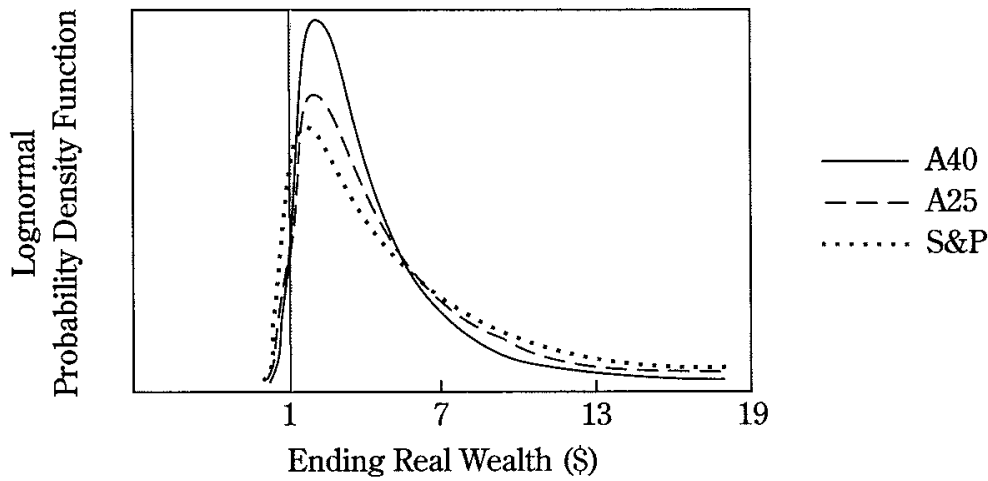

\begin{tabular}{lcccccrrr} 
& \multicolumn{7}{c}{ Percentiles of Distributions } \\
\cline { 2 - 8 } & 5 & 10 & 25 & 50 & 75 & 90 & 95 \\
\hline A40 & 1.16 & 1.45 & 2.13 & 3.26 & 4.98 & 7.30 & 9.17 \\
A25 & 1.10 & 1.44 & 2.27 & 3.77 & 6.25 & 9.87 & 12.94 \\
S\&P & 0.89 & 1.24 & 2.16 & 3.99 & 7.38 & 12.83 & 17.87 \\
\hline
\end{tabular}


Figure A-12. Twenty-Year Ending Real Wealth on Bonds, P46, S\&P

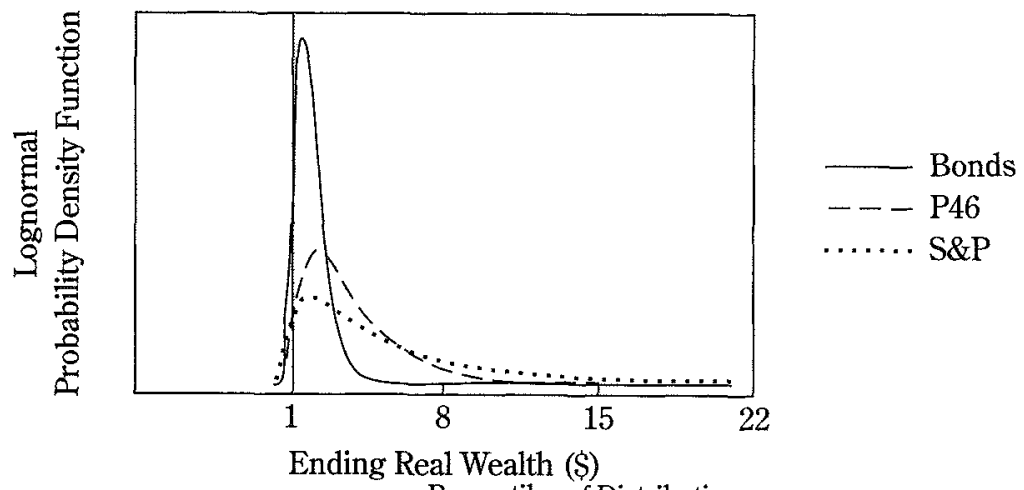

\begin{tabular}{lcccccrrr} 
& \multicolumn{7}{c}{ Percentiles of Distributions } \\
\cline { 2 - 8 } & 5 & 10 & 25 & 50 & 75 & 90 & 95 \\
\hline Bonds & 0.86 & 1.00 & 1.27 & 1.65 & 2.16 & 2.74 & 3.16 \\
P46 & 1.12 & 1.40 & 2.03 & 3.07 & 4.65 & 6.75 & 8.44 \\
S\&P & 0.89 & 1.24 & 2.16 & 3.99 & 7.38 & 12.83 & 17.87 \\
\hline
\end{tabular}

Figure A-13. Twenty-Year Ending Real Wealth on P46, A40

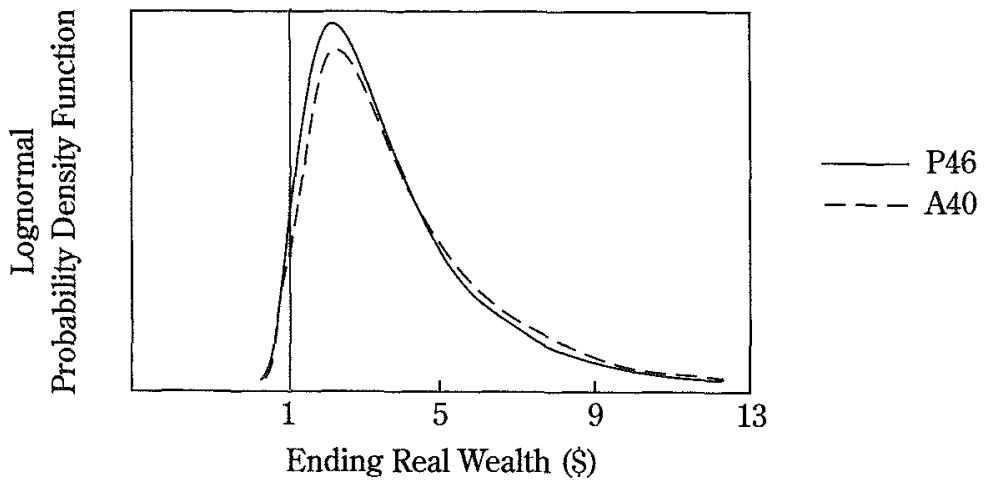

Percentiles of Distributions

\begin{tabular}{rccccccc} 
& 5 & 10 & 25 & 50 & 75 & 90 & 95 \\
\hline P46 & 1.12 & 1.40 & 2.03 & 3.07 & 4.65 & 6.75 & 8.44 \\
A40 & 1.16 & 1.45 & 2.13 & 3.26 & 4.98 & 7.30 & 9.17 \\
\hline
\end{tabular}


Figure A-14. Thirty-Year Ending Real Wealth on A70, A55, A40

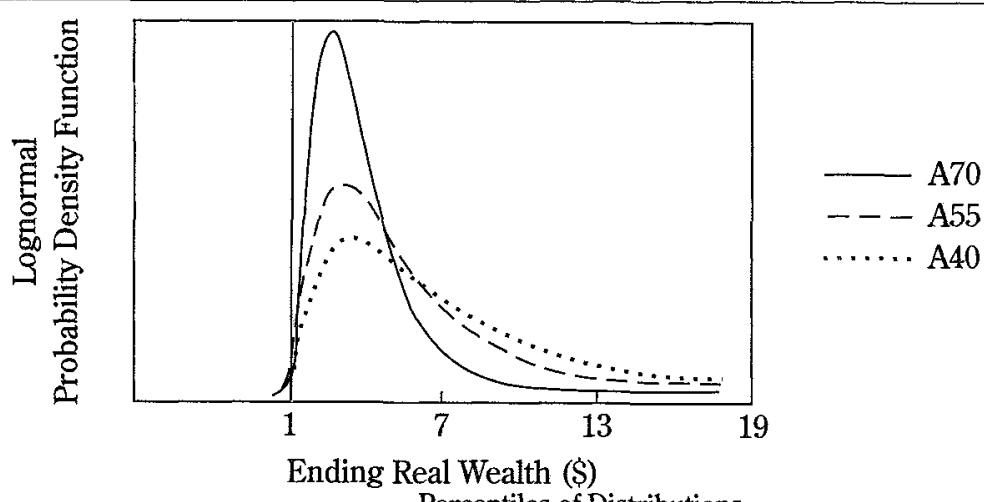

\begin{tabular}{rrrrrrrr} 
& \multicolumn{8}{c}{ Percentiles of Distributions } \\
\cline { 2 - 8 } & 5 & 10 & 25 & 50 & 75 & 90 & 95 \\
\hline A70 & 1.54 & 1.83 & 2.43 & 3.33 & 4.57 & 6.08 & 7.21 \\
A55 & 1.61 & 2.03 & 3.00 & 4.64 & 7.16 & 10.60 & 13.40 \\
A40 & 1.67 & 2.21 & 3.54 & 5.95 & 10.01 & 15.98 & 21.15 \\
\hline
\end{tabular}

Figure A-15. Thirty-Year Ending Real Wealth on A40, A25, S\&P

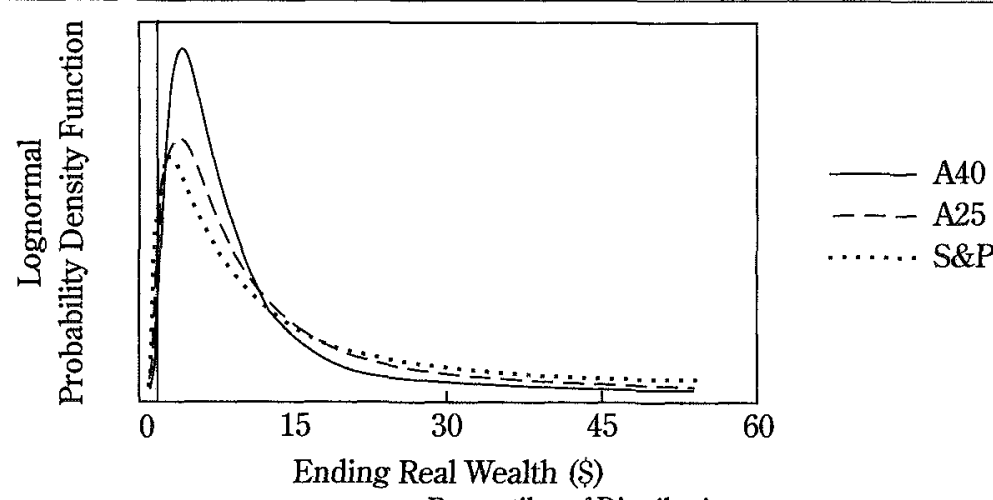

\begin{tabular}{lccccccc} 
& \multicolumn{7}{c}{ Percentiles of Distributions } \\
\cline { 2 - 7 } & 5 & 10 & 25 & 50 & 75 & 90 & 95 \\
\hline A40 & 1.67 & 2.21 & 3.54 & 5.95 & 10.01 & 15.98 & 21.15 \\
A25 & 1.63 & 2.28 & 3.99 & 7.41 & 13.76 & 24.03 & 33.55 \\
S\&P & 1.28 & 1.92 & 3.79 & 8.05 & 17.11 & 33.72 & 50.60 \\
\hline
\end{tabular}




\section{Shortfall Risk: Individual Investors}

Each line indicates the probabilities that a portfolio will earn less than Treasury bills for investment horizons of 1-30 years. Treasury-bill returns are often used to indicate returns available on bank saving deposits, short-term certificates of deposit, and other riskless investments.

Figure A-16. Shortfall Risk on Bonds, A70

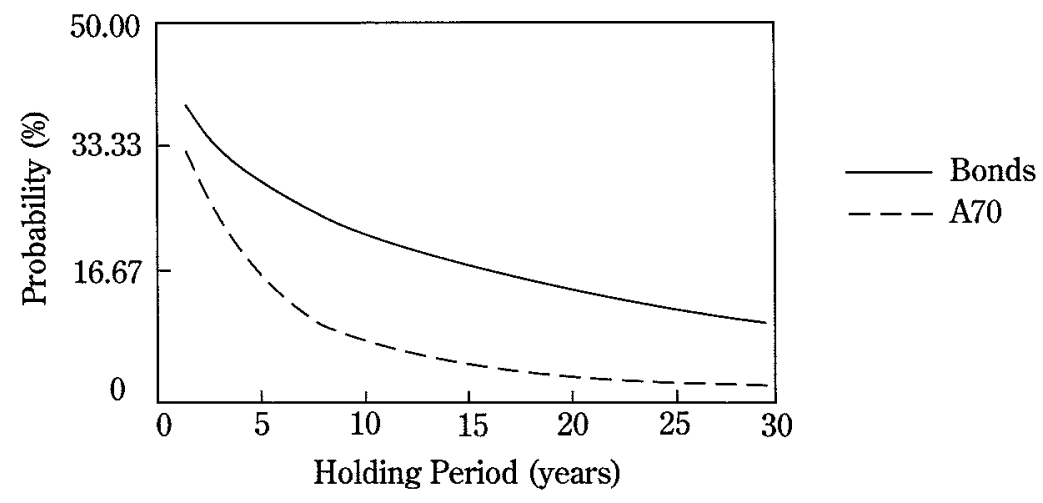


Figure A-17. Shortfall Risk on A70, A55, A40

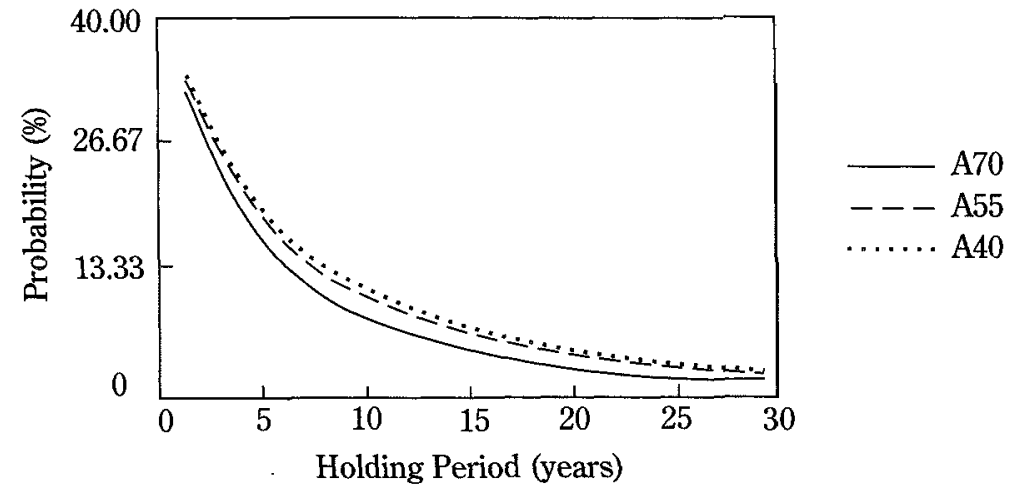

Figure A-18. Shortfall Risk on A40, A25, S\&P

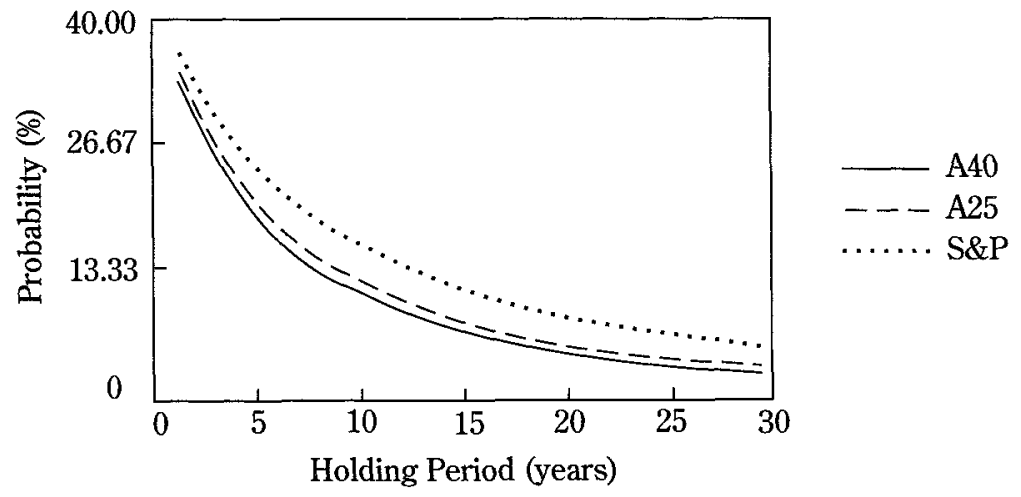


Probability Distributions of Ending Real Wealth: Pension Funds

Figure A-19. One-Year Ending Real Wealth on P64, P46

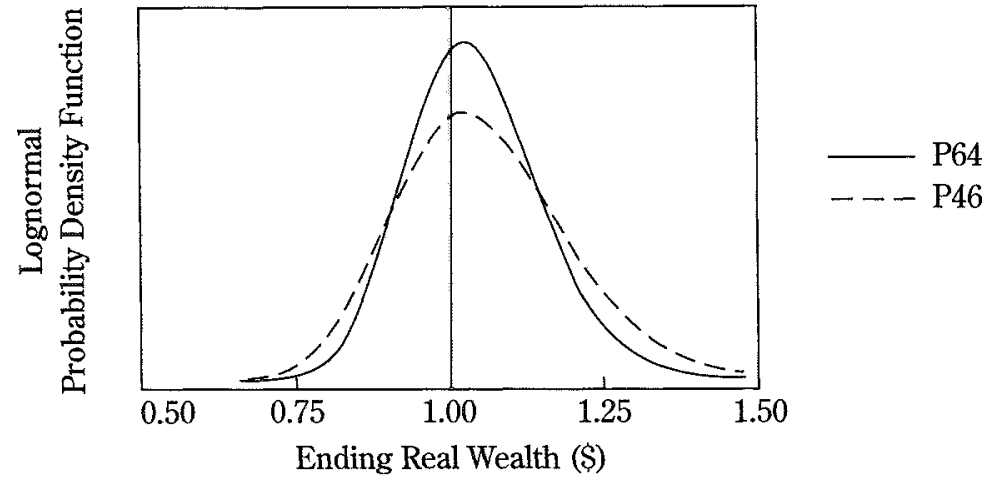

\begin{tabular}{cccccccc} 
& \multicolumn{7}{c}{ Percentiles of Distributions } \\
\cline { 2 - 8 } & 5 & 10 & 25 & 50 & 75 & 90 & 95 \\
\hline P64 & 0.87 & 0.90 & 0.96 & 1.04 & 1.11 & 1.19 & 1.23 \\
P46 & 0.84 & 0.88 & 0.95 & 1.04 & 1.14 & 1.24 & 1.30 \\
\hline
\end{tabular}

Figure A-20. Five-Year Ending Real Wealth on P64, P46

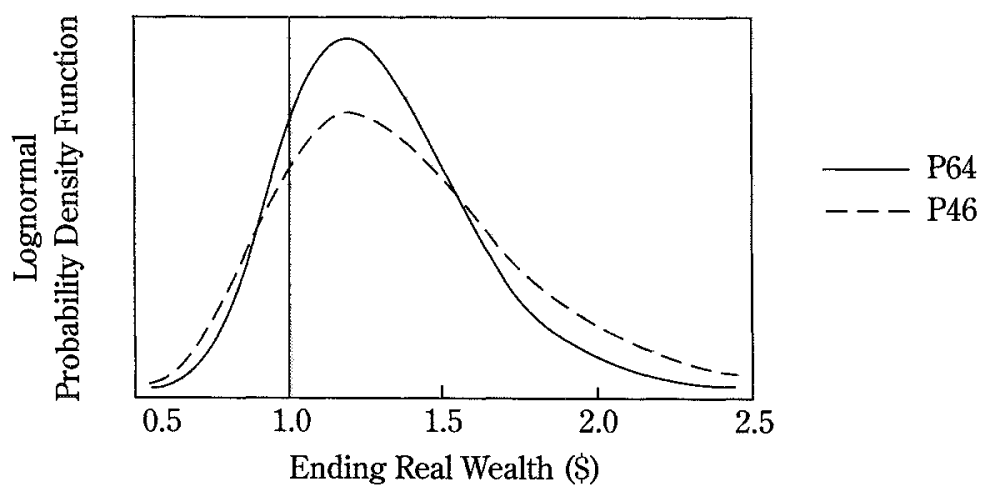

Percentiles of Distributions

\begin{tabular}{rrrrrrrr} 
& 5 & 10 & 25 & 50 & 75 & 90 & 95 \\
\hline P64 & 0.83 & 0.91 & 1.06 & 1.25 & 1.47 & 1.71 & 1.86 \\
P46 & 0.79 & 0.88 & 1.06 & 1.30 & 1.60 & 1.92 & 2.15 \\
\hline
\end{tabular}


Figure A-21. Ten-Year Ending Real Wealth on P64, P46

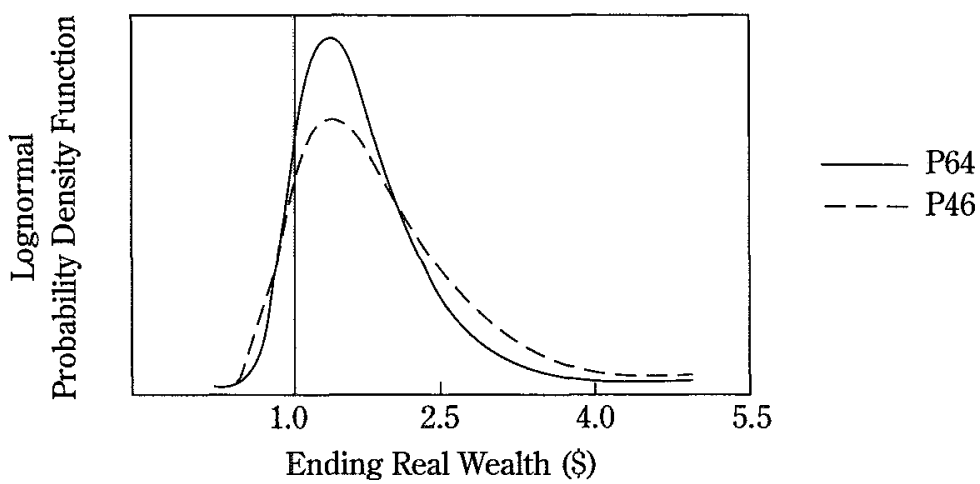

Ending Real Wealth (\$)

Percentiles of Distributions

\begin{tabular}{rccccccc} 
& 5 & 10 & 25 & 50 & 75 & 90 & 95 \\
\hline P64 & 0.90 & 1.02 & 1.26 & 1.59 & 2.01 & 2.48 & 2.82 \\
P46 & 0.85 & 0.99 & 1.29 & 1.73 & 2.32 & 3.02 & 3.54 \\
\hline
\end{tabular}

Figure A-22. Twenty-Year Ending Real Wealth on P64, P46

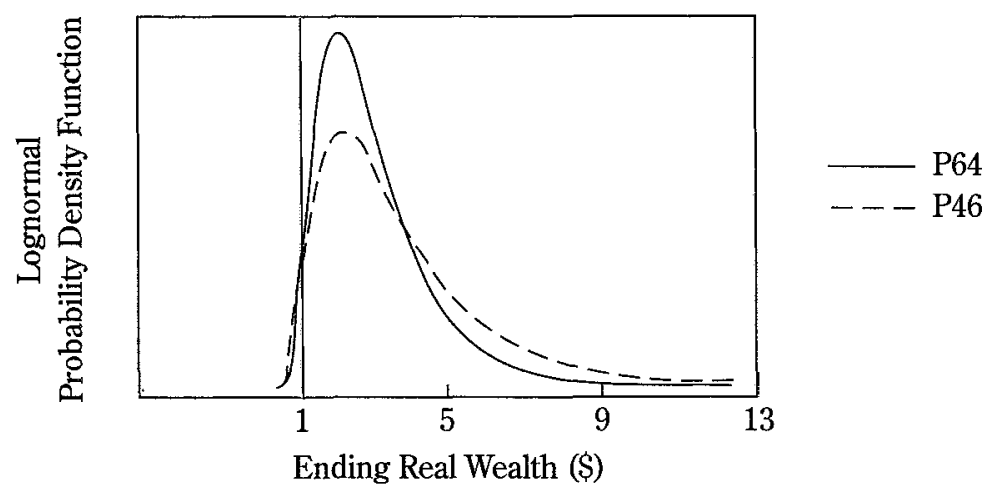

Percentiles of Distributions

\begin{tabular}{rrrrrrrr} 
& 5 & 10 & 25 & 50 & 75 & 90 & 95 \\
\hline P64 & 1.15 & 1.37 & 1.85 & 2.58 & 3.61 & 4.87 & 5.82 \\
P46 & 1.12 & 1.40 & 2.03 & 3.07 & 4.65 & 6.75 & 8.44 \\
\hline
\end{tabular}


Figure A-23. Thirty-Year Ending Real Wealth on P64, P46

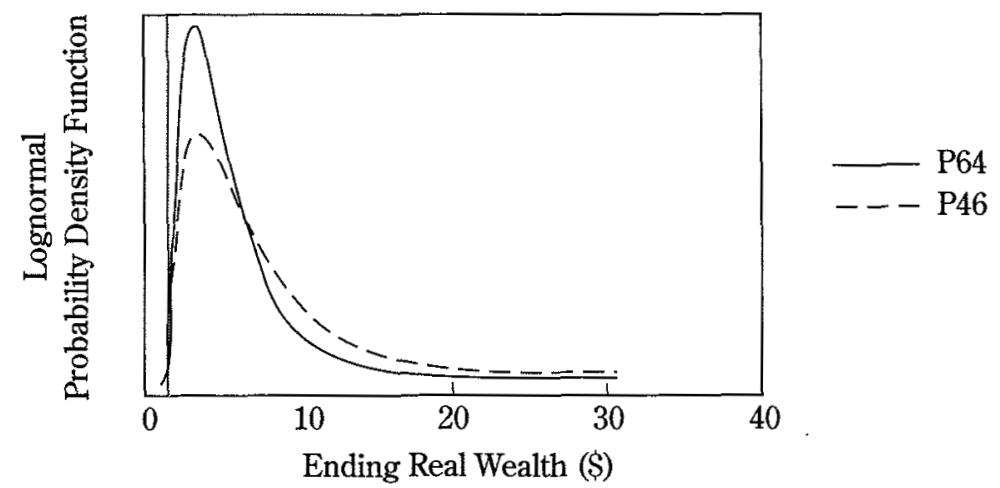

Percentiles of Distributions

\begin{tabular}{rrrrrrrr} 
& 5 & 10 & 25 & 50 & 75 & 90 & 95 \\
\hline P64 & 1.55 & 1.93 & 2.79 & 4.20 & 6.32 & 9.13 & 11.37 \\
P46 & 1.58 & 2.08 & 3.28 & 5.45 & 9.06 & 14.31 & 18.80 \\
\hline
\end{tabular}




\section{Shortfall Risk: Pension Funds}

Figure A-24. Shortfall Risk on P64, P46

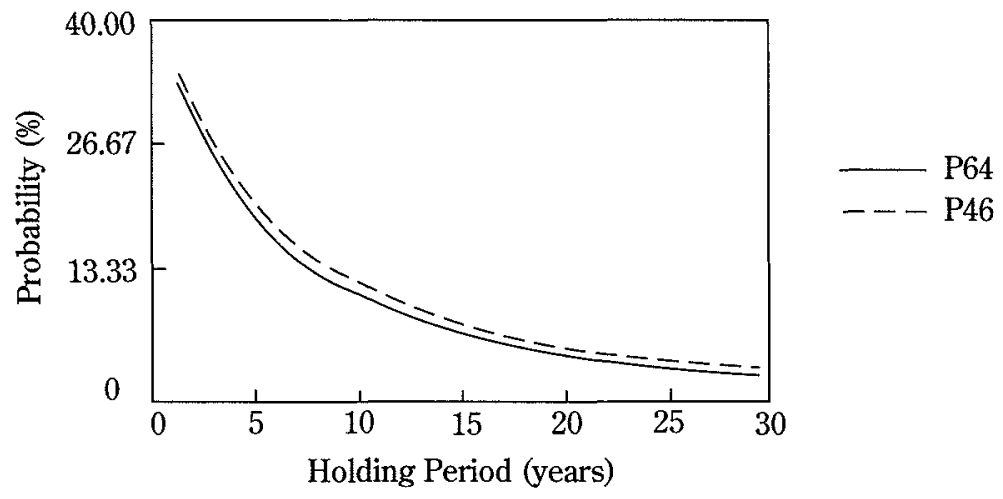


Table A-1. Probability Distributions of Ending Excess Wealth

\begin{tabular}{|c|c|c|c|c|c|c|c|c|c|}
\hline $\begin{array}{l}\text { Holding } \\
\text { Period } \\
\text { (years) }\end{array}$ & Percentile & $S \& P$ & $\mathrm{P} 46$ & $\mathrm{P} 64$ & Bonds & $\mathrm{A} 25$ & $\mathrm{~A} 40$ & A55 & $\mathrm{A} 70$ \\
\hline \multirow[t]{7}{*}{1} & 5 & 0.77 & 0.85 & 0.88 & 0.90 & 0.81 & 0.85 & 0.87 & 0.92 \\
\hline & 10 & 0.82 & 0.89 & 0.91 & 0.92 & 0.86 & 0.89 & 0.91 & 0.94 \\
\hline & 25 & 0.93 & 0.96 & 0.97 & 0.97 & 0.95 & 0.96 & 0.97 & 0.98 \\
\hline & 50 & 1.06 & 1.05 & 1.04 & 1.02 & 1.06 & 1.05 & 1.04 & 1.03 \\
\hline & 75 & 1.22 & 1.15 & 1.11 & 1.07 & 1.18 & 1.15 & 1.12 & 1.09 \\
\hline & 90 & 1.37 & 1.24 & 1.19 & 1.12 & 1.31 & 1.25 & 1.20 & 1.13 \\
\hline & 95 & 1.48 & 1.30 & 1.23 & 1.15 & 1.38 & 1.31 & 1.25 & 1.16 \\
\hline \multirow[t]{7}{*}{5} & 5 & 0.66 & 0.79 & 0.84 & 0.83 & 0.74 & 0.79 & 0.83 & 0.90 \\
\hline & 10 & 0.77 & 0.88 & 0.91 & 0.88 & 0.85 & 0.88 & 0.91 & 0.96 \\
\hline & 25 & 1.01 & 1.05 & 1.05 & 0.98 & 1.05 & 1.06 & 1.06 & 1.06 \\
\hline & 50 & 1.36 & 1.28 & 1.22 & 1.09 & 1.35 & 1.30 & 1.24 & 1.18 \\
\hline & 75 & 1.84 & 1.55 & 1.43 & 1.23 & 1.72 & 1.59 & 1.47 & 1.31 \\
\hline & 90 & 2.41 & 1.85 & 1.64 & 1.36 & 2.14 & 1.90 & 1.70 & 1.45 \\
\hline & 95 & 2.84 & 2.06 & 1.78 & 1.45 & 2.44 & 2.12 & 1.86 & 1.54 \\
\hline \multirow[t]{7}{*}{10} & 5 & 0.66 & 0.83 & 0.89 & 0.81 & 0.78 & 0.84 & 0.88 & 0.95 \\
\hline & 10 & 0.83 & 0.97 & 0.99 & 0.88 & 0.94 & 0.98 & 1.00 & 1.03 \\
\hline & 25 & 1.22 & 1.24 & 1.21 & 1.02 & 1.28 & 1.27 & 1.23 & 1.19 \\
\hline & 50 & 1.86 & 1.63 & 1.50 & 1.20 & 1.81 & 1.68 & 1.55 & 1.39 \\
\hline & 75 & 2.84 & 2.16 & 1.86 & 1.41 & 2.55 & 2.24 & 1.95 & 1.62 \\
\hline & 90 & 4.17 & 2.77 & 2.26 & 1.63 & 3.48 & 2.89 & 2.41 & 1.86 \\
\hline & 95 & 5.24 & 3.21 & 2.53 & 1.78 & 4.19 & 3.37 & 2.73 & 2.03 \\
\hline \multirow[t]{7}{*}{20} & 5 & 0.80 & 1.03 & 1.07 & 0.82 & 1.00 & 1.06 & 1.08 & 1.12 \\
\hline & 10 & 1.11 & 1.27 & 1.26 & 0.93 & 1.30 & 1.32 & 1.28 & 1.27 \\
\hline & 25 & 1.90 & 1.80 & 1.65 & 1.14 & 2.01 & 1.89 & 1.73 & 1.54 \\
\hline & 50 & 3.46 & 2.67 & 2.24 & 1.44 & 3.27 & 2.83 & 2.40 & 1.92 \\
\hline & 75 & 6.31 & 3.95 & 3.04 & 1.81 & 5.33 & 4.23 & 3.33 & 2.40 \\
\hline & 90 & 10.83 & 5.62 & 4.00 & 2.22 & 8.27 & 6.08 & 4.47 & 2.92 \\
\hline & 95 & 14.97 & 6.94 & 4.72 & 2.51 & 10.75 & 7.55 & 5.34 & 3.29 \\
\hline \multirow[t]{7}{*}{30} & 5 & 1.07 & 1.35 & 1.35 & 0.87 & 1.38 & 1.43 & 1.40 & 1.38 \\
\hline & 10 & 1.59 & 1.75 & 1.65 & 1.01 & 1.91 & 1.86 & 1.73 & 1.60 \\
\hline & 25 & 3.09 & 2.70 & 2.31 & 1.30 & 3.26 & 2.91 & 2.48 & 2.04 \\
\hline & 50 & 6.44 & 4.36 & 3.36 & 1.72 & 5.92 & 4.76 & 3.71 & 2.67 \\
\hline & 75 & 13.44 & 7.05 & 4.88 & 2.28 & 10.76 & 7.79 & 5.55 & 3.49 \\
\hline & 90 & 26.05 & 10.86 & 6.83 & 2.94 & 18.42 & 12.15 & 7.97 & 4.45 \\
\hline & 95 & 38.71 & 14.06 & 8.36 & 3.42 & 25.41 & 15.84 & 9.90 & 5.14 \\
\hline
\end{tabular}

Note: See text Table 1 for the portfolio asset allocations. 


\section{Appendix B: Risk-Return Trade-Offs Based on the Mean-Reversion Model}

\section{Probability Distributions of Ending Real Wealth: Individual Investors}

The following figures are distributions of 1-year to 30-year ending real wealth per dollar of original investment according to the mean-reversion model. Each figure compares the probability distributions of three portfolios. The vertical shaded lines denote wealth of $\$ 1$.

Figure B-1. One-Year Ending Real Wealth on T-Bills, Bonds, A70

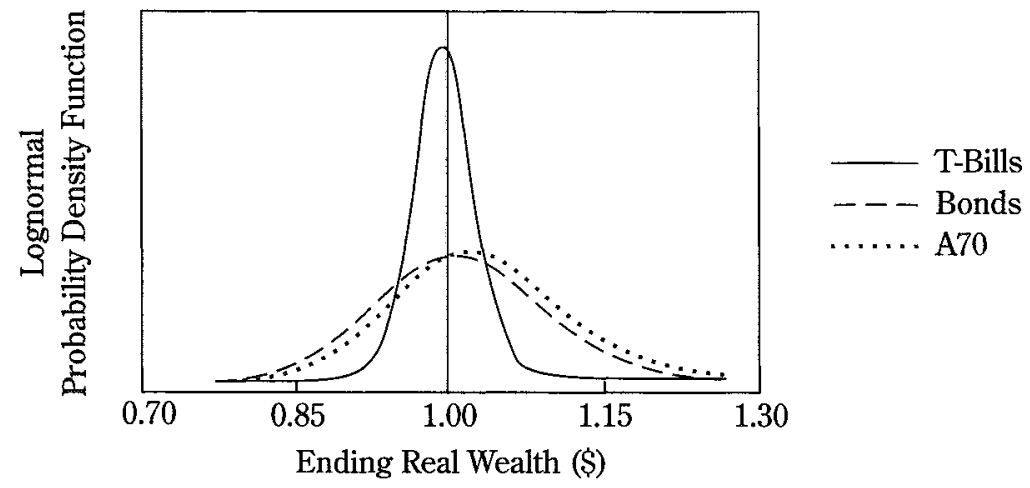

\begin{tabular}{lccccccc} 
& \multicolumn{8}{c}{ Percentiles of Distributions } \\
\cline { 2 - 8 } & 5 & 10 & 25 & 50 & 75 & 90 & 95 \\
\hline T-bills & 0.95 & 0.96 & 0.97 & 0.99 & 1.01 & 1.03 & 1.05 \\
Bonds & 0.88 & 0.91 & 0.96 & 1.01 & 1.07 & 1.12 & 1.16 \\
A70 & 0.90 & 0.93 & 0.97 & 1.03 & 1.08 & 1.14 & 1.17 \\
\hline
\end{tabular}


Figure B-2. One-Year Ending Real Wealth on A70, A55, A40

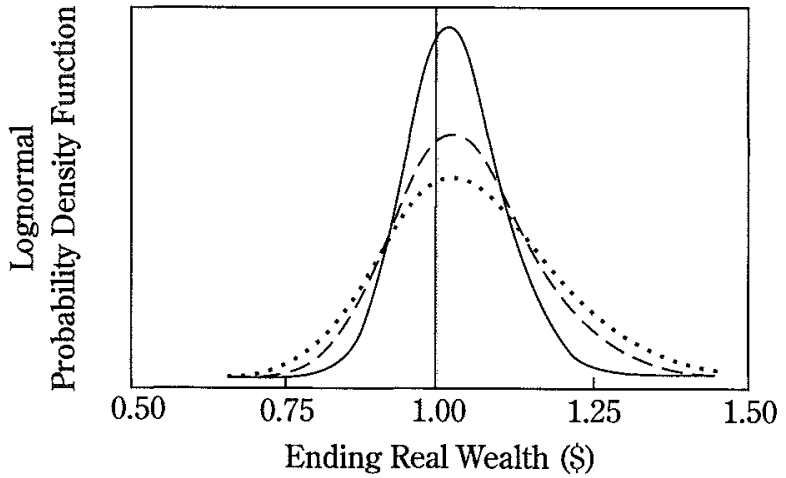

--- A55

...... A40

Percentiles of Distributions

\begin{tabular}{|c|c|c|c|c|c|c|c|}
\hline & 5 & 10 & 25 & 50 & 75 & 90 & 95 \\
\hline A70 & 0.90 & 0.93 & 0.97 & 1.03 & 1.08 & 1.14 & 1.17 \\
\hline A55 & 0.86 & 0.90 & 0.96 & 1.04 & 1.12 & 1.20 & 1.25 \\
\hline $\mathrm{A} 40$ & 0.84 & 0.88 & 0.95 & 1.05 & 1.15 & 1.25 & 1.31 \\
\hline
\end{tabular}

Figure B-3. One-Year Ending Real Wealth on A40, A25, S\&P

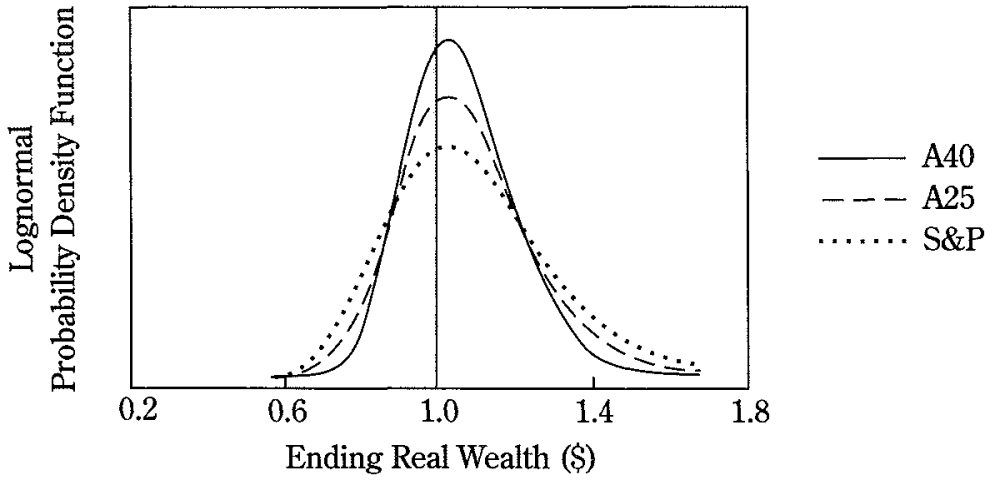

\begin{tabular}{lccccccc} 
& \multicolumn{7}{c}{ Percentiles of Distributions } \\
\cline { 2 - 8 } & 5 & 10 & 25 & 50 & 75 & 90 & 95 \\
\hline A40 & 0.84 & 0.88 & 0.95 & 1.05 & 1.15 & 1.25 & 1.31 \\
A25 & 0.80 & 0.85 & 0.94 & 1.05 & 1.18 & 1.30 & 1.38 \\
S\&P & 0.76 & 0.82 & 0.92 & 1.06 & 1.21 & 1.37 & 1.47 \\
\hline
\end{tabular}


Figure B-4. One-Year Ending Real Wealth on Bonds, P64, S\&P

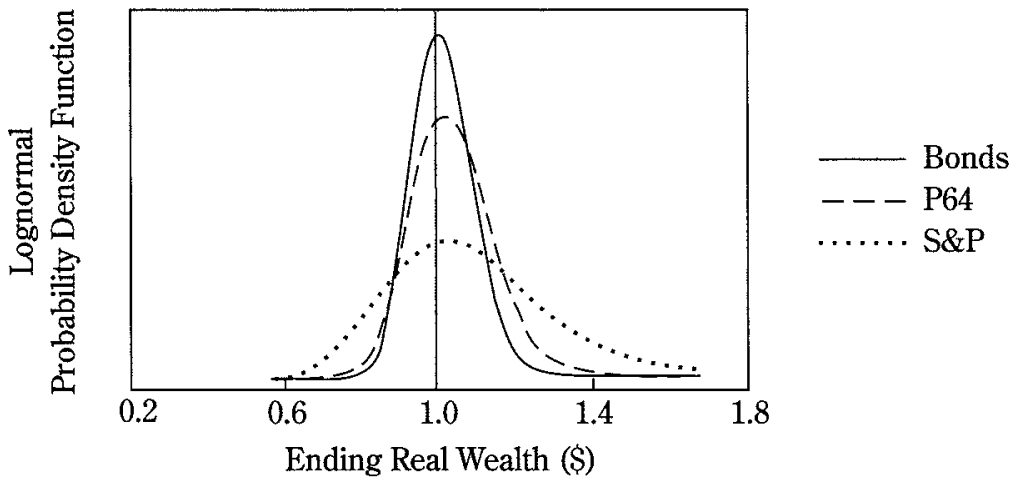

Percentiles of Distributions

\begin{tabular}{lccccccc} 
& 5 & 10 & 25 & 50 & 75 & 90 & 95 \\
\hline Bonds & 0.88 & 0.91 & 0.96 & 1.01 & 1.07 & 1.12 & 1.16 \\
P64 & 0.87 & 0.90 & 0.96 & 1.04 & 1.11 & 1.19 & 1.23 \\
S\&P & 0.76 & 0.82 & 0.92 & 1.06 & 1.21 & 1.37 & 1.47 \\
\hline
\end{tabular}

Figure B-5. Five-Year Ending Real Wealth on T-Bills, A70, A55

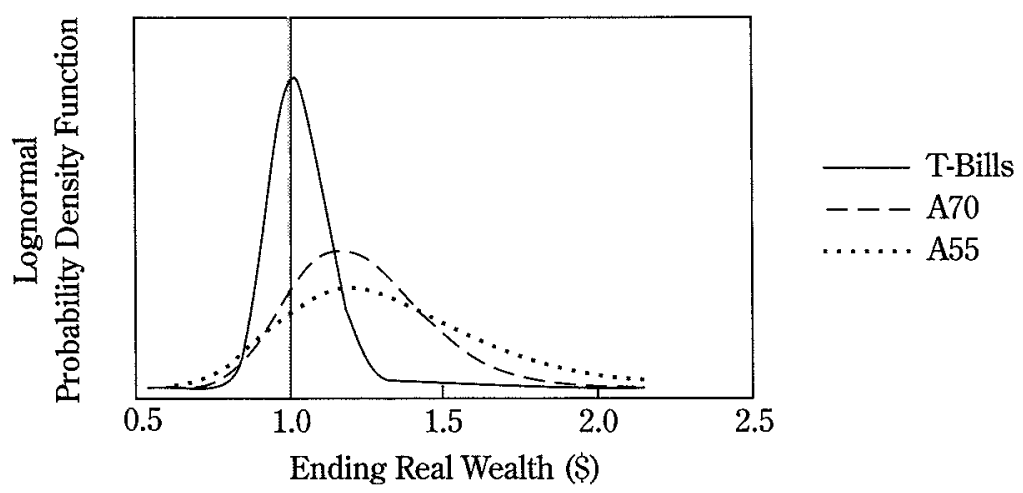

\begin{tabular}{lccccccc} 
& \multicolumn{7}{c}{ Percentiles of Distributions } \\
\cline { 2 - 7 } & 5 & 10 & 25 & 50 & 75 & 90 & 95 \\
\hline T-bills & 0.78 & 0.84 & 0.95 & 1.10 & 1.26 & 1.43 & 1.55 \\
A70 & 0.89 & 0.95 & 1.06 & 1.20 & 1.36 & 1.52 & 1.62 \\
A55 & 0.85 & 0.92 & 1.07 & 1.27 & 1.50 & 1.74 & 1.90 \\
\hline
\end{tabular}


Figure B-6. Five-Year Ending Real Wealth on A70, A55, A40

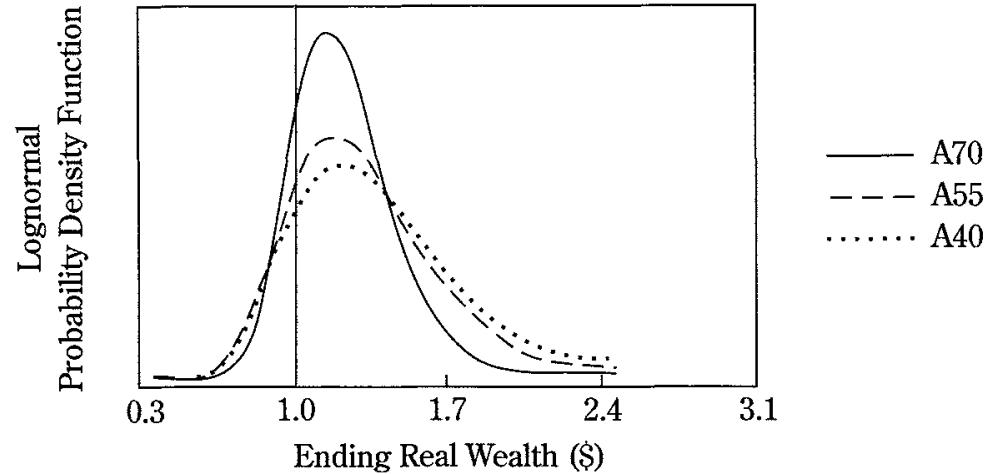

Percentiles of Distributions

\begin{tabular}{lccccccc} 
& 5 & 10 & 25 & 50 & 75 & 90 & 95 \\
\hline A70 & 0.89 & 0.95 & 1.06 & 1.20 & 1.36 & 1.52 & 1.62 \\
A55 & 0.85 & 0.92 & 1.07 & 1.27 & 1.50 & 1.74 & 1.90 \\
A40 & 0.83 & 0.92 & 1.09 & 1.32 & 1.60 & 1.90 & 2.11 \\
\hline
\end{tabular}

Figure B-7. Five-Year Ending Real Wealth on A40, A25, S\&P

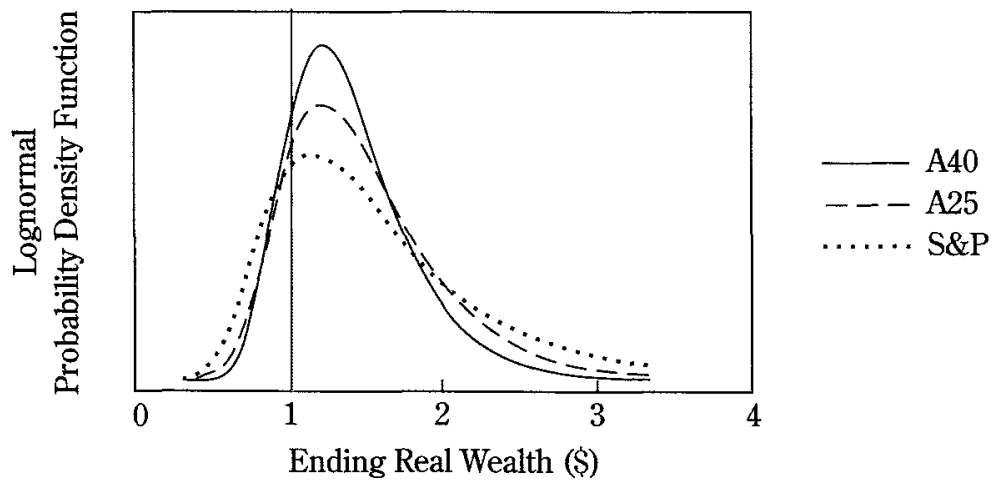

\begin{tabular}{lccccccc} 
& \multicolumn{7}{c}{ Percentiles of Distributions } \\
\cline { 2 - 7 } & 5 & 10 & 25 & 50 & 75 & 90 & 95 \\
\hline A40 & 0.83 & 0.92 & 1.09 & 1.32 & 1.60 & 1.90 & 2.11 \\
A25 & 0.78 & 0.88 & 1.09 & 1.37 & 1.72 & 2.12 & 2.40 \\
S\&P & 0.69 & 0.80 & 1.04 & 1.39 & 1.85 & 2.40 & 2.80 \\
\hline
\end{tabular}


Figure B-8. Ten-Year Ending Real Wealth on A70, A55, A40

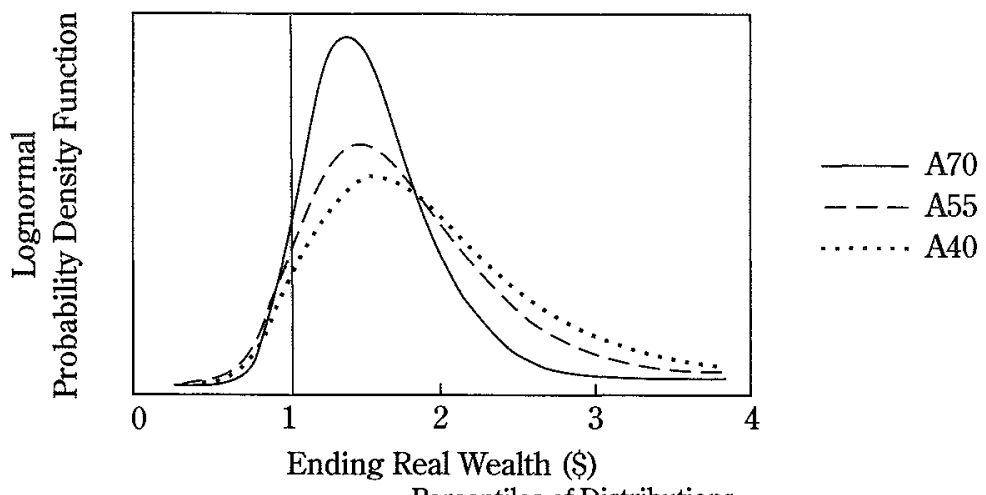

\begin{tabular}{lccccccc} 
& \multicolumn{7}{c}{ Percentiles of Distributions } \\
\cline { 2 - 8 } & 5 & 10 & 25 & 50 & 75 & 90 & 95 \\
\hline A70 & 0.95 & 1.04 & 1.23 & 1.47 & 1.76 & 2.08 & 2.29 \\
A55 & 0.91 & 1.04 & 1.29 & 1.64 & 2.09 & 2.60 & 2.96 \\
A40 & 0.95 & 1.09 & 1.38 & 1.78 & 2.31 & 2.92 & 3.36 \\
\hline
\end{tabular}

Figure B-9. Ten-Year Ending Real Wealth on A40, A25, S\&P

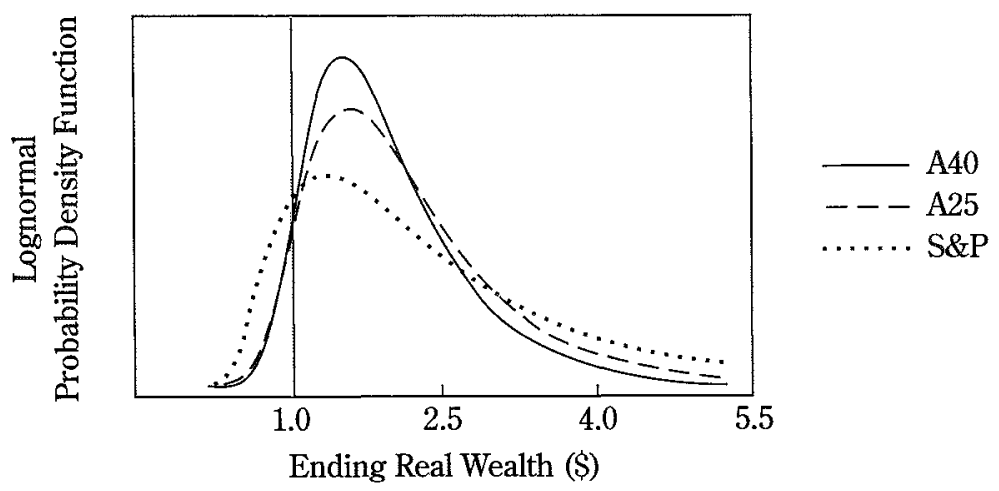

Percentiles of Distributions

\begin{tabular}{lccccccc} 
& 5 & 10 & 25 & 50 & 75 & 90 & 95 \\
\hline A40 & 0.95 & 1.09 & 1.38 & 1.78 & 2.31 & 2.92 & 3.36 \\
A25 & 0.95 & 1.11 & 1.44 & 1.92 & 2.57 & 3.33 & 3.89 \\
S\&P & 0.73 & 0.91 & 1.31 & 1.97 & 2.98 & 4.31 & 5.37 \\
\hline
\end{tabular}


Figure B-10. Twenty-Year Ending Real Wealth on A70, A55, A40

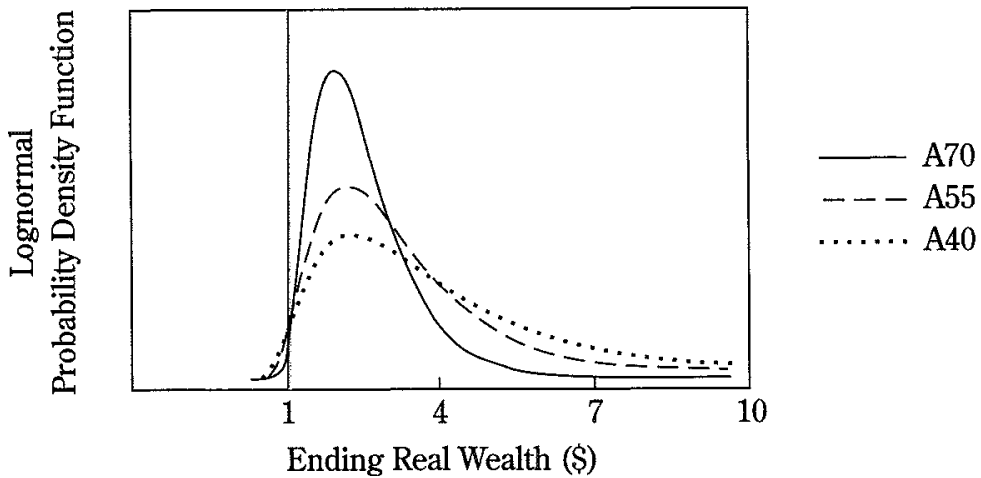

Ending Real Wealth (\$)

Percentiles of Distributions

\begin{tabular}{lrrrrrrr} 
& 5 & 10 & 25 & 50 & 75 & 90 & 95 \\
\hline A70 & 1.18 & 1.36 & 1.71 & 2.21 & 2.87 & 3.61 & 4.15 \\
A55 & 1.20 & 1.44 & 1.96 & 2.76 & 3.89 & 5.29 & 6.36 \\
A40 & 1.33 & 1.62 & 2.26 & 3.26 & 4.71 & 6.55 & 7.99 \\
\hline
\end{tabular}

Figure B-11. Twenty-Year Ending Real Wealth on A40, A25, S\&P

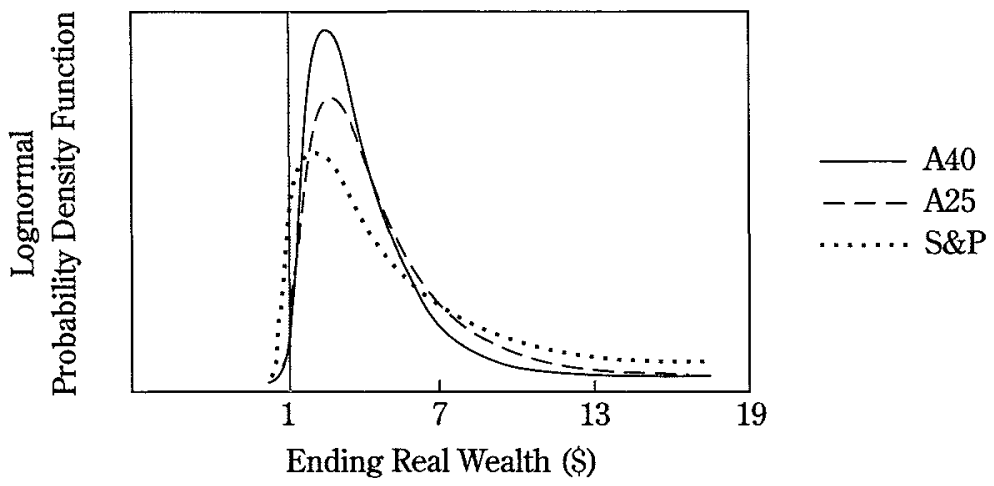

Percentiles of Distributions

\begin{tabular}{lcccccrr} 
& 5 & 10 & 25 & 50 & 75 & 90 & 95 \\
\hline A40 & 1.33 & 1.62 & 2.26 & 3.26 & 4.71 & 6.55 & 7.99 \\
A25 & 1.38 & 1.73 & 2.50 & 3.77 & 5.69 & 8.23 & 10.27 \\
S\&P & 0.97 & 1.32 & 2.23 & 3.99 & 7.13 & 12.03 & 16.45 \\
\hline
\end{tabular}


Figure B-12. Twenty-Year Ending Real Wealth on Bonds, P46, S\&P
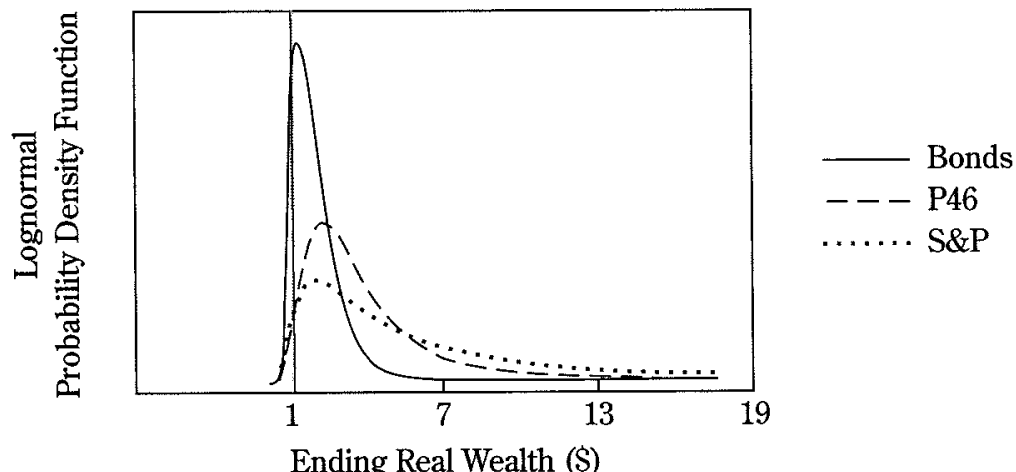

$---\mathrm{P} 46$

....... S\&P

Ending Real Wealth (\$)

Percentiles of Distributions

\begin{tabular}{lcccccrr}
\cline { 2 - 8 } & 5 & 10 & 25 & 50 & 75 & 90 & 95 \\
\hline Bonds & 0.74 & 0.89 & 1.19 & 1.65 & 2.30 & 3.09 & 3.69 \\
P46 & 1.13 & 1.36 & 1.84 & 2.59 & 3.63 & 4.92 & 5.91 \\
S\&P & 0.97 & 1.32 & 2.23 & 3.99 & 7.13 & 12.03 & 16.45 \\
\hline
\end{tabular}

Figure B-13. Twenty-Year Ending Real Wealth on P46, A40

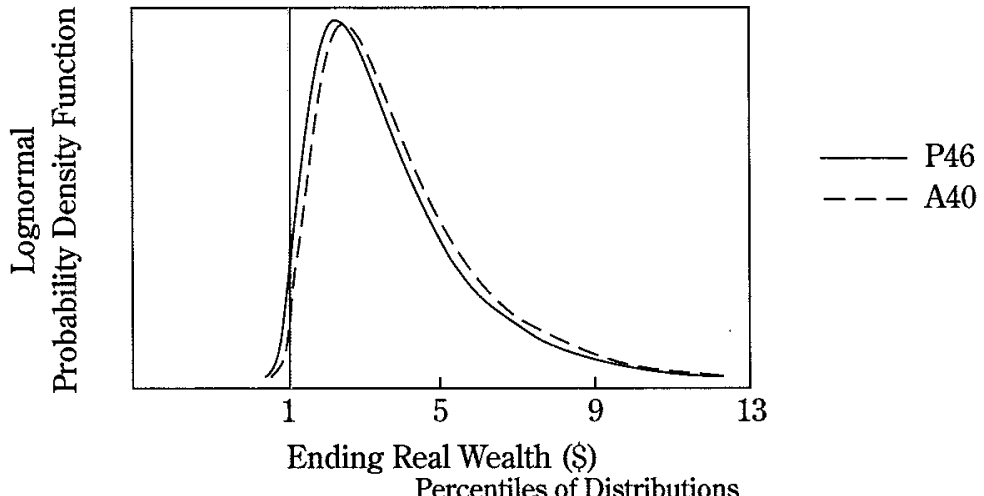

\begin{tabular}{rccccccc}
\multicolumn{7}{c}{} & \multicolumn{7}{c}{ Percentiles of Distributions } \\
\cline { 2 - 8 } & 5 & 10 & 25 & 50 & 75 & 90 & 95 \\
\hline P46 & 1.16 & 1.44 & 2.06 & 3.07 & 4.58 & 6.56 & 8.13 \\
A40 & 1.33 & 1.62 & 2.26 & 3.26 & 4.71 & 6.55 & 7.99 \\
\hline
\end{tabular}


Figure B-14. Thirty-Year Ending Real Wealth on A70, A55, A40

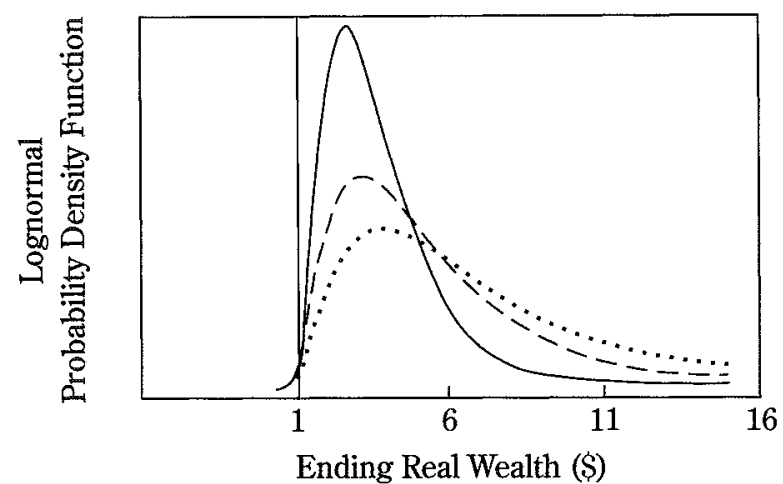

$-\mathrm{A} 70$

-- A55

…. A40

Ending Real Wealth (\$)

Percentiles of Distributions

\begin{tabular}{rrrrrrrr} 
& 5 & 10 & 25 & 50 & 75 & 90 & 95 \\
\hline A70 & 1.54 & 1.83 & 2.43 & 3.33 & 4.57 & 6.08 & 7.20 \\
A55 & 1.67 & 2.09 & 3.05 & 4.64 & 7.05 & 10.29 & 12.90 \\
A40 & 1.98 & 2.53 & 3.79 & 5.95 & 9.34 & 14.01 & 17.86 \\
\hline
\end{tabular}

Figure B-15. Thirty-Year Ending Real Wealth on A40, A25, S\&P

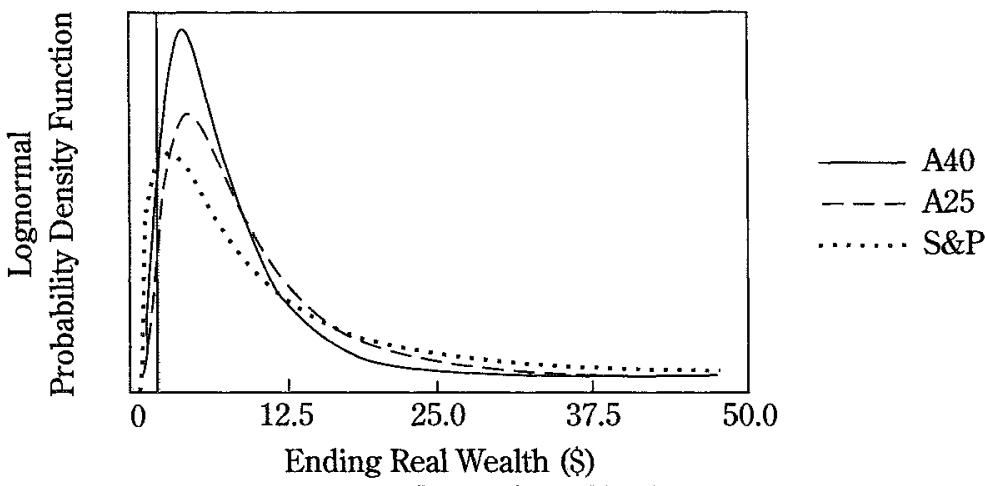

Percentiles of Distributions

\begin{tabular}{lccccrrr} 
& 5 & 10 & 25 & 50 & 75 & 90 & 95 \\
\hline A40 & 1.98 & 2.53 & 3.79 & 5.95 & 9.34 & 14.01 & 17.86 \\
A25 & 2.17 & 2.84 & 4.48 & 7.41 & 12.25 & 19.28 & 25.29 \\
S\&P & 1.42 & 2.08 & 3.95 & 8.05 & 16.41 & 31.15 & 45.71 \\
\hline
\end{tabular}




\section{Shortfall Risk: Individual Investors}

Each line indicates the probabilities that a portfolio will earn less than Treasury bills for investment horizons of 1-30 years. Treasury-bill returns are often used to indicate returns available on bank saving deposits, short-term certificates of deposit, and other riskless investments.

Figure B-16. Shortfall Risk on Bonds, A70

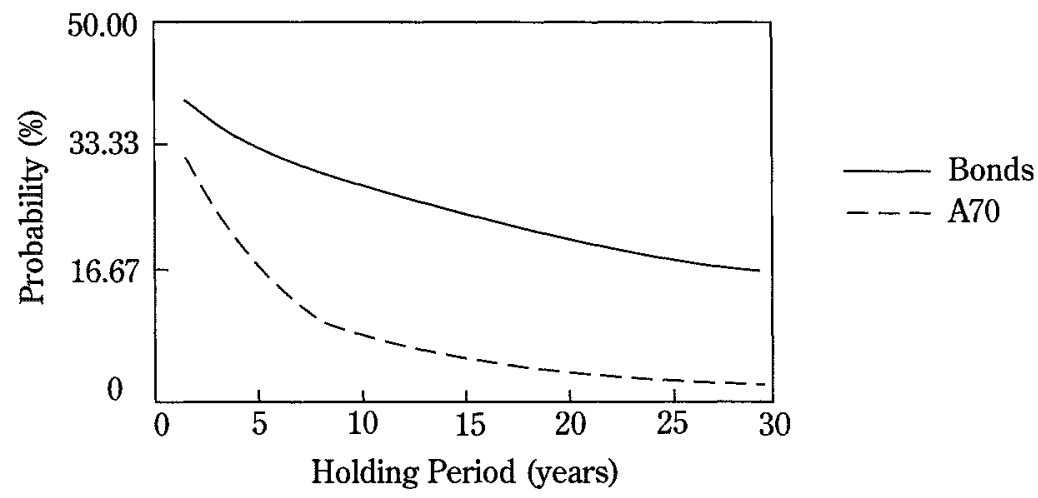


Figure B-17. Shortfall Risk on A70, A55, A40

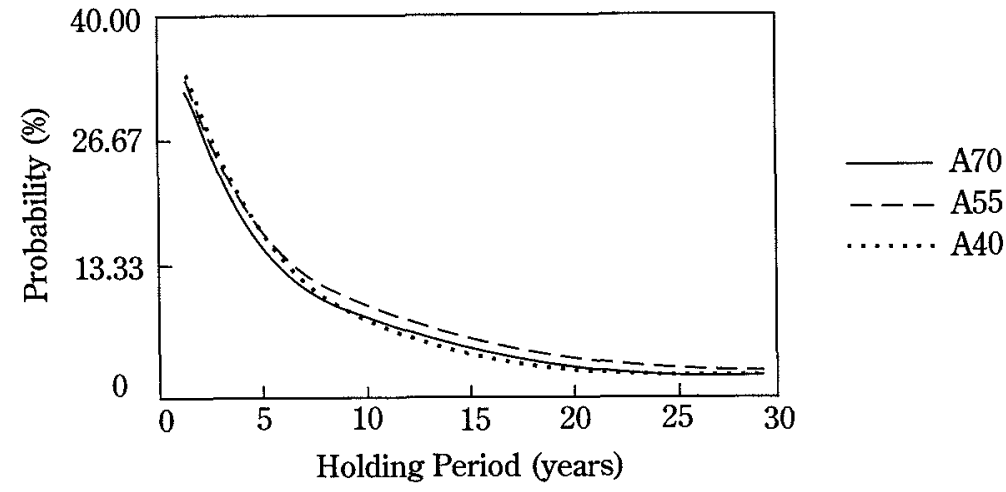

Figure B-18. Shortfall Risk on A40, A25, S\&P

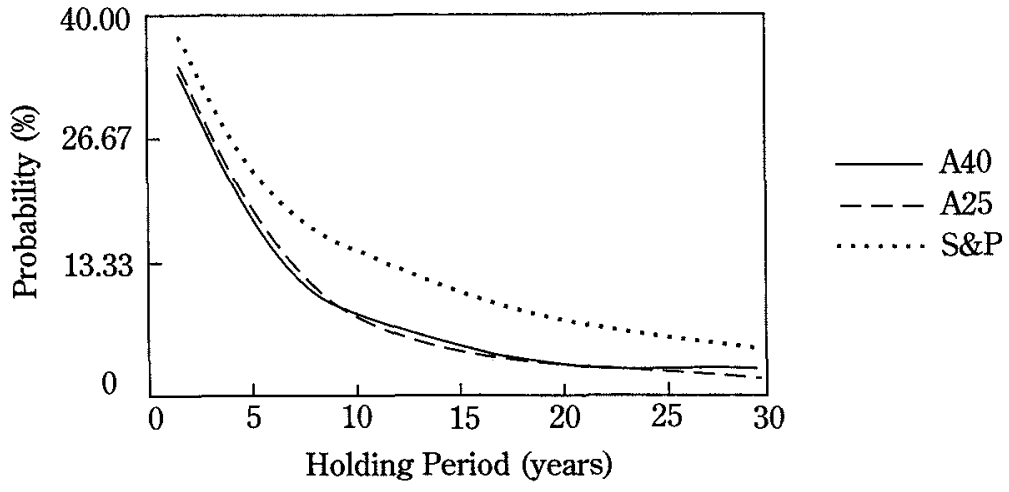




\section{Probability Distributions of Ending Real Wealth: Pension Funds}

Figure B-19. One-Year Ending Real Wealth on P64, P46

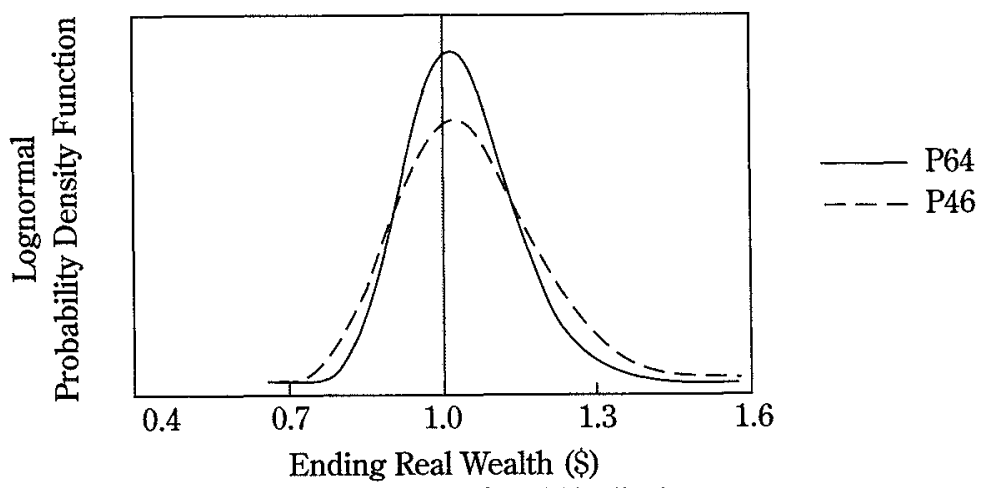

\begin{tabular}{cccccccc} 
& \multicolumn{7}{c}{ Percentiles of Distributions } \\
\cline { 2 - 8 } & 5 & 10 & 25 & 50 & 75 & 90 & 95 \\
\hline P64 & 0.87 & 0.90 & 0.96 & 1.04 & 1.11 & 1.19 & 1.23 \\
P46 & 0.84 & 0.88 & 0.95 & 1.04 & 1.14 & 1.24 & 1.30 \\
\hline
\end{tabular}

Figure B-20. Five-Year Ending Real Wealth on P64, P46

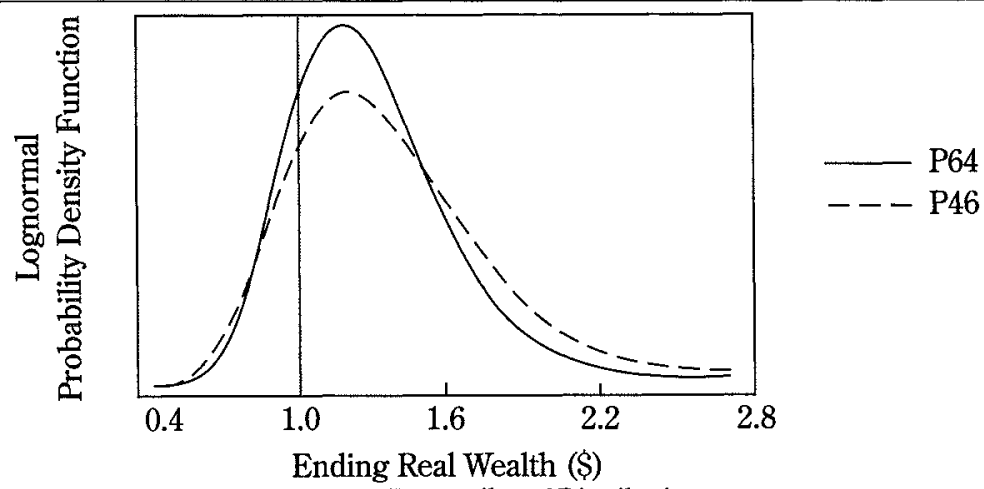

\begin{tabular}{cccccccc}
\multicolumn{7}{c}{} & \multicolumn{7}{c}{ Percentiles of Distributions } \\
\cline { 2 - 7 } & 5 & 10 & 25 & 50 & 75 & 90 & 95 \\
\hline P64 & 0.84 & 0.92 & 1.06 & 1.25 & 1.46 & 1.69 & 1.85 \\
P46 & 0.81 & 0.90 & 1.07 & 1.30 & 1.58 & 1.88 & 2.09 \\
\hline
\end{tabular}


Figure B-21. Ten-Year Ending Real Wealth on P64, P46

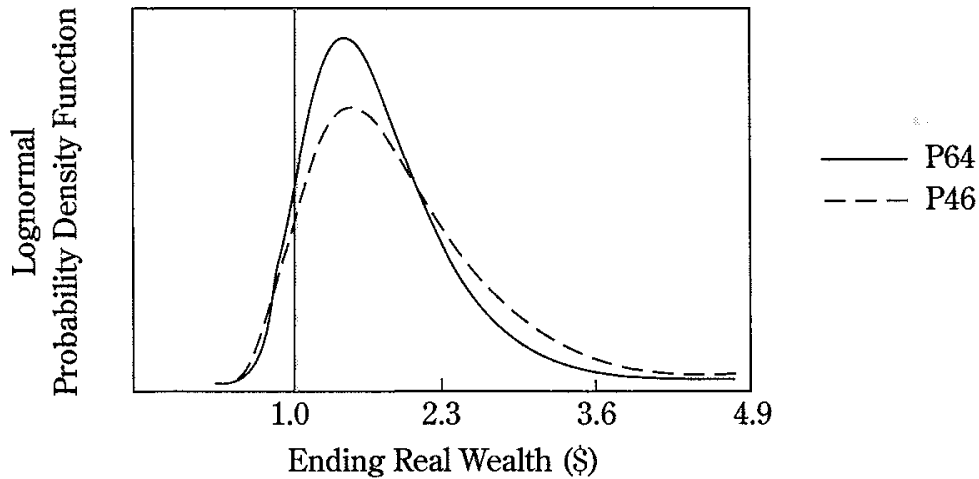

Ending Real Wealth (\$)

Percentiles of Distributions

\begin{tabular}{rrrrrrrr} 
& 5 & 10 & 25 & 50 & 75 & 90 & 95 \\
\hline P64 & 0.89 & 1.01 & 1.25 & 1.59 & 2.02 & 2.50 & 2.88 \\
P46 & 0.87 & 1.06 & 1.31 & 1.73 & 2.30 & 2.96 & 3.44 \\
\hline
\end{tabular}

Figure B-22. Twenty-Year Ending Real Wealth on P64, P46

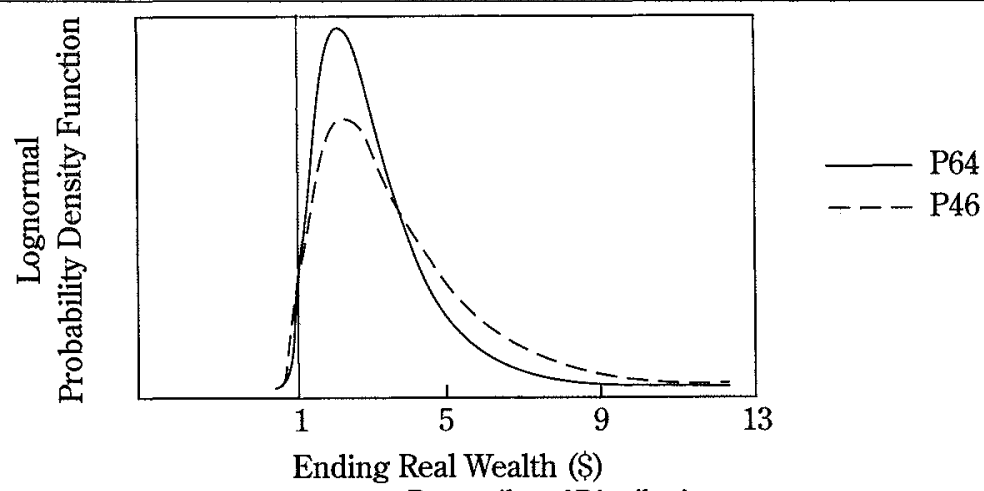

Percentiles of Distributions

\begin{tabular}{lccccccc} 
& 5 & 10 & 25 & 50 & 75 & 90 & 95 \\
\hline P64 & 1.13 & 1.36 & 1.84 & 2.59 & 3.63 & 4.92 & 5.91 \\
P46 & 1.16 & 1.44 & 2.06 & 3.07 & 4.58 & 6.56 & 8.13 \\
\hline
\end{tabular}


Figure B-23. Thirty-Year Ending Real Wealth on P64, P46

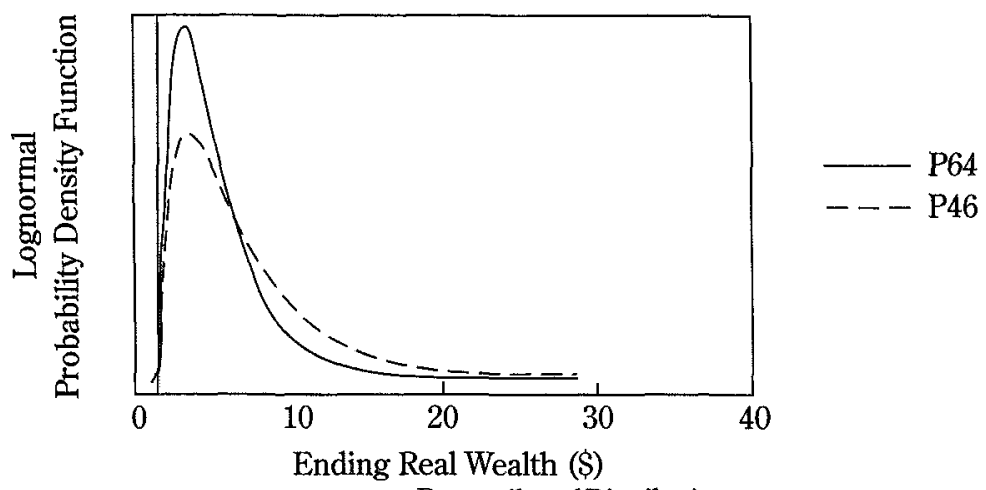

Ending Real Wealth (\$)

Percentiles of Distributions

\begin{tabular}{rrrrrrrr} 
& 5 & 10 & 25 & 50 & 75 & 90 & 95 \\
\hline P64 & 1.52 & 1.91 & 2.77 & 4.20 & 6.37 & 9.26 & 11.58 \\
P46 & 1.66 & 2.15 & 3.34 & 5.45 & 8.89 & 13.80 & 17.96 \\
\hline
\end{tabular}




\section{Shortfall Risk: Pension Funds}

Figure B-24. Shortfall Risk on P64, P46

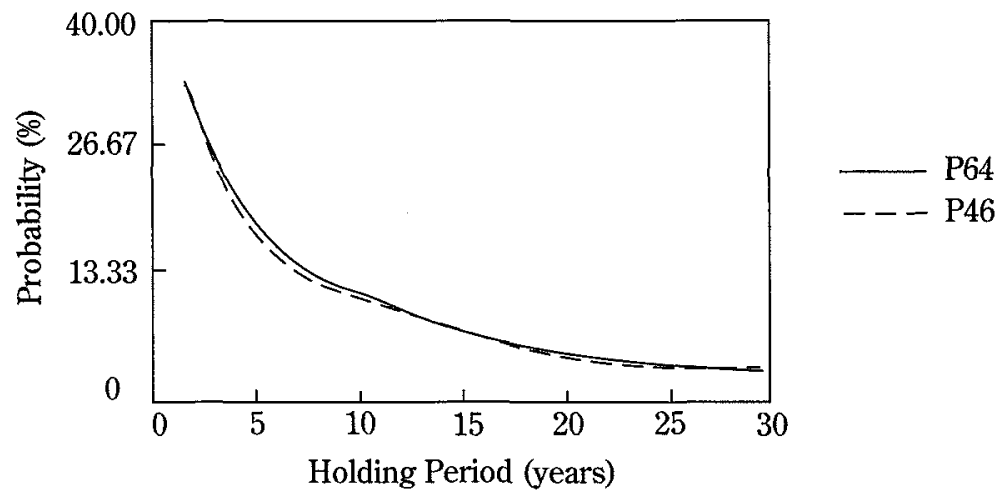


Table B-1. Probability Distributions of Ending Excess Wealth

\begin{tabular}{|c|c|c|c|c|c|c|c|c|c|}
\hline $\begin{array}{l}\text { Holding } \\
\text { Period } \\
\text { (years) }\end{array}$ & Percentile & S\&P & P46 & P64 & Bonds & A25 & A40 & A55 & A70 \\
\hline \multirow[t]{7}{*}{1} & 5 & 0.77 & 0.85 & 0.88 & 0.90 & 0.81 & 0.85 & 0.87 & 0.92 \\
\hline & 10 & 0.82 & 0.89 & 0.91 & 0.92 & 0.86 & 0.89 & 0.91 & 0.94 \\
\hline & 25 & 0.93 & 0.96 & 0.97 & 0.97 & 0.95 & 0.96 & 0.97 & 0.98 \\
\hline & 50 & 1.06 & 1.05 & 1.04 & 1.02 & 1.06 & 1.05 & 1.04 & 1.03 \\
\hline & 75 & 1.22 & 1.15 & 1.11 & 1.07 & 1.18 & 1.15 & 1.12 & 1.09 \\
\hline & 90 & 1.37 & 1.24 & 1.19 & 1.12 & 1.31 & 1.25 & 1.20 & 1.13 \\
\hline & 95 & 1.48 & 1.30 & 1.23 & 1.15 & 1.38 & 1.31 & 1.25 & 1.16 \\
\hline \multirow[t]{7}{*}{5} & 5 & 0.69 & 0.83 & 0.85 & 0.78 & 0.78 & 0.83 & 0.86 & 0.90 \\
\hline & 10 & 0.80 & 0.91 & 0.92 & 0.84 & 0.88 & 0.92 & 0.93 & 0.96 \\
\hline & 25 & 1.03 & 1.07 & 1.05 & 0.95 & 1.08 & 1.08 & 1.07 & 1.06 \\
\hline & 50 & 1.36 & 1.28 & 1.22 & 1.09 & 1.35 & 1.30 & 1.24 & 1.18 \\
\hline & 75 & 1.81 & 1.53 & 1.42 & 1.26 & 1.68 & 1.56 & 1.45 & 1.31 \\
\hline & 90 & 2.33 & 1.79 & 1.62 & 1.43 & 2.05 & 1.83 & 1.67 & 1.45 \\
\hline & 95 & 2.71 & 1.97 & 1.76 & 1.54 & 2.31 & 2.02 & 1.81 & 1.54 \\
\hline \multirow[t]{7}{*}{10} & 5 & 0.70 & 0.85 & 0.88 & 0.71 & 0.93 & 0.93 & 0.90 & 0.90 \\
\hline & 10 & 0.87 & 0.99 & 0.99 & 0.80 & 1.07 & 1.06 & 1.01 & 0.99 \\
\hline & 25 & 1.25 & 1.25 & 1.20 & 0.97 & 1.37 & 1.32 & 1.24 & 1.16 \\
\hline & 50 & 1.86 & 1.63 & 1.50 & 1.20 & 1.81 & 1.68 & 1.55 & 1.39 \\
\hline & 75 & 2.78 & 2.13 & 1.87 & 1.48 & 2.38 & 2.14 & 1.93 & 1.65 \\
\hline & 90 & 3.98 & 2.71 & 2.28 & 1.79 & 3.05 & 2.66 & 2.36 & 1.94 \\
\hline & 95 & 4.93 & 3.12 & 2.56 & 2.01 & 3.54 & 3.04 & 2.66 & 2.13 \\
\hline \multirow[t]{7}{*}{30} & 5 & 1.19 & 1.42 & 1.33 & 0.70 & 1.86 & 1.71 & 1.45 & 1.27 \\
\hline & 10 & 1.73 & 1.82 & 1.63 & 0.86 & 2.40 & 2.14 & 1.78 & 1.50 \\
\hline & 25 & 3.22 & 2.75 & 2.29 & 1.19 & 3.68 & 3.13 & 2.52 & 1.97 \\
\hline & 50 & 6.44 & 4.36 & 3.36 & 1.72 & 5.92 & 4.76 & 3.71 & 2.67 \\
\hline & 75 & 12.88 & 6.91 & 4.92 & 2.49 & 9.53 & 7.24 & 5.45 & 3.62 \\
\hline & 90 & 24.02 & 10.45 & 6.94 & 3.46 & 14.63 & 10.56 & 7.72 & 4.76 \\
\hline & 95 & 34.87 & 13.39 & 8.52 & 4.22 & 18.90 & 13.23 & 9.50 & 5.61 \\
\hline
\end{tabular}

Note: See text Table 1 for the portfolio asset allocations. 


\section{References}

Ambachtsheer, Keith P. 1987. "Pension Fund Asset Allocation: In Defense of a 60/40 Equity/Debt Asset Mix." Financial Analysts Journal (September/October):14-24. (Fall):69-71.

1989. "The Persistence of Investment Risk." The Journal of Portfolio Management

Arnott, Robert D. 1989. “Letters to the Editor.” Financial Analysts Journal (May/June):79.

Barker, Robert. 1969. Managing Educational Endowments. Report to the Ford Foundation from the Advisory Committee on Endowment Management, Robert Barker, Chairman.

Bodie, Zvi, Robert C. Merton, and William F. Samuelson. 1992. "Labor Supply Flexibility and Portfolio Choice in a Life Cycle Model." Jourmal of Economic Dynamics and Control, vol. 16: $427-49$.

Bogle, John C. 1994. Bogle on Mutual Funds: New Perspectives for the Intelligent Investor. Homewood, Ill.: Richard D. Irwin.

Breen, W., L. Glosten, and R. Jagannathan. 1989. "Economic Significance of Predictable Variations in Stock Index Returns.” The Journal of Finance (December):1177-90.

Butler, Kirt C., and Dale L. Domian. 1991. "Risk, Diversification, and the Investment Horizon." The Journal of Portfolio Management, vol. 17, no. 3:41-47.

1992-93. "Long-Run Returns on Stock and Bond Portfolios: Implications for Retirement Planning." Financial Services Review, vol. 2, no. 1:41-49.

Campbell, J.Y., and Y. Hamao. 1992. "Predictable Stock Returns in the United States and Japan: A Study of Long-Term Capital Market Integration." The Jourmal of Finance (March):43-70.

Campbell, John Y., and Robert J. Shiller. 1988. "Stock Prices, Earnings, and Expected Dividends." The Journal of Finance (July):661-76.

Chandy, P. R., and William Reichenstein. 1992. "Stock Market Timing: A Modest Proposal." AAII Joumal (April):7-10.

Chang, Eric C., and Roger D. Huang. 1990. "Time-Varying Return and Risk in the Corporate Bond Market." Journal of Financial and Quantitative Analysis (September):323-40.

Chen, Nai-Fu, Richard Roll, and Stephen A. Ross. 1986. "Economic Forces and the Stock Market." The Journal of Business, vol. 59, no. 3:383-403.

Cutler, David M., James Poterba, and Lawrence H. Summers. 1991. "Speculative Dynamics." Review of Economic Studies (May):529-46.

De Bondt, Werner F.M., and Richard Thaler. 1985. "Does the Stock Market Overreact?” The Journal of Finance (July):793-808.

1987. "Further Evidence on Investor Overreaction and Stock Market Seasonalities." The Journal of Finance (July):557-81.

Fama, Eugene F. 1990. "Stock Returns, Expected Returns, and Real Activity." The Journal of Finance (September):1089-108. 
Fama, Eugene F., and Kenneth R. French. 1988a. "Dividend Yields and Expected Stock Returns." Joumal of Financial Economics (October):3-26.

1988b. "Permanent and Temporary Components of Stock Prices." Journal of Political Economy (April):246-73.

1989. "Business Conditions and Expected Returns on Stock and Bonds." Journal of Financial Economics (November):23-50.

Ferson, Wayne E., and Campbell R. Harvey. 1991. "The Variation of Economic Risk Premiums." Joumal of Political Economy, vol. 99, no. 2:385-415.

French, Kenneth R. 1990. "Forecasting Risk Premia for Stocks and Bonds." In Quantifying the Market Risk Premium Phenomenon for Investment Decision Making. Charlottesville, Va.: Institute of Chartered Financial Analysts.

Goetzmann, William N. 1993. "Patterns in Three Centuries of Stock Market Prices." The Jourmal of Business, vol. 66 , no. $2: 249-70$.

Ibbotson, Roger G., Laurence B. Siegel, and Kathryn S. Love. 1985-86. "World Wealth: Market Values and Returns." The Journal of Portfolio Management, vol. 12, no. 1: 4-23.

Ibbotson and Associates. 1994. Stocks, Bonds, Bills and Inflation. 1994 Yearbook. Chicago, Ill.: Ibbotson Associates.

Keim, Donald B., and Robert F. Stambaugh. 1986. "Predicting Returns in the Stock and Bond Markets.” Journal of Financial Economics (December):357-90.

Leibowitz, Martin L., and William S. Krasker. 1988. "The Persistence of Risk: Stocks versus Bonds over the Long Term." Financial Analysts Journal (November/December):40-47.

Leibowitz, Martin L., and Terence C. Langetieg. 1989. "Shortfall Risk and the Asset Allocation Decision: A Simulation Analysis of Stock and Bond Risk Profiles." The Journal of Portfolio Management (Fall):61-68.

Lo, Andrew W., and A. Craig MacKinley. 1988, "Stock Market Prices Do Not Follow Random Walks: Evidence from a Single Specification Test." The Review of Financial Studies (Spring):4166.

Malkiel, Burton G. 1990. A Random Walk Down Wall Street. 5th ed. New York: Norton Press.

McEnally, Richard W. 1985. "Time Diversification: The Surest Route to Lower Risk?" The Joumal of Pontfolio Management (Summer):24-26.

McQueen, Grant. 1992. “Long-Horizon Mean-Reverting Stock Prices Revisited.” Journal of Financial and Quantitative Analysis (March):1-18.

McQueen, Grant, and Steven Thorley. 1991. "Are Stock Returns Predictable? A Test Using Markov Chains." The Journal of Finance (March):239-63.

Merton, Robert C. 1969. "Lifetime Portfolio Selection under Uncertainty: The Continuous-Time Case." Review of Economics and Statistics (August):247-57.

Nelson, Charles R. 1990. "Are Stock Returns Predictable? A Critique of the Evidence." In Quantifying the Market Risk Premium Phenomenon for Investment Decision Making. Charlottesville, Va.: Institute of Chartered Financial Analysts. 
Peavy, John W. III, and Katrina F. Sherrerd. 1990. Cases in Portfolio Management. Charlottesville, Va.: Association for Investment Management and Research.

Poterba, James M., and Lawrence H. Summers. 1988. "Mean Reversion in Stock Prices: Evidence and Implications." Journal of Financial Economics (October):27-60.

Reichenstein, William. 1986. “When Stock Is Less Risky than Treasury Bills.” Financial Analysts Journal (November/December):71-75.

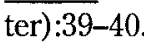

1987. "On Standard Deviation and Risk." The Journal of Portfolio Management (Win-

Reichenstein, William, and Steven P. Rich. 1993. "The Market Risk Premium and Long-Term Stock Returns." The Journal of Portfolio Management (Summer):63-72.

1994. "Predicting Long-Horizon Stock Returns: Evidence and Implications." Financial Analysts Journal (January/February):73-76.

Samuelson, Paul A. 1969. "Lifetime Portfolio Selection by Dynamic Stochastic Programming." Review of Economics and Statistics (August):239-46.

. 1989. "The Judgment of Economic Science on Rational Portfolio Management: Indexing, Timing, and Long-Horizon Effects." The Journal of Portfolio Management (Fall):4-12.

1990. "Asset Allocation Could Be Dangerous to Your Health." The Journal of Portfolio Management (Spring):5-8.

Sharpe, William F. 1990. "Investor Wealth Measures and Expected Return." In Quantifying the Market Risk Premium Phenomenon for Investment Decision Making. Charlottesville, Va.: Institute of Chartered Financial Analysts.

Shiller, Robert J. 1990. "The Historical Evidence." In Quantifying the Market Risk Premium Phenomenon for Investment Decision Making. Charlottesville, Va.: Institute of Chartered Financial Analysts.

Siegel, Jeremy. 1992. "The Real Rate of Interest from 1800-1990-A Study of the U.S. and the U.K." Journal of Monetary Economics, vol. 29:227-52.

Summers, Lawrence H. 1990. "Predicting Expected Returns." In Quantifying the Market Risk Premium Phenomenon for Investment Decision Making. Charlottesville, Va.: Institute of Chartered Financial Analysts. 